\title{
Determinación de curvas de absorción de nutrientes en cultivo de Palma Aceitera (Elaeis Guineensis) bajo riego en previvero y vivero, Santo Domingo de los Colorados, Ecuador, 2007
}

\section{Autor:}

Ing. César Rodrigo Pillajo 


\section{Resumen}

Este trabajo, se enmarca en el área nutricional del cultivo de palma de aceite (Elaeis guineensis Jacq.), con el híbrido Tenera de la Estación Experimental INIAP Sto. Domingo, fase de vivero, el objetivo pretende determinar la absorción de nutrientes, a efectos de incrementar rendimientos y mejor desarrollo con su adecuada aplicación.

Los objetivos específicos, establecer un vivero y determinar la nutrición requerida de macro y microelementos en el primer año de vida, determinada por la absorción, y obtener tablas de requerimientos nutricionales y de humedad, por ser la palma un cultivode gran importancia socioeconómica en el Ecuador. La investigación se llevó a cabo en Hda Palmacífica parroquia La Unión Esmeraldas Ecuador Se aplicó el Diseño de Bloques Completos al Azar con siete tratamientos en previvero y vivero, con cuatro repeticiones. Los parámetros evaluados del desarrollo morfológico y la absorción delos nutrientes: N, P, K, Ca, Mg, S, Cu, B, Fe, Zn y Mn, de: raíz, pseudotallo(estipe), hojas (foliolos) y raquis. Los resultados en previvero a los 105 días, dan alta significación para el tratamiento T5 con fertilización de 5 g.l planta de 12-12-17-2 .con $35.3 \mathrm{~cm}$ de altura, 5 hojas y $10.2 \mathrm{~mm}$ de diámetro de estipe. Al finalizar la fase de vivero al mes 11, el tratamiento destacado en altura de $90 \mathrm{~cm}$. fue el T4, con fertilización completa de 195 g. de 12-12-17-2 + 117 g. de fertilizantes simples. Luego con 13 hojas/ pl. el tratamiento T5 con 260 g.12-12-17-2 + 159 g.de simples . En diámetro de estipe con $71 \mathrm{~mm}$ el tratamiento T6 con 325 g.de 12-1217-2 + 195 g. de simples. Se acepta la hipótesis alternativa de existir efectos diferentes entre tratamientos. Se concluye queen previvero, el tratamiento T5 con 5 g./pl.de Nitrofoska, es el que demostró mejor altura de plantas y peso de materia fresca y seca. En Vivero hasta el mes 11, la absorción de nutrientes fue: N: 3.25; P: 0.344; K:2.52; Ca: 1.96; Mg: 0.60; S: 0.12; Cu:0.0032; B:0.0035; Fe:0.035; Zn:0.0034; Mn:0.0134 g./planta. La humedad necesaria en nuestro medio para plantas de vivero, se establece que requiere de $500 \mathrm{cc} /$ planta/día, lo que significa una lámina de $10.2 \mathrm{~mm}$./día y en un año completo 3.723 $\mathrm{mm}$. En este caso, en los meses de mayo a diciembredel 2008 ( 240 días), se requirió de 1395 mm, o sea 13.950 m3 de agua/ha para riego por aspersión. Se recomienda para previvero el tratamiento T5 y para vivero el tratamiento T4.

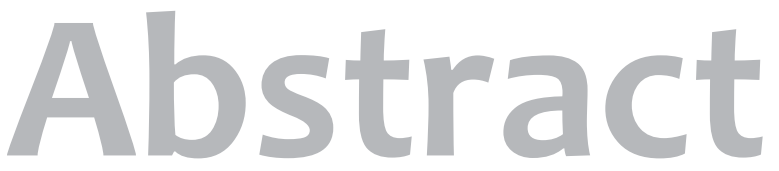

This work has been framed in the nutritional area of the oil palm tree growing (Elaeis guineensis Jacq), with the hybrid Tenera from the Experimental Field INIAP Santo Domingo, during the seedling phase. The aim is to determine the nutrient absorption, in order to raise the production and a better development with an appropriate application. The specific objectives are to establish a seedling, to determine the required nutrition of major and minor elements in the firs year, determined by the absorption and to get tables for nutritiona requirements and humidity. Because the oil palm tree is very important in the society and economy of Ecuador. It was applied the completed Blocks Design by Azar with seven treatments in pre- seedling and seedling four times. The evaluated parameters of morphologic development and nutrients absorption : N, P,K, Ca, Mg, S, Cu, B, Fe, $\mathrm{Zn}$ and $\mathrm{Mn}$ from the root, pseudo trunk ( estipe ) leaves (foliolos) and raquis. The results in pre seedlings at the 11 month, the significant in high $90 \mathrm{~cm}$ was T4, with completed fertilization of $195 \mathrm{~g}$. opf 12-12-17-2 +117 g. of simple fertilizers. After, with 13 leaves /pl. The treatment T5 with 260 g. $12-12-17-2+159$ g. pf simple. The wide of estipe with $71 \mathrm{~mm}$ the treatment T6 with $325 \mathrm{~g}$. of $12-12-17-2+195 \mathrm{~g}$ of simple. It is acceptable the alternative hypothesis that different effects may exist among treatments. In conclusion, in the pre seedling phase, the 
treatment $T_{5}$ with $5 \mathrm{~g} / \mathrm{pl}$. of Nitrofoska, showed a better high plant and weight of fresh and dry materials. In seedling, until the 11 month, the nutrients absorption was N: 3.25; P: 0:344; K: 2.52; Ca: 1.96; Mg: 0.60; S: 0.12; Cu: 0.0032; B: 0.0035; Fe: 0.035; Zn: 0.0034; Mn: 0.0134 g./ plant. Needed humidity in our environment for seedling is established in $500 \mathrm{cc} /$ plant/day. It means $10.2 \mathrm{~mm}$./day and in a completed year $3.723 \mathrm{~mm}$. In this situation, from May to December 2008 (240 days), it was required $1395 \mathrm{~mm}$, that is $13.950 \mathrm{m3}$ of water/ha to water with aspersion. The treatment $\mathrm{T}_{5}$ is recommended for pre seedling and T4 for seedling.

\section{Introducción}

La Palma de Aceite (Elaeis guineensis Jacq.,) planta oleaginosa perenne, se cultiva en la república del Ecuador desde hace más de 50 años. Hasta el 2001, la superficie plantada era de 162.202 ha., según el III Censo Agropecuario Nacional (INEC-MAG-SICA). Al 2008 superan las 230.000 ha., debido a su creciente demanda. Cultivo considerado de mayor bondad por la captación de la energía solar y transformarla en aceite vegetal, identificándolo como el Dorado de los Trópicos (Mutert. E W)

La investigación, se enmarcó en la nutrición del cultivo de palma de aceite (Elaeis guineensis Jacq.), con el híbrido Tenera del INIAP Estación Sto. Domingo, fase de vivero, con el objetivo de determinar la absorción nutrimentos, a efectos de proveer la adecuada nutrición al cultivo de palma desde su primer año en vivero y previvero e incrementar los rendimientos en el desarrollo.

Se requiere desde luego la producción de plantas de calidad con óptima nutrición, siendo en esta etapa fenológica del cultivo, la que garantizará los mejores resultados a largo plazo, pues las prácticas adecuadas de manejo y aplicación oportuna de nutrientes, desde su primera fase de vida, determinarán la mejor productividad de la futura plantación.

\section{- Importancia}

Se vislumbra un promisorio futuro por la demanda de sus productos en especial alimenticios y en la obtención de Bio-Diesel, lo que supone un incremento más intenso de nuevas superficies de cultivo. Además, se realizan constantes prácticas de renovación de las áreas de plantaciones viejas, mayores a los 20 años reemplazándolas con nuevas plantas, por lo tanto, se requiere de una constante producción de plantas de vivero.

La nutrición adecuada a través de la fertilización, es una de las prácticas agronómicas más importantes para el normal desarrollo y producción de cultivos. La palma de aceite particularmente, requiere la provisión adecuada de macro y micronutrientes en forma balanceada. Esta investigación pretende obtener la información de las óptimás cantidades de los elementos nutritivos requeridos en la fase de vivero a través del método de absorción de los órganos vegetativos de la planta, analizados en laboratorio.

El estudio permitió realizar eficazmente los programás de nutrición para proveer en forma oportuna las cantidades de acuerdo al desarrollo fenológico del cultivo. Los insumos en el caso de los fertilizantes, son más costosos cada día y en varias ocaciones se aplican cantidades excesivas como también deficitarias o desbalanceadas de los verdaderos requerimientos que proporcionados eficazmente, repercuten en los rendimientos y en la economía del sectos agrícola del país.

Las condiciones ecológicas son favorables para el desarrollo del cultivo en especial entre las provincias de Santo Domingo de los Tsáchilas y Esmeraldas. Existe gran apertura de la Universidad Tecnológica Equinoccial Campus Santo Domingo y la Hda Palmera del Pacífico 
“Palmacífica” y estudiantes de Ingeniería Agropecuaria realizan visitas prácticas y pasantías como complemento de su formación académica en cultivos tropicales. Además, no existen estudios en el medio sobre absorción de nutrientes en fase de vivero de palma.

\section{Objetivos}

\section{General}

Determinar la cantidad de nutrientes que deben subministrarse con precisión al cultivo de palma de aceite (Elaeis guineensis) en fase de vivero; en la Hda. Palmacífica, mediante la fertilización balanceada y periódica.

\section{Específicos}

- Determinar en forma cualitativa y cuantitativa los macro y micronutrientes requerido en palma aceitera expresado en curvas de absorción.

- Obtener información de óptimos requerimientos nutricionales y de humedad del cultivo de palma aceitera que garantice plantas de óptima calidad en menor tiempo.

- Determinar contenido de humedad a capacidad de campo, para la proveer riego adecuado; la cual facilitará el mejor aprovechamiento de nutrientes.

\section{Hipótesis alternativa:}

Los efectos son diferentes entre tratamientos con diferentes dosis nutritivas.

Su comprobación permite conocer, recomendar y aplicar la mejor nutrición vegetal, en vivero, de palma, mejorando la emisión foliar, altura, diámetro de estipe a través de la fertilización y amenorar tiempo de permanencia en vivero.

\section{Materiales, Métodos y Procedimientos}

\section{Metodología}

\section{Métodos y procedimientos}

Lugar de ejecución

- País: Ecuador

- Provincia: Esmeraldas

- Cantón: Quinindé

- Parroquia: La Unión

- Sector: El Rocío.- Hda. Palmera del Pacífico "Palmacífica"

- Coordenadas Geográficas: Long W 79 $27^{\prime}$ y Lat. N $0^{\circ} 05^{\prime}$. UTM: E 170671598; N 0010600

\section{- En previvero}

La fase de previvero, se inició con la construcción del cobertizo para previvero con material de la zona como caña guadúa, alambre sarán, cuezco de palma para piso de calles y cáscara de arroz para tratamientos del ensayo, con el aporte de la contraparte. Se realizó análisis de suelo para previvero, se construyó platabandas de 1 metro de ancho y 20 metros de largo con fundas negras de $14 \times 20 \mathrm{~cm}$. Se sembró semillas pregerminadas del híbrido Tenera INIAP Estación Sto. Domingo.

La siembra se hizo igual con la entidad contraparte, puesto que en el mismo previvero, se propagaron unas 15.000 plantas para plantación de aproximadamente unas 85 has en la propiedad. Cuando las plántulas tuvieron 4 semanas, se apartó cuatro platabandas para el ensayo. Para tal efecto, se seleccionó las plántulas mejor conformadas y de tamaño uniforme. 
Estableciéndose así el ensayo en 4 platabandas (4 repeticiones) como lo establece el diseño de previvero en el anexo correspondiente.

El resultado de análisis de laboratorio de nutrimentos, dió la interpretación de elementos como se indica en el cuadro1

\section{Cuadro No 1}

\section{Resultados de análisis de nutrimentos del sustrato para previvero}

\begin{tabular}{|c|c|c|c|c|c|c|c|c|c|c|c|}
\hline & $\%$ & \multicolumn{10}{|c|}{ Ppm. } \\
\cline { 3 - 12 } pH. & Mo. & NH4 & P & Cu & B & Fe & Zn & Mn & K & Ca & Mg \\
\hline 5.6 & 4.48 & 17.78 & 32.56 & 7.80 & 0.86 & 2.26 .4 & & 6.8 & 2.2 & 6.9 & 2.1 \\
\hline Me. & M & & & & & & & & & & \\
Ac. & & B & A & A & A & A & M & M & A & M & M \\
\hline
\end{tabular}

$A=$ alto; $M=$ médio; $B=$ bajo;

Los resultados del análisis de laboratório, demostraron encontrarse bajo en Nitrógeno, por tanto, se puso mayor énfasis en suplir este elemento de acuerdo a lo que se especifica en el cuadro 3

\section{- En Vivero}

El material utilizado para el llenado de fundas de vivero fue a base de tierra del mismo sitio de la propiedad, tomado de una capa de $5 \mathrm{~cm}$. de cultivo de palma. Se acopió material para el sustrato con pailoder y volquetas, luego se tomó una muestra para análisis de laboratorio. Se llenaron fundas negras de $45 \times 39 \mathrm{~cm}$.en la cantidad que se requería para el número de plantas del ensayo que fue en número de 1120 macetas. El resultado de análisis de laboratorio de elementos se indica en el Cuadro No2.

\section{Cuadro No 2}

Resultados de análisis de nutrimentos del suelo para vivero

\begin{tabular}{|c|c|c|c|c|c|c|c|c|c|c|c|c|}
\hline pH. & M.O. & NH4 & P & S & K & Ca & Mg & Cu & B & Fe & Zn & Mn \\
\hline & $\%$ & \multicolumn{3}{|c|}{ Ppm. } & \multicolumn{7}{|c|}{ Meq/100 g. } & \multicolumn{7}{c|}{ Ppm. } \\
\hline 6.38 & 1.34 & 15.47 & 34.05 & 21.04 & 1.97 & 8.00 & 1.70 & 11.80 & 0.66 & 275 & 6.50 & 7.30 \\
\hline LAC & B & B & A & A & A & M & M & A & A & A & M & M \\
\hline
\end{tabular}

$A=$ alto; $M=$ médio; $B=$ bajo; $E=$ exceso

\section{- Materiales de estudio:}

- Semillas pregerminadas de palma de aceite: Híbrido Tenera (INIAP) procedentes del Instituto Nacional Autónomo de Investigaciones Agropecuarias INIAP Estación Experimental Sto. Domingo.

\section{- $\quad$ Fuentes de fertilizantes:}

- $\quad$ Fertilizantes simples utilizados conocidos con los siguientes nombres comerciales: Nitrato de amonio $\left(\mathrm{NO}_{3} \mathrm{NH}_{4}\right)$ 33.5 \%; Fosfato diamónico DAP.(( $\left.\left.\mathrm{NH}_{4}\right)_{2} \mathrm{HPO}_{4}\right)$ 18-46-0 \%; Muriato de potasio $\mathrm{KCl}(60 \%$ de $\mathrm{K} 2 \mathrm{O})$; Sulfato de magnesio $\left(2 \mathrm{MgSO}_{4}\right) 49 \% \mathrm{HP}_{4}$. Acido bórico $17 \%$.

- $\quad$ Fertilizantes compuestos Nitrofoska 12-12-17-2

\section{- Programa de Nutrición}

- $\quad$ Nutrición para Previvero

Dados los resultados del análisis de laboratorio, se procedió a realizar las dosificaciones de nutrientes para los tratamientos del diseño como se demuestra en el cuadro3. Los tres primeros tratamientos $\mathrm{T}_{1}, \mathrm{~T}_{2}, \mathrm{~T}_{3}$, a base de fertilizantes con elementos simples indicados en el párrafo anterior con dosis baja, óptima y alta. y los tratamientos T4, 
T5, T6 a base de Nitrofoska más dosis de Nitrógeno a base de Nitrato de amonio. El tratamiento T7 es el testigo sin fertilización.

\section{Cuadro No 3}

Tratamientos y fertilización aplicada en previvero: Dosis en gramos/ planta.

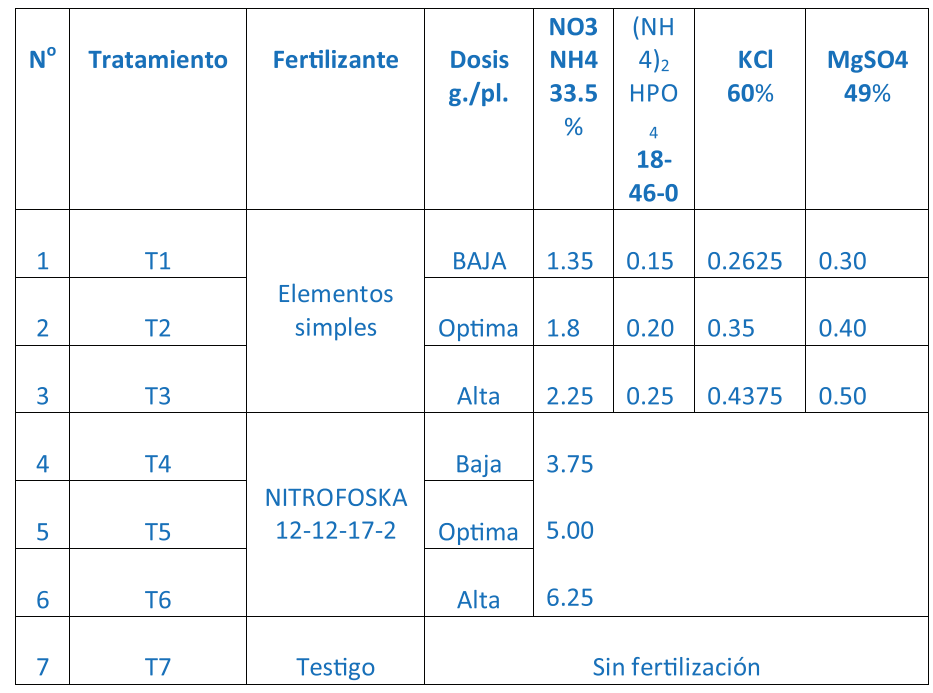

\section{- Nutrición para Vivero:}

- De acuerdo a los resultados del análisis de laboratorio, se realizó las dosificaciones de nutrientes para cada tratamiento del diseño de la investigación. Esto con el apoyo de cuadros recomendados por la Estación Experimental INIAP para el caso del Hibrido Tenera. Se calculó las dosis para los tres primeros tratamientos T1, T2, T3, a base de fuentes de fertilizantes comerciales con elementos simples indicados en el Cuadro No 4, con las dosis baja, óptima y alta de fertilizantes simples como son:

- Nitrato de amonio $\left(\mathrm{NO}_{3} \mathrm{NH}_{4}\right) 33.5 \%$; Fosfato diamónico DAP. $\left(\left(\mathrm{NH}_{4}\right)_{2} \mathrm{HPO}_{4}\right)$ 18-46-0 \%; Muriato de potasio $\mathrm{KCl}(60 . \%$ de $\mathrm{K} 2 \mathrm{O})$; Sulfato de magnesio ( $2 \mathrm{MgSO}_{4}$ ) 49\% $\mathrm{HP}_{4}$. Acido bórico 17\%, los que eran proporcionados por la contraparte (Hda. Palmacífica) y estaban disponibles en bodega.
- Para los tratamientos T4, T5, T6 se aplicó el fertilizante compuesto Nitrofoska (12-12-17-2) más dosis de fertilizantes simples indicados anteriormente en dosis baja, óptima y alta. El tratamiento T7 es el testigo sin fertilización.

\section{Cuadro No 4}

Tratamientos y nutrición aplicada en vivero en g./planta

\begin{tabular}{|c|c|c|c|c|c|c|c|c|c|}
\hline $\mathbf{N}$ & Tratamiento & Fertilizantes & $\begin{array}{l}\text { Dos } \\
\text { g./ }\end{array}$ & & $\begin{array}{c}\mathrm{NO3} \\
\mathrm{NH} 4 \\
33.5 \\
\%\end{array}$ & $\begin{array}{c}(\mathrm{NH} 4)_{2} \\
\mathrm{HPO}_{4} \\
18-46-0\end{array}$ & $\begin{array}{l}\mathrm{KCl} \\
60 \%\end{array}$ & $\begin{array}{l}\text { MgSO } \\
449 \%\end{array}$ & $\begin{array}{c}\text { Acido } \\
\text { Bóric } \\
17 \%\end{array}$ \\
\hline 1 & $\mathrm{~T} 1$ & \multirow{3}{*}{$\begin{array}{c}\text { Elementos } \\
\text { simples }\end{array}$} & \multicolumn{2}{|c|}{ Baja } & 135 & 14.3 & 18.8 & 30.8 & \\
\hline 2 & $\mathrm{~T} 2$ & & \multicolumn{2}{|c|}{ Optima } & 180 & 22 & 25 & 41 & \\
\hline 3 & T3 & & \multicolumn{2}{|c|}{ Alta } & 225 & 23.8 & 31.3 & 51.3 & 3.0 \\
\hline 4 & $\mathrm{~T} 4$ & \multirow{3}{*}{$\begin{array}{c}\text { Nitrofosk } \\
12-12-17-2\end{array}$} & Baja & 195 & 57 & 12 & 13.5 & 34.5 & \\
\hline 5 & T5 & & Optima & 260 & 76 & 19 & 18 & 46 & \\
\hline 6 & T6 & & ALTA & 325 & 95 & 20 & 22.5 & 57.5 & \\
\hline 7 & $\mathrm{T7}$ & Testigo & & & & ertiliza & & & \\
\hline
\end{tabular}

\section{- Diseño experimental Previvero:}

El Diseño utilizado fue el de Bloques Completos al Azar (DBCA) con cuatro repeticiones. Un testigo absoluto (ver esquema en Anexo 1), cuyos 7 tratamientos se describen en el cuadro anterior. Se utilizó la Prueba de Tukey al 5\%.

- Características de las parcelas experimentales en previvero:

Área total del ensayo......................56 m2

$\mathrm{N}^{\circ}$ total de plantas en el ensayo.. .2800

$\mathrm{N}^{\circ}$ de parcelas. .28

$\mathrm{N}^{\circ}$ Bloques. $\ldots . . .4$

$\mathrm{N}^{\circ}$ parcelas por bloque. .7

Distancia entre plantas $10 \mathrm{~cm}$

Distancia entre hileras. $.10 \mathrm{~cm}$.

$\mathrm{N}^{\circ}$ de plantas por parcela. .100

$\mathrm{N}^{\circ}$ de plantas por bloque. .700 
$\mathrm{N}^{0}$ de tratamientos...................................

$\mathrm{N}^{\circ}$ de plantas a evaluadas por parcela.......10

Total plantas a evaluar en el ensayo..........280

No de plantas para vivero por parcela......40

Total de plantas utilizadas para vivero: ...1120

Se muestrearon 10 plantas élites prototipo, de cada tratamiento para análisis de laboratorio: 3 por parcela, con un total de 84 plantas analizadas en previvero.

El porcentaje de mortalidad en previvero en todos los tratamientos fertilizados fue del $3 \%$ de manera general en tratamientos y repeticiones, y en el testigo el $4 \%$ debido a la fuerte temporada invernal característica de la zona del ensayo. El tiempo total de permanencia de plantas en en previvero fueron de 3.5 meses (105 días)

\section{- Variables estudiadas y métodos:}

- $\quad$ Altura de planta, en cm.

- $\quad \mathrm{N}^{\circ}$ de hojas,

- Diámetro de pseudotallo a $1 \mathrm{~cm}$. desde el suelo.

- $\quad \mathrm{N}^{\circ}$ de días desde la siembra al trasplante a vivero.

- Porcentaje de mortalidad durante la fase de previvero por bloques y tratamientos

- Peso fresco y seco de plantas.

- Datos cualitativos y cuantitativos de nutrientes absorbidos por planta

- En vivero

- Factores en estudio: Fertilización y riego

- $\quad$ Fertilizantes simples

- $\quad$ Fertilizantes compuestos Nitrofoska + fertilizantes sim- ples

- $\quad$ La primera dosis del fertilizante D A P se aplicó desde el trasplante a vivero y luego según la tabla del manejo del ensayo

- $\quad$ Lámina de riego

- Volumen total de agua en el ciclo

- Volumen de agua por planta en el ciclo

- Curva de humedad para riego

- $\quad$ Absorción de nutrientes

\section{- Diseño experimental:}

En vivero se utilizó el mismo Diseño de Bloques Completos al Azar (DBCA) con cuatro repeticiones un testigo sin fertilizar (Anexo No 11), cuyos tratamientos en número de 7, se describen en el Cuadro $\mathrm{N}^{\circ} 4$ anterior.

\section{Cuadro No 5}

Esquema del ADEVA

\begin{tabular}{|c|c|}
\hline Fuente de variación & Grados de libertad \\
\hline Total $\quad(t r-1)$ & 27 \\
\hline Tratamientos $\quad(t-1)$ & 6 \\
\hline Repeticiones $\quad(r-1)$ & 3 \\
\hline$(t-1)(r-1)$ & 18 \\
\hline
\end{tabular}

Pruebas de significación: Prueba de Tukey al 5\%

\section{- Características de las parcelas experimentales}

- $\quad$ Área total del experimento: ............1120 m2

- $\quad$ Número total de plantas $\quad$ :..............1120

- $\quad \mathrm{N}^{0}$ de parcelas.....................................28

- $\quad$ Área por bloque.................................280 m2

- $\quad \mathrm{N}^{\circ}$ de plantas por bloque....................280

- $\quad \mathrm{N}^{0}$ Bloques.......................................... 4 
- $\quad \mathrm{N}^{\circ}$ parcelas por bloque...........................7

- $\quad$ Distancia entre plantas............................1 m.

- $\quad$ Distancia entre hileras.............................1 m.

- $\quad \mathrm{N}^{0}$ de tratamientos...................................7

- $\quad$ Área de cada tratamiento (parcela)........40 m2

- $\quad \mathrm{N}^{\circ}$ de plantas por parcela......................40

- $\quad N^{\circ}$ de plantas a evaluar por parcela......16

- $\quad \mathrm{N}^{\circ}$ de plantas por efecto de borde...... 24

- $\quad$ Total plantas a evaluar en el ensayo...448

Se muestrearon 224 plantas élites prototipo para análisis 8 por unidad experimental (parcela)

\section{- Las variables estudiadas y parámetros:}

- $\quad$ Altura de planta, en cm.

- $\quad \mathrm{N}^{\circ}$ de hojas,

- Diámetro de pseudotallo en $\mathrm{cm}$.

- $\quad$ Tiempo desde el trasplante hasta el trasplante definitivo.

- $\quad$ Porcentaje de mortalidad durante la fase de vivero por tratamientos

- Peso fresco y peso seco de raíz, tallo, hojas.

- Datos cualitativos y cuantitativos de nutrientes absorbidos por planta.

- Plantas enfermás con anillo clorótico por tratamiento

- Estimación económica de la utilidad

\section{- Materiales de campo y oficina}

Computadora de escritorio y portatil, CDs, impresora, papel inen A4, Fhash memory, programás estadísticos, Bibliografía especializada, Telefonía celular y convencional, Cámara fotográfica, cámara de video, Lupa, brújula, Navegador GPS, Infocus, pantalla, Calculadora, perforadora, engrapadora, Tensiómetro, Balanza analítica, Laborato- rio, Flexómetro, estacas, , rótulos: grande y pequeños, pintura, libreta de campo, resultados de análisis de laboratorio, Previvero: cobertizo de caña guadúa y sarán, alambre liso, Semillas y plantas de palma híbrido Tenera INIAP, fundas de polietileno para previvero y vivero negras y trasparentes, marcadores, lápices, borradores, cartulinas, lisímetro, terreno para vivero,equipo de riego por aspersión, tensiómetro, agua, sustrato para fundas, fibra de palma de aceite, cuesco de palma, tamo de arroz, agroquímicos: fertilizantes simples y fórmulas compuestas, insecticidas, fungicidas, herbidida, aspersores manuales de mochila, machetes, palas, regla milimetrada, calibrador o pie de rey, huqueador, tableros de madera triple. Vehículo para transportación, tractor agrícola, tractor bull doser, cargadora mecánica, volquetas, botas equipo de trabajo de campo.

\section{Resultados y Discusión}

- Previvero

- Crecimiento de plántulas

Las platabandas sembradas con semilla pregerminada de palma aceitera que fueron utilizadas en el ensayo fueron en número de cuatro de acuerdo al diseño establecido (Anexo No1)

El porcentaje de mortalidad en previvero de las plántulas en todos los tratamientos fertilizados fue del 3\% de manera general y en el testigo el $4 \%$ en especial debido a la fuerte temporada invernal característica de la zona del ensayo.

El tiempo total de permanencia de plantas como se indicó antes en en previvero, fue de 105 días (3.5 meses). 
Foto No 1 Previvero y establecimiento de investigación

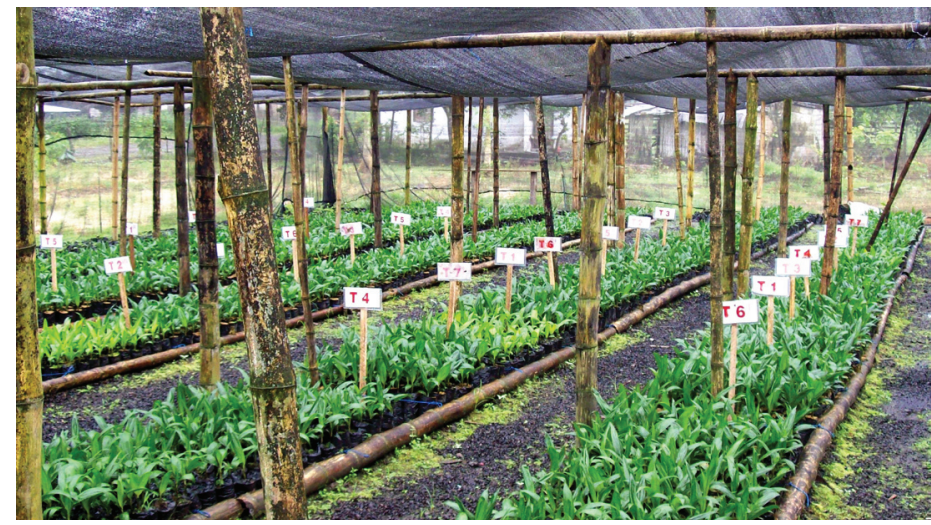

En vivero el porcentaje de mortalidad fue del o \% en todos los tratamientos, por cuanto se seleccionó plantas de las mejores características para la investigación.Y además se dieron las condiciones necesarias de humedad, y controles fitosanitarios a todo el vivero. Aunque si se notó deficiencias nutritivas con amarillamiento de las hojas en el tratamiento T7 lo cual era normal por ser éste el tratamiento testigo sin fertilización.Los datos del desarrollo morfológico de las plantas desde la fase de previvero, se presentan en varios los cuadros.

\section{- $\quad$ Altura de plántulas en previvero:}

Esta se evaluó, diferenciando los tratamientos con fertilización, seleccionándose los mejores tratamientos, que alcanzaron la mayor altura, siendo estos: $\mathrm{T}_{5}, \mathrm{~T}_{3}, \mathrm{~T}_{1}, \mathrm{y} \mathrm{T} 4$.

\section{Cuadro No 6}

\section{Altura de plántulas en $\mathrm{cm}$. por mes en previvero}

\begin{tabular}{|l|c|c|c|}
\hline \multirow{2}{*}{ Tratamientos } & \multicolumn{3}{|c|}{ Días desde la siembra } \\
\cline { 2 - 4 } & 30 & 60 & 90 \\
\hline Fertilizados & 11,5 & 17,3 & 26,7 \\
\hline Sin fertilizar & 11,2 & 16,9 & 22,3 \\
\hline
\end{tabular}

En el Gráfico No 1, los datos demuestran la curva de crecimiento en altura desde el primer mes de las plantas en previvero. Se puede apreciar la diferencia que existe entre la línea de tratamientos fertilizados frente al testigo sin fertilización.

Las dos líneas de la curva se distinguen unidas hasta los 60 días (2 meses) de vida de plántulas y luego se separan. Esto se debe a que se inició la nutrición de tratamientos a las 6 semanas de la siembra en previvero conforme al calendario de nutrición Anexo 8, basándose también a las recomendaciones de la guía de campo de Rankine y Fairhurst Vol. I. para previvero Llegando a la altura total de $26.7 \mathrm{~cm}$. para tratamientos fertilizados y de 22.3 para el testigo.

\section{Gráfico No 1}

\section{Curva de crecimiento de plántulas en previvero}

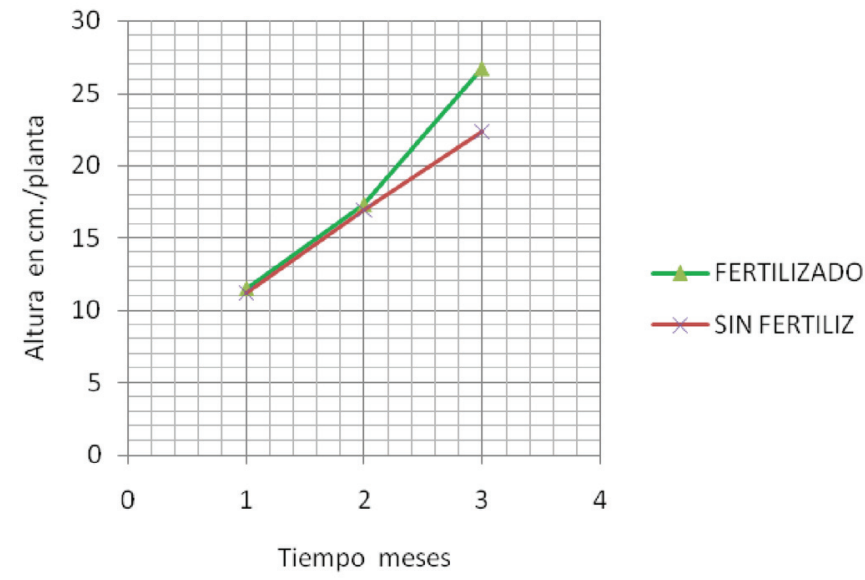

Los datos del Gráfico No 2 demuestran la diferencia entre tratamientos con fertilizantes y la línea de tendencia de crecimiento en altura de plantas frente al testigo sin fertilización. 


\section{Gráfico No 2}

\section{Barras del crecimiento en altura con la línea de tendencia}

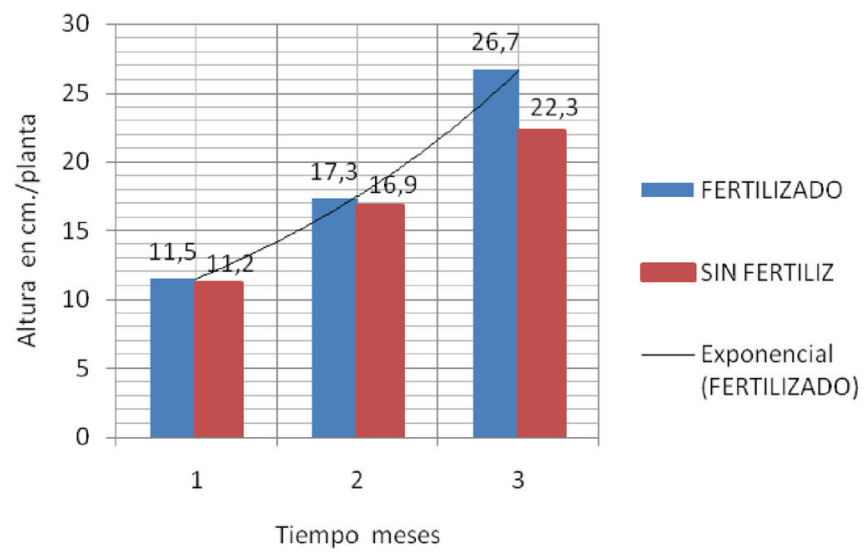

- Análisis de variancia a los 105 días (3.5 meses al finalizar la etapa de previvero)

Seguidamente los datos que se presentan en el Cuadro No 7 dmuestran que alcanzaron las plántulas en previvero a los 105 días, tanto en altura, número de hojas y diámetro de estipe y el análisis estadístico de acuerdo al diseño experimental de bloques completos al azar DCBA.

\section{Cuadro No 7}

Crecimiento total en altura, número de hojas y diámetro de estipe de plántulas al finalizar la fase de previvero ( 3.5 mes)

\begin{tabular}{|c|c|c|c|}
\hline Tratamiento & $\begin{array}{c}\text { Altura } \\
\text { cm. }\end{array}$ & No Hojas & $\varnothing$ Estipe $\mathbf{m m}$. \\
\hline T1 & 34,4 & 5,1 & 10,1 \\
\hline T2 & 31,5 & 4,6 & 9,4 \\
\hline T3 & 34,5 & 5,0 & 10,0 \\
\hline T4 & 34,3 & 5,3 & 9,9 \\
\hline T5 & 35,4 & 5,3 & 10,2 \\
\hline T6 & 32,9 & 5,1 & 10,2 \\
\hline T7 & 26,5 & 4,3 & 8,0 \\
\hline
\end{tabular}

En crecimiento de altura de plántulas, se notó una alta significación para tratamientos a la salida del previvero, analizados en el
Adeva del Cuadro No 8, mediante prueba de significación de Tukey,al 5\% cuadro 9, se detectan 4 rangos de significación, sobresaliendo en el primer rango el tratamiento T5 con una altura de planta de $35.4 \mathrm{~cm}$., con la aplicación de una dosis de 5 g./planta de Nitrofoska, seguido del T3 con una altura de $34.5 \mathrm{~cm}$. con la aplicación de $3.4 \mathrm{~g}$./pl. de mezcla de fertilizantes simples, que demostraron mejor altura de plantas.

En último lugar estuvo el tratamiento T7 testigo sin fertilizar con $26.53 \mathrm{~cm}$. de altura como se demuestra también en el gráfico de barras $\mathrm{N}^{\circ} 3$.

El coeficiente de variación en la variable altura de planta, es del 2,05\%, lo que indica un adecuado manejo del experimento.

\section{Cuadro No 8}

Análisis de varianza para altura de plantas a los 105 días (3.5 meses)

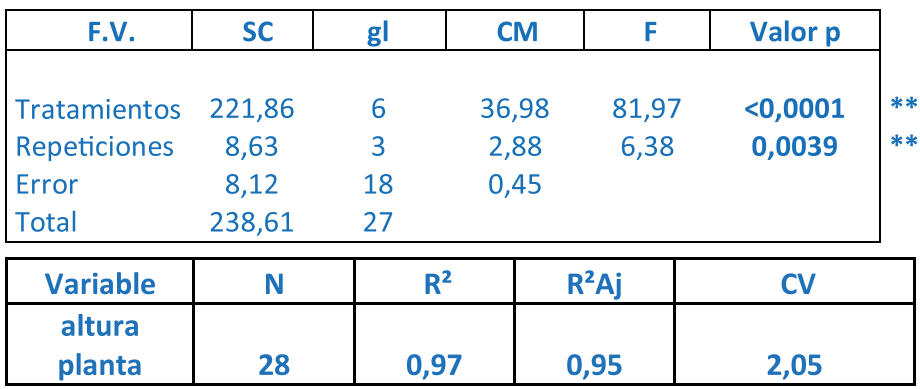

\section{Cuadro No 9}

Promedios altura de plantas a los 105 días a prueba de Tukey al 5\%

\begin{tabular}{|cccccc|}
\hline \multicolumn{7}{c|}{ Test : Tukey Alfa: 0,05 } \\
Tratamientos & Medias & & & & \\
\hline T5 & 35,35 & A & & & \\
T3 & 34,50 & A & B & & \\
T1 & 34,45 & A & B & & \\
T4 & 34,33 & A & B & & \\
T6 & 32,95 & & B & C & \\
T2 & 31,53 & & & C & \\
T7 & 26,53 & & D & & D \\
\hline
\end{tabular}


Gráfico No.3

Altura de plantas a los 105 días

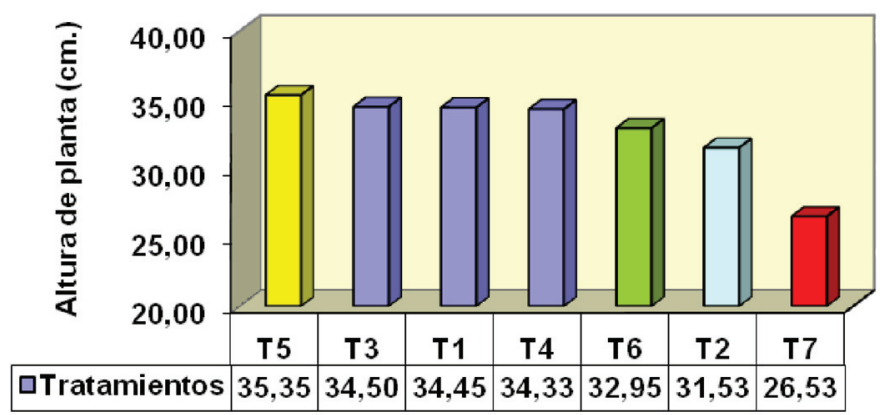

- Número de hojas a 105 días (3.5 meses)

Sobre el desarrollo de hojas de plántulas a la salida de previvero, existió alta significación estadística para tratamientos, analizados en el Cuadro No 10. Mediante prueba de significación de Tukey,al 5\%, del Cuadro No 11, se detectan 4 rangos en los promedios, sobresaliendo en el primer rango el mismo tratamiento T5 como lo fue en altura de planta, en este caso, con 5 hojas por planta (promedio estadístico 5.22) con una aplicación de 5 g. de Nitrofoska, y el tratamiento T4 dentro del mismo rango con 5 hojas por planta con la aplicación de $3.75 \mathrm{~g}$. de Nitrofoska y en el último rango el tratamiento T7 testigo sin fertilización con 4 hojas (promedio estadístico 4.28).

Los resultados obtenidos, demuestran que en la nutrición de plántulas, desde previvero, es notable por la aplicación de fertilizantes, en este caso de la fórmula completa de macronutrientes de la mezcla química, a base de: N12\% - P12\% - K 17\% - Mg 2\%.

\section{Cuadro No 10}

Análisis de variancia para número de hojas a los 105 días.

\begin{tabular}{|l|c|c|c|c|c|}
\hline \multicolumn{1}{|c|}{ F.V. } & SC & gl & CM & F & Valor $p$ \\
\hline Tratamientos & 3,54 & 6 & 0,59 & 88,03 & $<0,0001$ \\
Repeticiones & 0,03 & 3 & 0,01 & 1,33 & $\mathbf{0 , 2 9 5 3}$ \\
Error & 0,12 & 18 & 0,01 & & \\
Total & 3,69 & 27 & & & \\
\hline
\end{tabular}

\section{Cuadro No 11}

Promedios del número de hojas a los 105 días

\begin{tabular}{|c|c|c|c|c|c|}
\hline \multicolumn{3}{|c|}{ Test : Tukey Alfa: 0,05 } & & & \\
\hline Tratamientos & Medias & $\mathrm{n}$ & & & \\
\hline T5 & 5,28 & A & & & \\
\hline T4 & 5,28 & A & & & \\
\hline T1 & 5,13 & A & B & & \\
\hline T6 & 5,1 & A & B & & \\
\hline T3 & 5,03 & & B & & \\
\hline T2 & 4,55 & & & C & \\
\hline T7 & 4,28 & & & & D \\
\hline
\end{tabular}

\section{Gráfico No 4}

Número de hojas por plantas a los 105 días

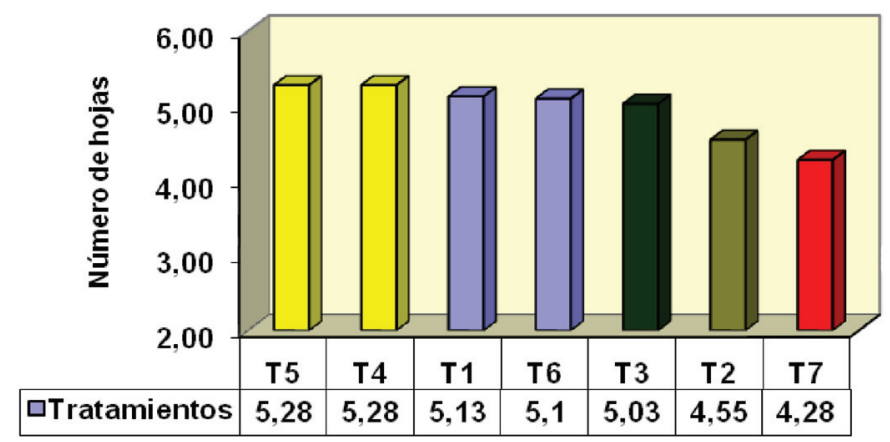

- Diámetro de estipe a los 105 días (3.5 meses)

La formación del estipe de plantas, en los primeros meses no se nota diferenciación debido al inicio de desarrollo de plántulas, pero se realizó el análisis estadístico igualmente al finalizarse la etapa de previvero, en el que se notó una alta significación para tratamientos según indica el Cuadro No 12 del análisis de variancia.

La prueba de significación de Tukey, al 5\% Cuadro No 13, detecta 3 rangos de significación, sobresaliendo en el primero el tratamiento T5 con un diámetro de $10.2 \mathrm{~mm}$., con la aplicación de una dosis de 5 g./planta de Nitrofoska , seguido del T6 en el mismo rango con 10.1 mm.con aplicación de 6.25 g./pl. de Nitrofoska, los que demostraron mejor altura de plantas y coloración verde más oscura. 
En el último lugar estuvo el tratamiento T7 testigo sin fertilizar con $8 \mathrm{~mm}$. de diámetro como lo demuestra también el Gráfico No 4.

\section{Cuadro No 12}

Análisis de varianza para diámetro del estipe

\begin{tabular}{|l|c|c|c|c|c|}
\hline \multicolumn{1}{|c|}{ F.V. } & SC & gl & CM & F & Valor $\mathbf{p}$ \\
\hline \multicolumn{7}{|c|}{} \\
Tratamientos & 14,32 & 6 & 2,39 & 72,05 & $<0,0001$ \\
Repeticiones & 0,26 & 3 & 0,09 & 2,6 & 0,0838 \\
Error & 0,6 & 18 & 0,03 & & \\
Total & 15,18 & 27 & & & \\
\hline
\end{tabular}

\section{Cuadro No 13}

Promedios del diámetro de estispe a los 105 días

\begin{tabular}{|c|c|c|c|c|}
\hline \multicolumn{3}{|c|}{$\begin{array}{l}\text { Test : Tukey Alfa: } 0,05 \text { DMS: 0,42531 } \\
\text { Error: 0,0331 gl: } 18\end{array}$} & & \\
\hline Tratamientos & Medias & $\mathrm{n}$ & & \\
\hline T5 & 10,23 & $A$ & & \\
\hline T6 & 10,15 & A & & \\
\hline T1 & 10,15 & A & & \\
\hline T3 & 9,95 & A & & \\
\hline T4 & 9,90 & A & & \\
\hline T2 & 9,43 & & B & \\
\hline T7 & 8,05 & & & C \\
\hline
\end{tabular}

\section{Gráfico No 5}

Diámetro de estipe a los 105 días (3.5 meses)

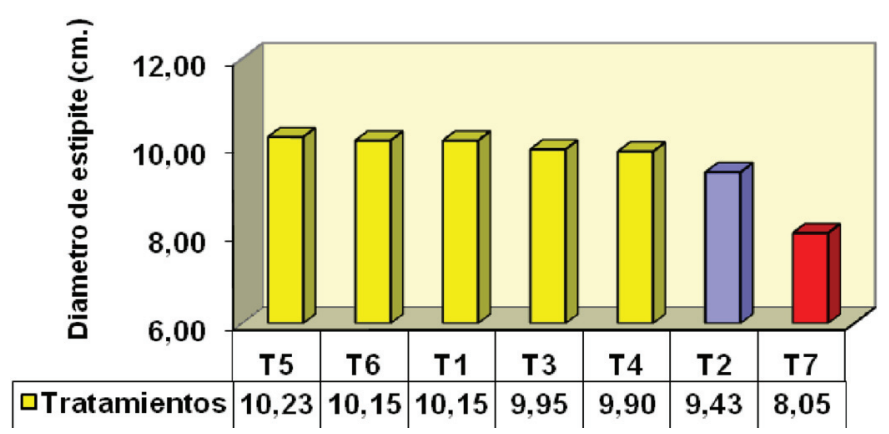

\section{- Vivero}

La fase de vivero que se inicia desde el trasplante del previvero con plántulas con cepellón de tierra por estar enfundadas, lo cual protege del estrés y mejora el desarrollo radicular, de tal manera que el crecimiento de la planta continua en un mejor ambiente tanto de luz como de espaciamiento, en el presente caso, sedistanciaron en vivero a $1 \mathrm{~m} \times 1 \mathrm{~m}$. Además se proporcionó las condiciones necesarias de humedad y la nutrición en esta etapa de vida de las plantas.

Foto $\mathrm{N}^{\circ} 2$ Vivero de palma Elaeis Gineensis de 6 meses

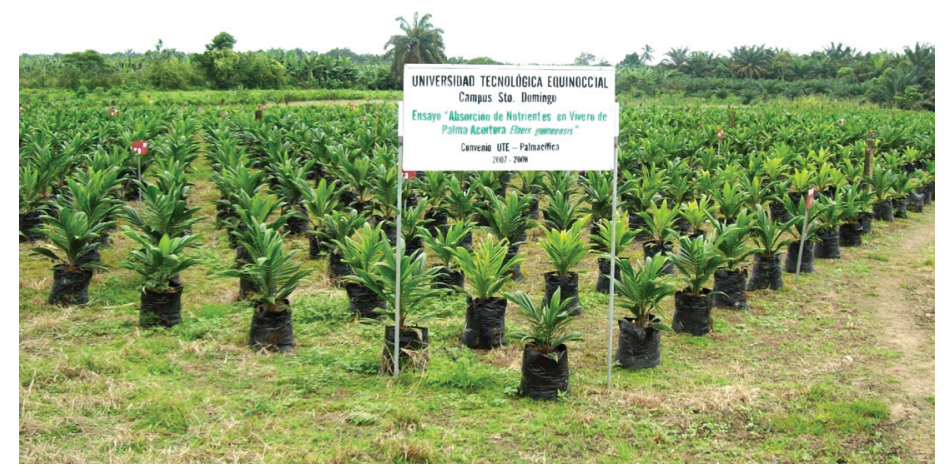

- $\quad$ Altura de plantas en vivero

Este parámetro se ha evaluado mensualmente desde el trasplante 105 días (3.5 meses) hasta los 11 meses (330 días) edad que se considera un tamaño adecuado para el trasplante al sitio definitivo

En el Cuadro No 14, se muestra el desarrollo en altura mensual desde la fase de previvero del mes 1 hasta el mes 11, una altura promedio de los tratamientos fertilizados que mejor se destacaron en el ensayo como fueron el T4, T6, T5, T1. Frente al testigo T7 sin fertilización.

Se presenta en el Gráfico No 5 la curva de crecimiento en altura de planta en centímetros con la línea de tendencia, frente al tratamiento sin fertilizar. Así como demostración en barras con la curva de tendencia de crecimiento en el Gráfico No 6 


\section{Cuadro No 14}

\section{Crecimiento de plantas por mes (altura en cm.)}

\begin{tabular}{|l|c|c|c|c|c|c|c|c|c|c|c|}
\hline Tiempo & $\mathbf{1}$ & $\mathbf{2}$ & $\mathbf{3}$ & $\mathbf{4}$ & $\mathbf{5}$ & $\mathbf{6}$ & $\mathbf{7}$ & $\mathbf{8}$ & $\mathbf{9}$ & $\mathbf{1 0}$ & $\mathbf{1 1}$ \\
\hline C. Fert & 11,6 & 17,3 & 26,5 & 34,2 & 37,2 & 40,1 & 45,9 & 57,5 & 63,3 & 72,8 & 89,2 \\
\hline
\end{tabular}

\begin{tabular}{|l|l|l|l|l|l|l|l|l|l|l|l|}
\hline S. Fert & 10,74 & 16,8 & 22,2 & 26,7 & 27,8 & 29,0 & 33,6 & 42,8 & 47,3 & 50,9 & 60,8 \\
\hline & & & & & & & & & & & \\
\hline
\end{tabular}

\section{Gráfico No 6}

\section{Curva de crecimiento de altura por mes}

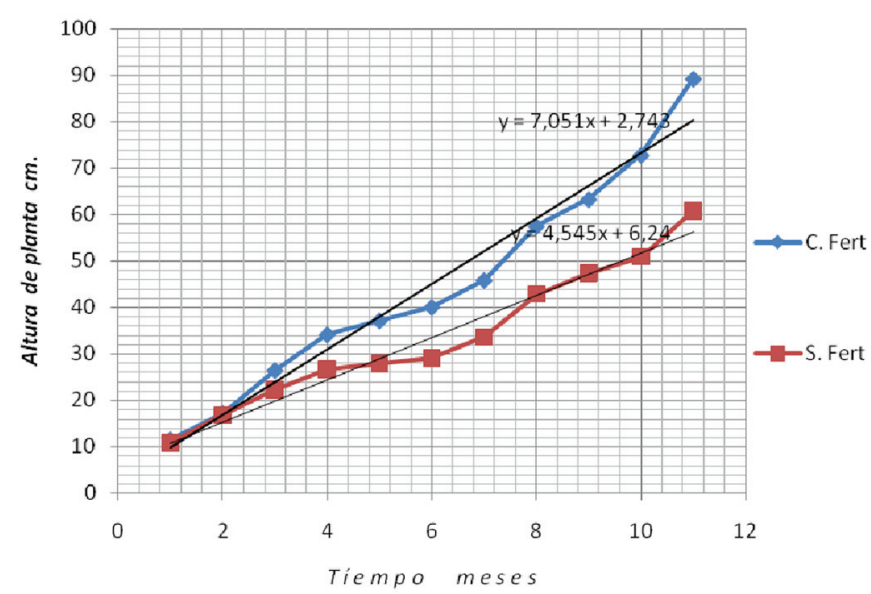

\section{Gráfico No 7}

Curva de tendencia de crecimiento por mes

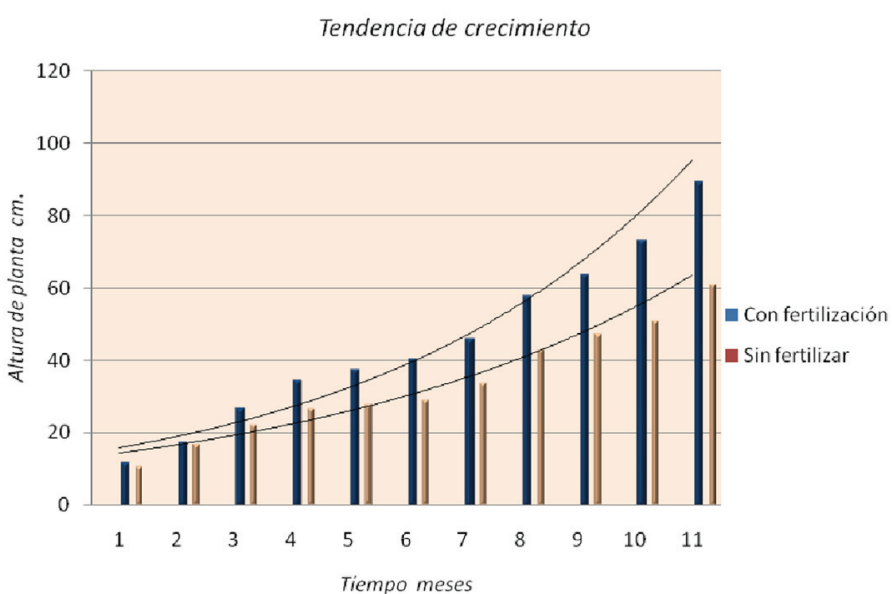

- Análisis de varianza a los 180 días (6 meses) para altura de planta a los 180 días, se indica en el Cuadro No 15, una alta significación para tratamientos.

La prueba de significación de Tukey, al 5\%, detecta 5 rangos de significación, (cuadro 16) sobresaliendo en el primero el tratamiento T5 con una altura de $40.8 \mathrm{~cm}$. con la dosis de 260 gramos de Nitrofoska azul (12-12-17-2) más fertilizantes simples 76 g. de Nitrato de amonio $\left(\mathrm{NO}_{3} \mathrm{NH}_{4}\right) 33.5$ \%; 19 g. de Fosfato diamónico DAP.(( $\left.\left.\mathrm{NH}_{4}\right)_{2} \mathrm{HPO}_{4}\right) 18$ 46-0 \%; 18 g.de Muriato de potasio $\mathrm{KCl}(60 . \%$ de $\mathrm{K} 2 \mathrm{O}) ; 46$ g. de Sulfato de magnesio $\left(2 \mathrm{MgSO}_{4}\right) 49 \% \mathrm{HP}_{4}$. y más 3 gramos de Acido bórico $17 \%$,como se indica en el cuadro 4 de tratamientos para vivero.

En último lugar se ubica el tratamiento T7 testigo sin fertilizar con $28.95 \mathrm{~cm}$. de altura como se demuestra también el Gráfico No 7.

\section{Cuadro No 15}

Análisis de la varianza para altura a los 180 días (6 meses)

\begin{tabular}{|c|c|c|c|c|c|}
\hline Variable & $\mathbf{N}$ & \multicolumn{2}{|c|}{$\mathrm{R}^{2}$} & $R^{2} A j$ & CV \\
\hline $\begin{array}{c}\text { Altura } 6 \\
\text { meses }\end{array}$ & 28 & \multicolumn{2}{|c|}{0,98} & 0,98 & 1,59 \\
\hline F.V. & SC & $\mathrm{gl}$ & $\mathrm{CM}$ & $F$ & Valor $p$ \\
\hline Tratamientos & 408,23 & 6 & 68,04 & 187,02 & $<0,0001$ \\
\hline Repeticiones & 3,42 & 3 & 1,14 & 3,14 & 0,051 \\
\hline Error & 6,55 & 18 & 0,36 & & \\
\hline Total & 418,21 & 27 & & & \\
\hline
\end{tabular}

\section{Cuadro No 16}

Promedios altura de plantas a los 180 días

\begin{tabular}{|c|c|c|c|c|c|}
\hline \multicolumn{6}{|c|}{ Test : Tukey Alfa: 0,05 } \\
\hline Tratamientos & Medias & & & & \\
\hline T5 & 40,85 & A & & & \\
\hline T6 & 39,95 & A & B & & \\
\hline $\mathrm{T} 1$ & 39,93 & A & B & & \\
\hline T4 & 39,5 & A & B & & \\
\hline T3 & 39,18 & & B & & \\
\hline T2 & 37,03 & & & C & \\
\hline $\mathrm{T7}$ & 28,95 & & & & D \\
\hline
\end{tabular}

Según el análisis estadístico para altura de plantas de vivero 


\section{Gráfico No 8}

\section{Altura de plantas a los 180 días}

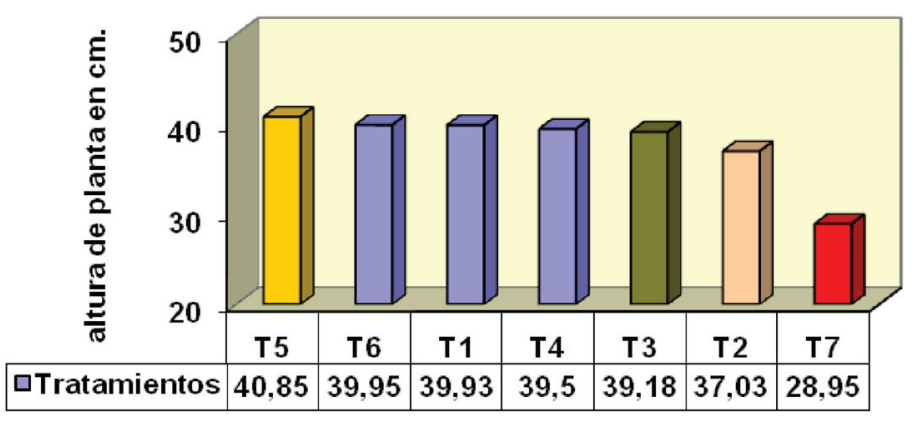

- Número de Hojas por planta en vivero a los 180 días (6 meses)

Sobre el desarrollo del número de hojas en vivero a los 1830 días, existió alta significación para tratamientos, como lo expresa el Cuadro No 17.

Mediante prueba de Tukey al 5\%, se detectan 5 rangos en los promedios, sobresaliendo en el primer rango losl tratamientos T4 y T6 (cuadro 18), en este caso, con 8 hojas por planta (promedio estadístico 8.18 y 8.05), con la dosis de 195 gramos. de Nitrofoska azul, más 57 g. de Nitrato de amonio $\left(\mathrm{NO}_{3} \mathrm{NH}_{4}\right) 33.5$ \%; 12 g. de Fosfato diamónico DAP.(( $\left.\left.\mathrm{NH}_{4}\right)_{2} \mathrm{HPO}_{4}\right)$ 18-46-0 \%; 13.5 g.de Muriato de potasio $\mathrm{KCl}(60 . \%$ de $\mathrm{K} 2 \mathrm{O}) ; 34.5 \mathrm{~g}$. de Sulfato de magnesio $\left(2 \mathrm{MgSO}_{4}\right) 49 \% \mathrm{HP}_{4}$.y más 3 gramos de Acido bórico 17\%,como se indica en el Cuadro No 4 de tratamientos. En el último rango, se ubica el tratamiento T7 testigo sin fertilización con 6 hojas.

\section{Cuadro No 17}

Análisis de varianza para número de hojas a 180 días (6 meses)

\begin{tabular}{|c|c|c|c|c|c|c|}
\hline \multicolumn{2}{|c|}{ Variable } & $\mathbf{N}$ & $\mathrm{R}^{2}$ & $\mathrm{R}^{2} \mathrm{Aj}$ & \multicolumn{2}{|r|}{ CV } \\
\hline \multicolumn{2}{|c|}{ № hojas 6 meses } & 28 & 0,83 & 0,75 & \multicolumn{2}{|c|}{4,65} \\
\hline F.V. & SC & $\mathrm{gl}$ & $\mathrm{CM}$ & $\mathrm{F}$ & Valor $p$ & \\
\hline Tratamientos & 10,33 & 6 & 1,72 & 14,33 & $<0,0001$ & $* *$ \\
\hline Repeticiones & 0,52 & 3 & 0,17 & 1,45 & 0,2624 & ns \\
\hline Error & 2,16 & 18 & 0,12 & & & \\
\hline Total & 13,01 & 27 & & & & \\
\hline
\end{tabular}

\section{Cuadro No 18}

Promedios número de hojas a los 180 días

\begin{tabular}{|c|c|c|c|c|}
\hline \multicolumn{5}{|c|}{ Test : Tukey Alfa: 0,05 } \\
\hline Tratamientos & Medias & & & \\
\hline T4 & 8,18 & A & & \\
\hline T6 & 8,05 & A & & \\
\hline T1 & 7,73 & A & B & \\
\hline T5 & 7,70 & A & B & \\
\hline T2 & 7,15 & & B & \\
\hline T3 & 7,00 & & B & C \\
\hline $\mathrm{T7}$ & 6,33 & & & C \\
\hline
\end{tabular}

\section{Gráfico No 9}

Número de hojas a los 180 días

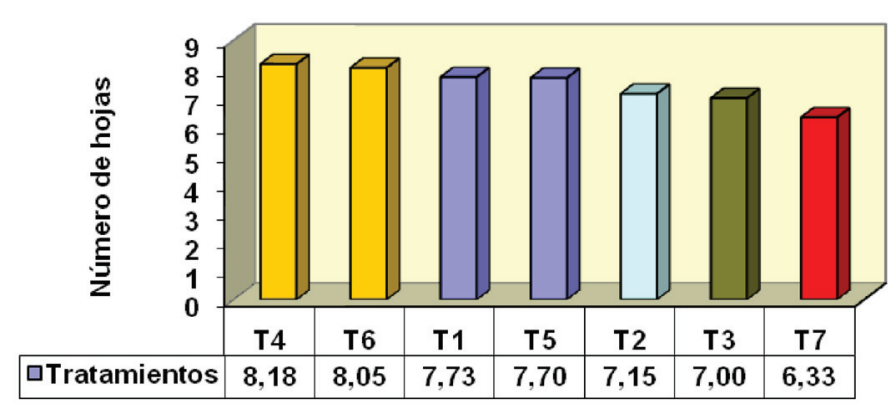

\section{- Diámetro de estipe a los 180 días (6 meses)}

Del análisis estadístico para diámetro de estipe, realizado a los 6 meses de vivero, se notó una alta significación para tratamientos según el cuadro 19 del Adeva. La prueba de significación de Tukey, al 5\% del Cuadro No 20, demuestra 4 rangos de significación, sobresaliendo en el primer rango los tratamientos T6, T5 y T4.

El tratamiento T6 se fertilizó con la dosis de 325 gramos/planta de Nitrofoska azul (12-12-17-2) más fertilizantes simples $95 \mathrm{~g}$. de Nitrato de amonio $\left(\mathrm{NO}_{3} \mathrm{NH}_{4}\right) 33.5 \%$; 20 g. de Fosfato diamónico DAP.((NH4) $\mathrm{HPO}_{4}$ ) 18-46-0 \%; 22.5 g.de Muriato de potasio KCl( 60.\% de K2O); 57.5 g. de Sulfato de magnesio $\left(2 \mathrm{MgSO}_{4}\right) 49 \% \mathrm{HP}_{4}$.y más 3 gramos de Acido bórico $17 \%$,como se indica en el Cuadro No 4 de tratamientos para vivero. 
En último lugar estuvo para el tratamiento T7 testigo sin fertilizar con $17.5 \mathrm{~cm}$. de diámetro como lo demuestra también el Gráfico No 9 .

\section{Cuadro No 19}

Análisis de varianza para diámetro de estipe a los 180 días (6 meses)

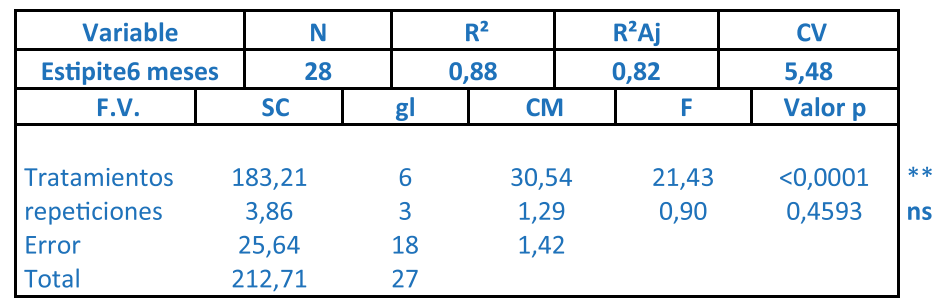

\section{Cuadro No 20}

\section{Promedios diámetro de estipe en mm. a los 180 días}

\begin{tabular}{|c|c|c|c|c|}
\hline \multicolumn{5}{|c|}{ Test : Tukey Alfa: 0,05 } \\
\hline Tratamientos & Medias & & & \\
\hline T6 & 25,00 & A & & \\
\hline T5 & 24,50 & A & & \\
\hline T4 & 23,00 & A & & \\
\hline T1 & 22,75 & A & B & \\
\hline T3 & 20,00 & & B & C \\
\hline T2 & 19,75 & & & C \\
\hline $\mathrm{T7}$ & 17,50 & & & C \\
\hline
\end{tabular}

\section{Gráfico No 10}

\section{Diámetro de estipe a los 180 días}

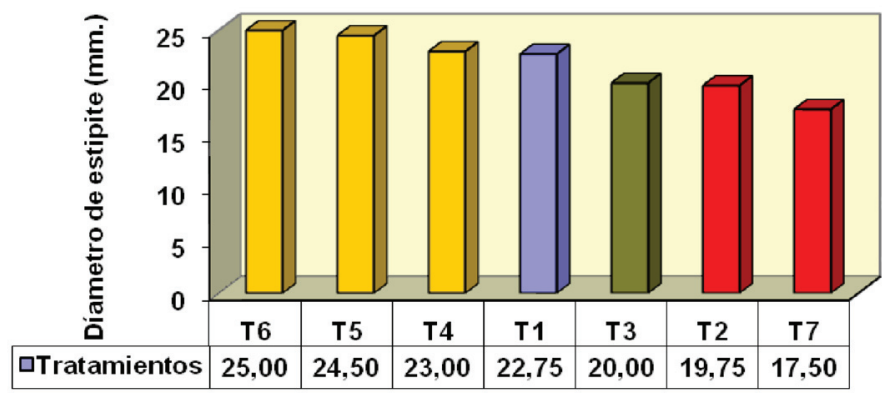

- Análisis de varianza a los 270 días (9 meses) para altura de planta

Según el análisis estadístico para altura de plantas al finalizar el periodo de vivero a los 270 días, se indica una alta significación para tratamientos en el Cuadro No 21.

La prueba de significación de Tukey, al 5\% cuadro 22, detecta 5 rangos de significación, sobresaliendo en el primer rango el tratamiento T4 con una altura de $64.90 \mathrm{~cm}$., con la dosis de 195 gramos de Nitrofoska azul (12-12-17-2) más fertilizantes simples 57 g. de Nitrato de amonio $\left(\mathrm{NO}_{3} \mathrm{NH}_{4}\right) 33.5 \%$; 12 g. de Fosfato diamónico DAP.((NH4) $\mathrm{HPO}_{4}$ ) 18-46-0 \%; 13.5 g.de Muriato de potasio $\mathrm{KCl}(60 . \%$ de $\mathrm{K} 2 \mathrm{O}) ; 34.5$ g. de Sulfato de magnesio $\left(2 \mathrm{MgSO}_{4}\right) 49 \% \mathrm{HP}_{4}$.y más 3 gramos de Acido bórico 17\%,como se indicó en el cuadro 4 de tratamientos para vivero.

En último lugar se ubica el tratamiento T7 testigo sin fertilizar con $47.33 \mathrm{~cm}$. de altura como se demuestra también el Gráfico No 10.

\section{Cuadro No 21}

Análisis de la varianza para altura a los 270 días (9 meses)

\begin{tabular}{|c|c|c|c|c|c|}
\hline Variable & $\mathbf{N}$ & \multicolumn{2}{|c|}{$\mathbf{R}^{2}$} & $\mathbf{R}^{2} \mathbf{A j}$ & CV \\
\hline Altura 9 meses & 28 & \multicolumn{2}{|c|}{0,97} & 0,96 & 2,09 \\
\hline F.V. & SC & gl & $\mathrm{CM}$ & $\mathrm{F}$ & Valor $p$ \\
\hline Tratamientos & 884 & 6 & 147,33 & 95,41 & $<0,0001$ \\
\hline Repeticiones & 30,15 & 3 & 10,05 & 6,51 & 0,0036 \\
\hline Error & 27,8 & 18 & 1,54 & & \\
\hline Total & 941,94 & 27 & & & \\
\hline
\end{tabular}

\section{Cuadro No 22}

Medias de altura de planta a los 270 días

\begin{tabular}{|crllll|}
\hline \multicolumn{2}{|l|}{ Test Tukey Alfa: 0,05} & & & \\
Tratamientos & Medias & & & & \\
\hline T4 & 64,90 & A & & & \\
T6 & 64,28 & A & B & & \\
T1 & 62,65 & A & B & & \\
T5 & 61,80 & & B & & \\
T2 & 58,75 & & & C & \\
T3 & 57,25 & & & C & D \\
T7 & 47,33 & & & & D \\
\hline
\end{tabular}




\section{Gráfico No 11}

Altura de planta a los 270 días

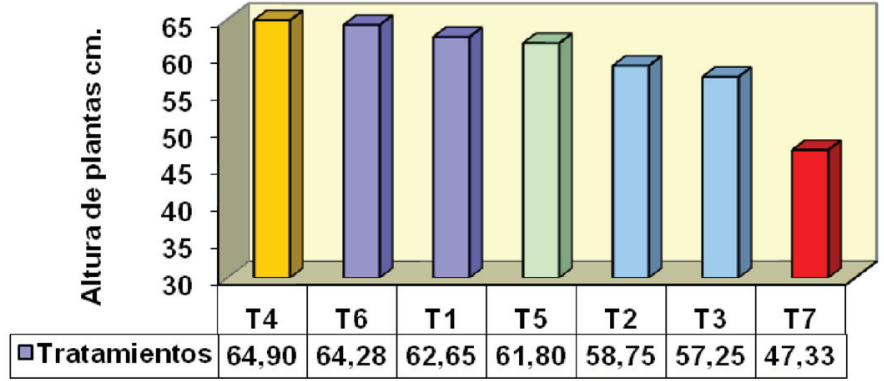

- Número de Hojas por planta en vivero a los 270 días (9 meses)

Sobre el desarrollo del número de hojas en vivero a los 270 días, existió alta significación para tratamientos, como lo expresa el Cuadro No 23.

Mediante prueba de Tukey al $5 \%$, se detectan 4 rangos en los promedios, sobresaliendo en el primer rango el tratamiento T4 (Cuadro No 19), en este caso, con 12 hojas por planta (promedio estadístico 12.18), con la dosis de 195 gramos. de Nitrofoska azul, más 57 g. de Nitrato de amonio $\left(\mathrm{NO}_{3} \mathrm{NH}_{4}\right) 33.5 \%$; 12 g. de Fosfato diamónico DAP. $\left(\left(\mathrm{NH}_{4}\right)_{2} \mathrm{HPO}_{4}\right)$ 18-46-0 \%; 13.5 g.de Muriato de potasio $\mathrm{KCl}$ ( 60.\% de $\mathrm{K} 2 \mathrm{O}) ; 34.5$ g. de Sulfato de magnesio $\left(2 \mathrm{MgSO}_{4}\right) 49 \% \mathrm{HP}_{4}$.y más 3 gramos de Acido bórico 17\%,como se indicó en el cuadro No 4. En el último rango, se ubica el tratamiento T7 testigo sin fertilización con 9 hojas.

\section{Cuadro No 23}

Análisis de varianza para número de hojas a 270 días (9 meses)

\begin{tabular}{|c|c|c|c|c|c|}
\hline Variable & $\mathrm{N}$ & \multicolumn{2}{|c|}{$\mathrm{R}^{2}$} & $\mathrm{R}^{2} \mathrm{Aj}$ & CV \\
\hline Num 9 meses & 28 & \multicolumn{2}{|c|}{0,81} & 0,72 & 4,35 \\
\hline F.V. & SC & gl & $\mathrm{CM}$ & $\mathrm{F}$ & Valor $p$ \\
\hline Tratamientos & 17,66 & 6 & 2,94 & 12,21 & $<0,0001$ \\
\hline Repeticiones & 1,15 & 3 & 0,38 & 1,59 & 0,2266 \\
\hline Error & 4,34 & 18 & 0,24 & & \\
\hline Total & 23,15 & 27 & & & \\
\hline
\end{tabular}

\section{Cuadro No 24}

Medias de número de hojas por planta a los 270 días

\begin{tabular}{|ccccc|}
\hline Test : Tukey Alfa: 0,05 & & & & \\
Tratamientos & Medias & & & \\
\hline T4 & 12,18 & A & & \\
T6 & 11,88 & A & B & \\
T1 & 11,73 & A & B & \\
T5 & 11,53 & A & B & \\
T2 & 11,15 & A & B & \\
T3 & 11,00 & & B & C \\
T7 & 9,58 & & & . \\
\hline
\end{tabular}

\section{Gráfico No 12}

\section{Número de hojas a los 270 días}

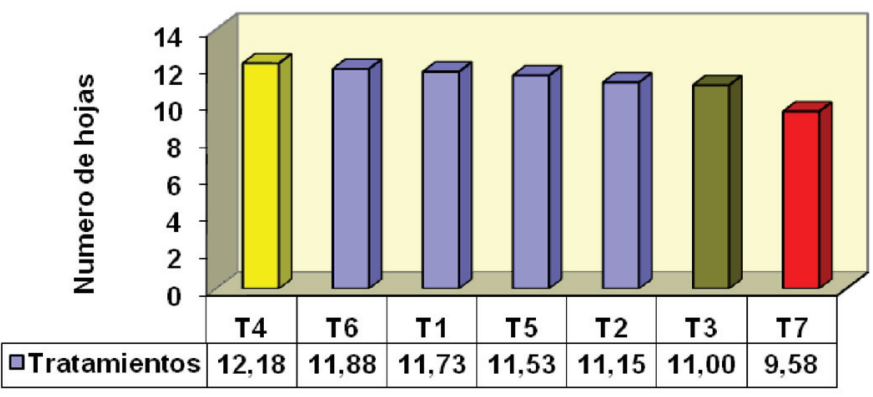

- Diámetro de estipe a los 270 días (9 meses)

Del análisis estadístico para diámetro de estipe, realizado a los 9 meses de vivero, se notó una alta significación para tratamientos según el cuadro 25 del Adeva. La prueba de significación de Tukey, al 5\% del Cuadro No 26, demuestra 3 rangos de significación, sobresaliendo en el primer rango el tratamiento $\mathrm{T}_{5}$ con un promedio de $47.5 \mathrm{~mm}$. de diámetro ocupando también el mismo rango los tratamientos T6, T1 y T4.

El tratamiento T5 se fertilizó con la dosis de 260 gramos/planta de Nitrofoska azul (12-12-17-2) más fertilizantes simples 76 g. de Nitrato de amonio $\left(\mathrm{NO}_{3} \mathrm{NH}_{4}\right) 33.5 \%$; 19 g. de Fosfato diamónico DAP.((NH4) $\mathrm{HPO}_{4}$ ) 18-46-o \%; 18 g.de Muriato de potasio KCl( 60.\% de K2O); 46 g. de Sulfato de magnesio $\left(2 \mathrm{MgSO}_{4}\right) 49 \% \mathrm{HP}_{4} \cdot \mathrm{y}$ más 3 gramos de Acido bórico 17\%,como se indicó en el Cuadro No 4 anteriormente. En último lugar estuvo para el tratamiento T7 testigo sin fertilizar con $28.25 \mathrm{~mm}$. 
de diámetro como lo demuestra también el Gráfico No 12.

\section{Cuadro No 25}

Análisis de varianza para diámetro de estipe a los 270 días ( 9 meses)

\begin{tabular}{|c|c|c|c|c|}
\hline Variable & $\mathrm{N}$ & $\mathrm{R}^{2}$ & $\mathrm{R}^{2} \mathrm{Aj}$ & $\mathrm{CV}$ \\
\hline Estipe 9 meses & 28 & 0,91 & 0,87 & 5,77 \\
\hline
\end{tabular}

\begin{tabular}{|c|c|c|c|c|c|}
\hline F.V. & SC & gl & $\mathrm{CM}$ & $F$ & Valor $p$ \\
\hline Tratamientos & 1077,71 & 6 & 179,62 & 31,35 & $<0,0001$ \\
\hline repeticiones & 14,11 & 3 & 4,7 & 0,82 & 0,4993 \\
\hline Error & 103,14 & 18 & 5,73 & & \\
\hline Total & 1194,96 & 27 & & & \\
\hline
\end{tabular}

\section{Cuadro No 26}

Medias de diámetro de estipe en mm.a los 270 días

\begin{tabular}{|c|c|c|c|c|}
\hline \multicolumn{5}{|c|}{ Test : Tukey Alfa: 0,05 } \\
\hline Tratamientos & Medias & $\mathbf{n}$ & & \\
\hline T5 & 47,50 & A & & \\
\hline T6 & 46,00 & A & & \\
\hline T1 & 45,25 & A & & \\
\hline T4 & 45,00 & A & & \\
\hline T2 & 39,25 & & B & \\
\hline T3 & 39,00 & & B & \\
\hline $\mathrm{T7}$ & 28,25 & & & C \\
\hline
\end{tabular}

\section{Gráfico No 13}

Diámetro de estipe a los 270 días (9 meses)

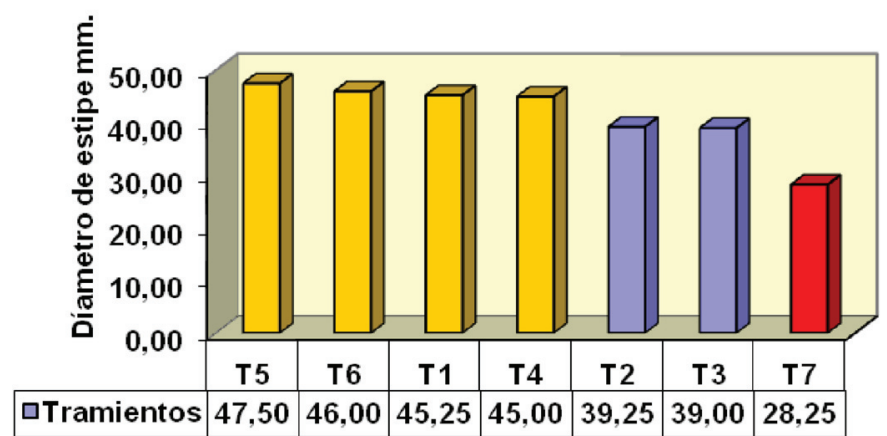

- Análisis de varianza a los 330 días (11 meses) para altura de planta

Según el análisis estadístico para altura de plantas al finalizar el periodo de vivero a los 330 días, se indica una alta significación para tratamientos.

La prueba de significación de Tukey, al 5\% cuadro 28, detecta 3 rangos de significación, sobresaliendo en el primer rango el tratamiento T4 con una altura de $89.60 \mathrm{~cm}$., con la dosis de 195 gramos de Nitrofoska azul (12-12-17-2) más fertilizantes simples 57 g. de Nitrato de amonio $\left(\mathrm{NO}_{3} \mathrm{NH}_{4}\right) 33.5 \%$; 12 g. de Fosfato diamónico DAP.(( $\left.\mathrm{NH}_{4}\right)_{2}$ $\mathrm{HPO}_{4}$ ) 18-46-0 \%; 13.5 g.de Muriato de potasio KCl( 60.\% de K2O); 34.5 g. de Sulfato de magnesio $\left(2 \mathrm{MgSO}_{4}\right) 49 \% \mathrm{HP}_{4}$.y más 3 gramos de Acido bórico al $17 \%$

Los tratamientos T6, T5 y T1, se ubican en el mismo rango. En último lugar se ubica el tratamiento T7 testigo sin fertilizar con 62.3 cm. de altura como se demuestra también el gráfico 13 de barras.

\section{Cuadro No 27}

Análisis de la varianza para altura a los 330 días (11 meses)

\begin{tabular}{|l|c|c|c|c|c|}
\hline \multicolumn{1}{|c|}{ Variable } & \multicolumn{2}{c|}{$\mathbf{N}$} & \multicolumn{1}{c|}{$\mathbf{R}^{\mathbf{2}}$} & $\mathbf{R}^{\mathbf{2}} \mathbf{A j}$ & $\mathbf{C V}$ \\
\hline \multicolumn{1}{|c|}{ altura planta } & \multicolumn{2}{c|}{$\mathbf{2 8}$} & $\mathbf{0 , 9 7}$ & $\mathbf{0 , 9 5}$ & $\mathbf{2 , 5 3}$ \\
\hline \multicolumn{1}{|c|}{ F.V. } & $\mathrm{SC}$ & $\mathrm{gl}$ & $\mathbf{C M}$ & $\mathbf{F}$ & Valor $\mathbf{p}$ \\
\hline Tratamientos & 2370,31 & 6 & 395,05 & 90,08 & $<0,0001$ \\
Repeticiones & 8,28 & 3 & 2,76 & 0,63 & $\mathbf{0 , 6 0 5 3}$ \\
Error & 78,94 & 18 & 4,39 & & \\
Total & 2457,53 & 27 & & & \\
Tot
\end{tabular}

\section{Cuadro No 28}

Promedios altura de planta a los 330 días

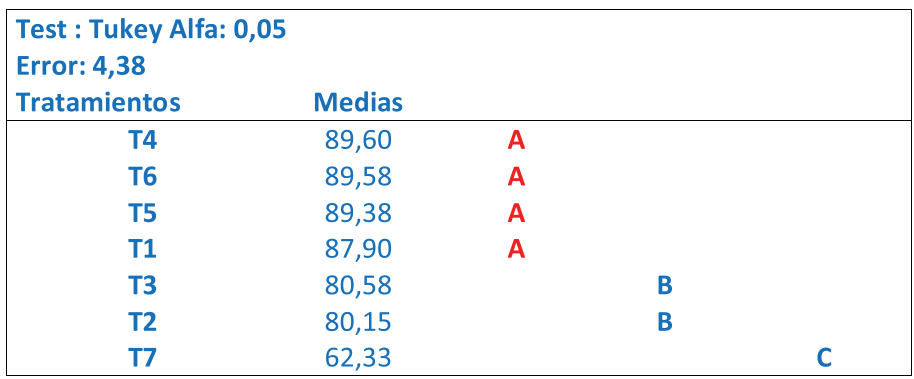


Foto3 Planta de vivero de 11 meses

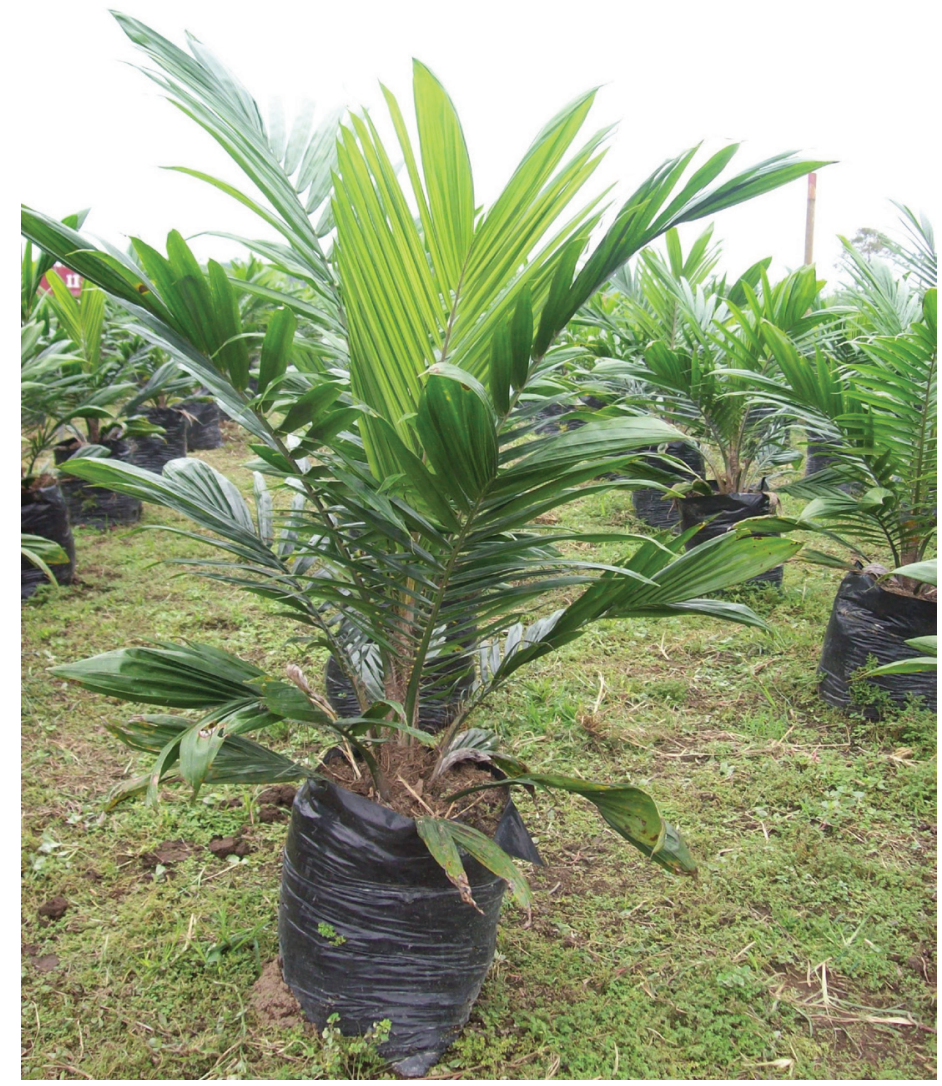

\section{Gráfico No 14}

Altura de planta a los 330 días (11 meses)

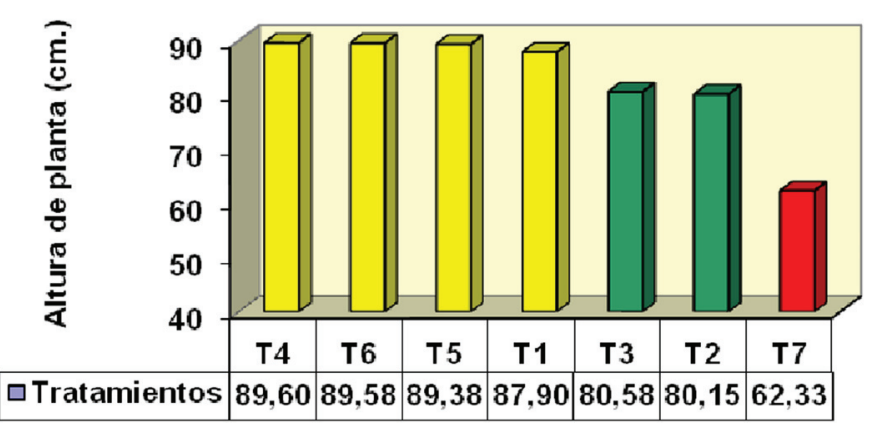

- Número de Hojas por planta en vivero a los 330 días (11 meses)

El número de hojas se ha evaluado mensualmente desde el primer mes hasta el mes décimo primero (330 días) de edad que se considera un tamaño adecuado de plantas para el trasplante al sitio definitivo. El cuadro 17, indica el desarrollo del número de hojas desde la fase de previvero del mes 1 hasta el mes 11, .Los tratamientos fertilizados que mejor se destacaron en el ensayo fueron T5, T4, T6 y T1. Frente al testigo T7 sin fertilización. Se puede notar que en esta fase, se forma en promedio una hoja por mes de las plántulas.

Se demuestra en el gráfico 9 la curva de crecimiento de número de hojas por planta con la línea de tendencia, frente al tratamiento sin fertilización.

\section{Cuadro No 29}

Número de hojas/planta por mes

\begin{tabular}{|c|c|c|c|c|c|c|c|c|c|c|c|}
\hline Meses & $\mathbf{1}$ & $\mathbf{2}$ & $\mathbf{3}$ & $\mathbf{4}$ & $\mathbf{5}$ & $\mathbf{6}$ & $\mathbf{7}$ & $\mathbf{8}$ & $\mathbf{9}$ & $\mathbf{1 0}$ & $\mathbf{1 1}$ \\
\hline Fertilizado & 1 & 2 & 3 & 5 & 6 & 8 & 9 & 11 & 12 & 12 & 13 \\
\hline Sin fertilizar & 1,0 & 2,0 & 3,0 & 4,0 & 5 & 6 & 8 & 9 & 10 & 10,0 & 11 \\
\hline
\end{tabular}

\section{Gráfico No 15}

Número de hojas por mes

NÚMERO DE HOJAS POR MES

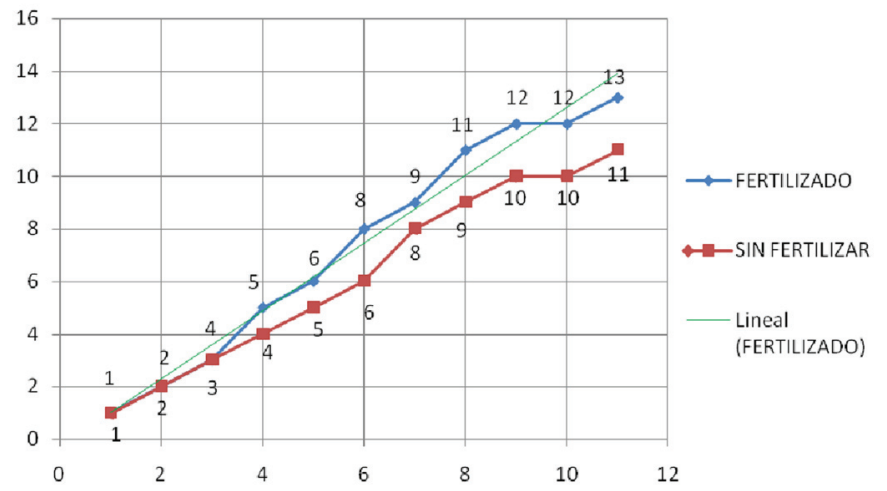


El desarrollo del número de hojas en vivero a los 330 días, existió alta significación para tratamientos, como lo expresa el cuadro 30. Mediante prueba de Tukey al 5\%, se detectan 3 rangos en los promedios, sobresaliendo en el primer rango el tratamiento T5 (cuadro 31), en este caso, con 13 hojas por planta (promedio estadístico 13.10), con la dosis de 260 gramos. de Nitrofoska azul, más 76 g. de Nitrato de amonio $\left(\mathrm{NO}_{3} \mathrm{NH}_{4}\right) 33.5 \%$; 19 g. de Fosfato diamónico DAP.(( $\left.\mathrm{NH}_{4}\right)_{2}$ $\mathrm{HPO}_{4}$ ) 18-46-o \%; 18 g.de Muriato de potasio KCl( 60.\% de K2O); 46 g. de Sulfato de magnesio $\left(2 \mathrm{MgSO}_{4}\right) 49 \% \mathrm{HP}_{4} \cdot$.y más 3 gramos de Ácido bórico $17 \%$,como se indica en el cuadro 4 de tratamientos.

En el último rango, se ubica el tratamiento T7 testigo sin fertilización con 11 hojas.

En la nutrición de las plántulas, se refleja notablemente la respuesta a la fertilización completa.

\section{Cuadro No 30}

Análisis de varianza para número de hojas a 330 días (11 meses)

\begin{tabular}{|c|c|c|c|c|}
\hline Variable & $\mathbf{N}$ & $\mathbf{R}^{2}$ & $\mathbf{R}^{2} \mathrm{Aj}$ & $\mathrm{CV}$ \\
\hline № hojas 11 meses & 28 & 0,78 & 0,67 & 3,61 \\
\hline
\end{tabular}

\begin{tabular}{|l|c|c|c|c|c|}
\hline \multicolumn{1}{|c|}{ F.V. } & SC & gl & CM & F & Valor $p$ \\
\hline Tratamientos & 12,63 & 6 & 2,11 & 10,63 & $<0,0001$ \\
Repeticiones & 0,16 & 3 & 0,05 & 0,27 & 0,8488 \\
Error & 3,56 & 18 & 0,2 & & \\
Total & 16,35 & 27 & & & \\
\hline
\end{tabular}

\section{Cuadro No 31}

Promedios de número de hojas a los 330 días (11 meses)

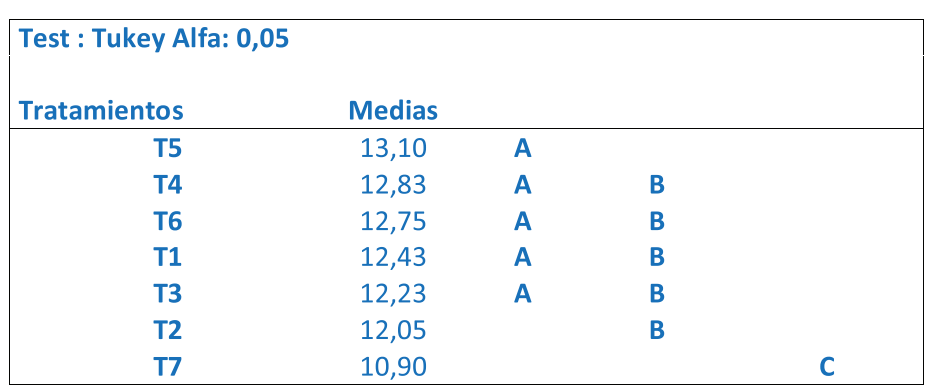

\section{Gráfico No 16}

Número de hojas a los 330 días (11 meses)

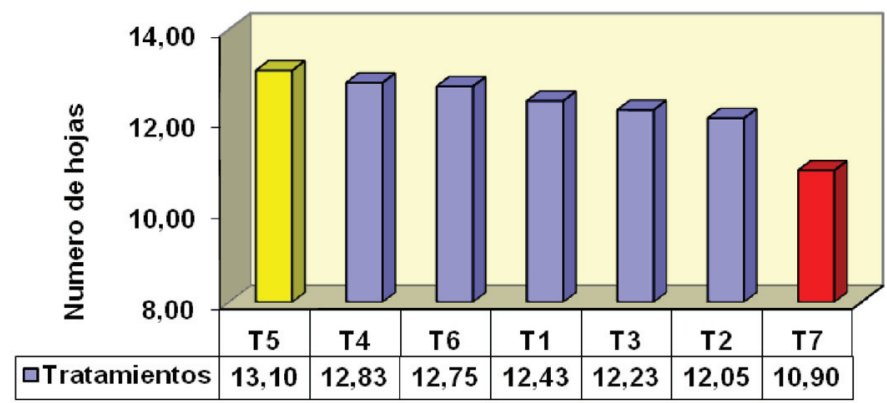

\section{- Diámetro de estipe a los 330 días (11 meses)}

Del análisis estadístico para diámetro de estipe, realizado a los 11 meses de vivero, se notó una alta significación para tratamientos según el cuadro 30 del Adeva. La prueba de significación de Tukey, al 5\% del cuadro 31, demuestra 4 rangos de significación, sobresaliendo en el primer rango los tratamiento T6 y T5 con promedios de $7.1 \mathrm{~cm}$. y $6.98 \mathrm{~cm}$. de diámetro respectivamente. El tratamiento T6 se fertilizó con la dosis de 325 gramos/planta de Nitrofoska azul (12-12-17-2) más fertilizantes simples $95 \mathrm{~g}$. de Nitrato de amonio $\left(\mathrm{NO}_{3} \mathrm{NH}_{4}\right) 33.5 \%$; $20 \mathrm{~g}$. de Fosfato diamónico DAP.(( $\left.\left.\mathrm{NH}_{4}\right)_{2} \mathrm{HPO}_{4}\right)$ 18-46-0 \%; 22.5 g.de Muriato de potasio $\mathrm{KCl}(60 . \%$ de $\mathrm{K} 2 \mathrm{O}) ; 57.5 \mathrm{~g}$. de Sulfato de magnesio $\left(2 \mathrm{MgSO}_{4}\right)$ $49 \% \mathrm{HP}_{4} \cdot$ y más 3 gramos de Acido bórico $17 \%$, como se indica en el cuadro 4 de tratamientos para vivero.

En último lugar estuvo para el tratamiento T7 testigo sin fertilizar con $4.88 \mathrm{~cm}$. de diámetro como lo demuestra también el gráfico de barras $\mathrm{N}^{\circ} 14$. 


\section{Cuadro No 32}

Análisis de varianza para diámetro de estipe a los 330 días (11 meses)

\begin{tabular}{|l|c|c|c|c|c|}
\hline \multicolumn{7}{|c|}{ F.V. } & SC & gl & CM & F & Valor $\mathbf{p}$ \\
\hline \multicolumn{7}{|c|}{ Tratamientos } & 13,37 & 6 & 2,23 & 46,65 & $<0,0001$ \\
Repeticiones & 0,13 & 3 & 0,04 & 0,92 & 0,4491 \\
Error & 0,86 & 18 & 0,05 & & \\
Total & 14,37 & 27 & & & \\
To*
\end{tabular}

\section{Cuadro No 33}

Promedios del diámetro de estipe a los 330 días (11 meses)

\begin{tabular}{|c|c|c|c|c|}
\hline Test : Tukey Al & $0,05 \mathrm{DN}$ & & & \\
\hline Tratamientos & Medias & & & \\
\hline T6 & 7,10 & A & & \\
\hline T5 & 6,98 & A & & \\
\hline T1 & 6,70 & A & B & \\
\hline T4 & 6,60 & A & B & C \\
\hline T3 & 6,33 & & B & C \\
\hline T2 & 6,15 & & & C \\
\hline T7 & 4,88 & & & \\
\hline
\end{tabular}

\section{Foto 4}

Estipe en plántula de vivero

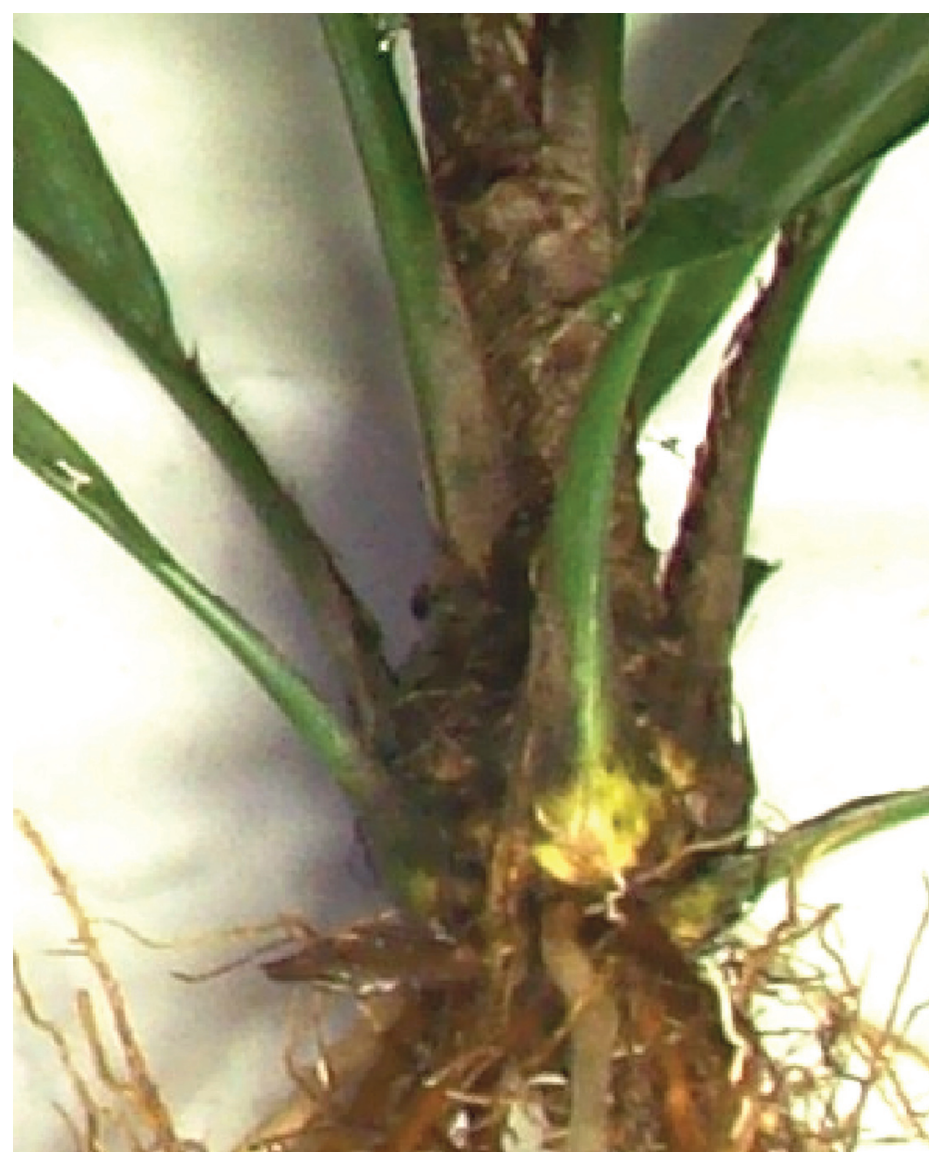

\section{Gráfico No 17}

Diámetro se estipe a los 330 días (11 meses)

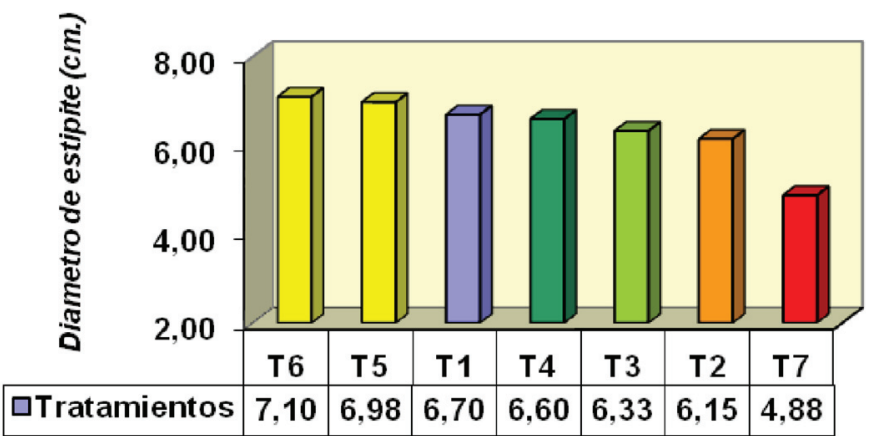

\section{Cuadro No 34}

Diámetro del estipe en vivero por mes en $\mathrm{mm}$.

\begin{tabular}{l}
\begin{tabular}{|l|c|c|c|c|c|c|c|c|c|c|c|}
\hline Tiempo & 1 & 2 & 3 & 4 & 5 & 6 & 7 & 8 & 9 & 10 & 11 \\
\hline C. Fert & 2,0 & 4,5 & 9,0 & 11,2 & 14 & 23,6 & 29 & 34 & 46,0 & 60,0 & 68,5 \\
\hline S. Fert & 2 & 4,6 & 6,7 & 8,0 & 12 & 17,6 & 21 & 25 & 28,0 & 40,0 & 49,0 \\
\hline
\end{tabular} \\
\hline
\end{tabular}

\section{Gráfico No 18}

Curva de crecimiento del estipe por mes de tratamientos fertilizados y testigo

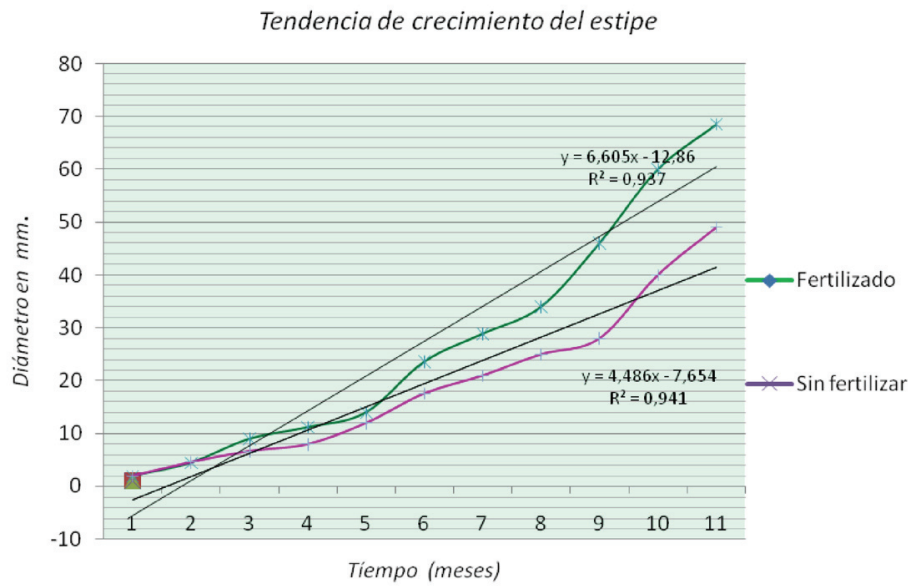




\section{Gráfico No 18}

Barras de la tendencia de crecimiento del estipe Tendencia de crecimiento del estipe

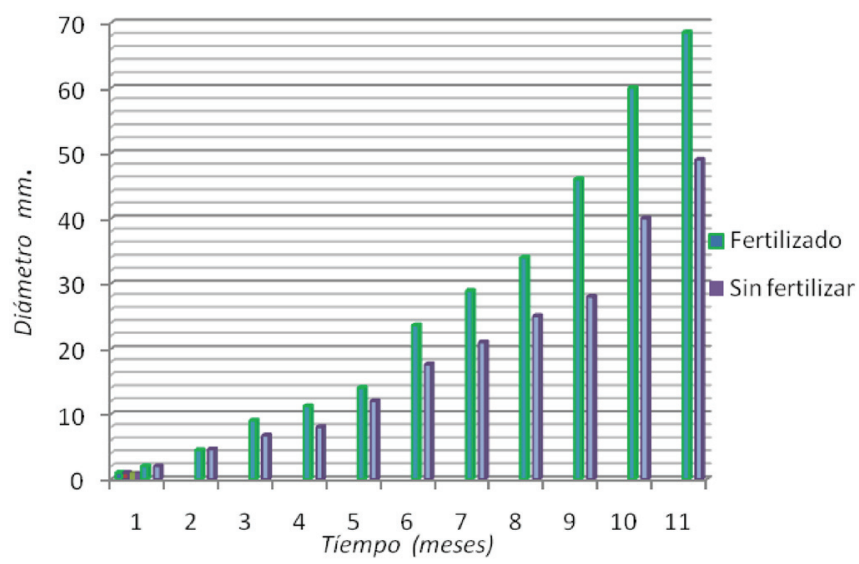

\section{- Plantas con anillo clorótico}

Al respecto se indica que sobre la infección de plantas con el virus causante del anillo clorótico, no existió significación en el ataque, pues el porcentaje fue del 1 al 1,5\% del total de plantas. Lo que si se puede recalcar que las plantas más atacadas corresponde a las más suculentas o vigorosas independientemente de estar o no fertilizadas.

\section{- Matería seca (Ms)}

\section{- Peso fresco y seco de plántulas de previvero}

El peso de plántulas por tratamiento se presenta en el Cuadro No 23. El tratamiento, que numéricamente se destaca en primer lugar con el mayor peso de materia seca, es el tratamiento T6 con la mayor dosis de aplicación de fertilizantes, luego el tratamiento (T5) de menor dosificación. Lo interesante es observar que en un tercer lugar, se destaca el tratamiento de menor cantidad aplicada de fertilizante (T1).

\section{Cuadro No 35}

Peso fresco y seco en gramos / planta, \% de humedad y \% de materia seca en Previvero al zer mes

\begin{tabular}{|c|c|c|c|c|c|c|c|c|}
\hline \multicolumn{2}{|c|}{ Tratamientos } & T1 & T2 & T3 & T4 & T5 & T6 & $\mathrm{T7}$ \\
\hline $\begin{array}{l}\text { Peso } \\
\text { fresco }\end{array}$ & $\begin{array}{l}\text { Plántula } \\
\text { con raíz }\end{array}$ & 18.59 & 16.98 & 18.81 & 17.57 & 18.69 & 19.27 & 9.02 \\
\hline & $\%$ Humedad & 69.0 & 70.8 & 69.0 & 66.7 & 70.9 & 67.3 & 55.0 \\
\hline $\begin{array}{l}\text { Peso } \\
\text { seco }\end{array}$ & $\begin{array}{l}\text { Luego de } \\
\text { estufa }\end{array}$ & 4.87 & 4.38 & 4.86 & 4.77 & 4.98 & 5.07 & 3.37 \\
\hline & $\%$ M. seca & 31.0 & 29.2 & 31.0 & 33.3 & 29.1 & 32.7 & 45.0 \\
\hline
\end{tabular}

\section{Gráfico No 19}

Peso de materia seca en gramos por planta

\section{Peso de materia seca}

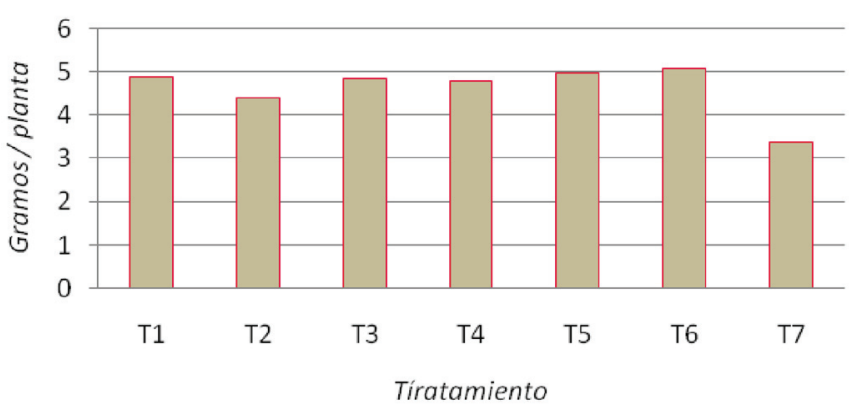

Foto No 5 Plántula de previvero

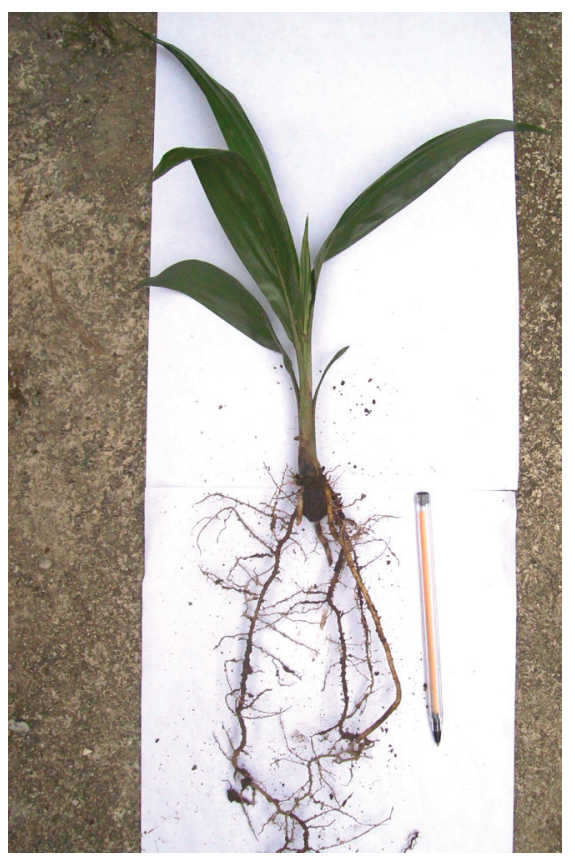




\section{Gráfico No 20}

Porcentaje de materia seca y humedad por tratamientos

\section{Porcentaje de materia seca y humedad}

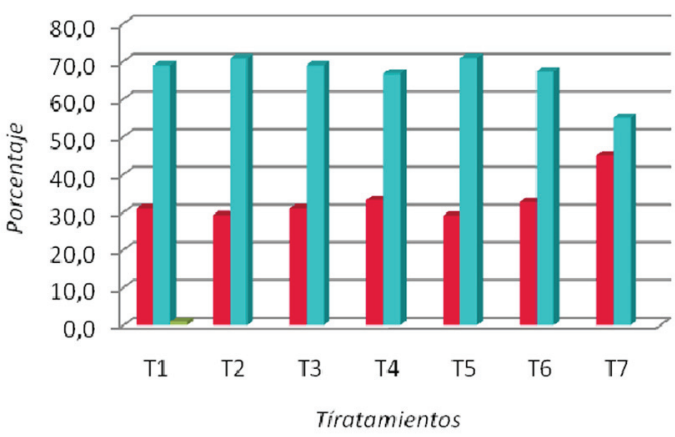

- Procesamiento de plántulas de palma para análisis de laboratorio

Las plantas muestreadas en el campo de cada tratamiento, son transpordas adecuadamente y luego de extraidas con el mayor cuidado de la maceta o funda a fin de no perder niguna fracción de sus órganos, en especial de las raíces.

Seguidamente, se lavan con agua. Las muestras así preparadas son ingresadas al laboratorio, en donde, se separan sus órganos vegetativos como son raíces, estipe y hojas y se etiquetan por sus tratamientos para ser registrado su peso fresco y luego pasan a la estufa para ser deshidratadas y tomar su peso seco y continuar luego con los respectivos análisis de absorción de nutrientes

\section{Foto No 6}

\section{Separación de órganos vegetativos}

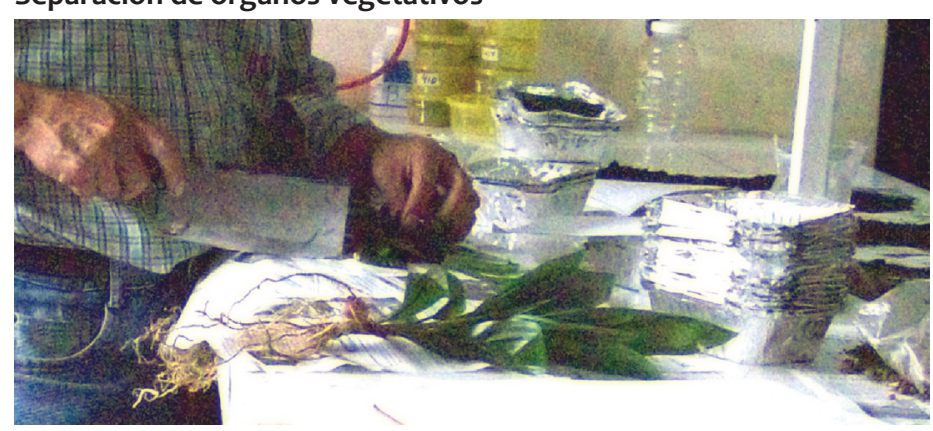

\section{Foto No 7}

\section{Hojas de palma 6 meses}

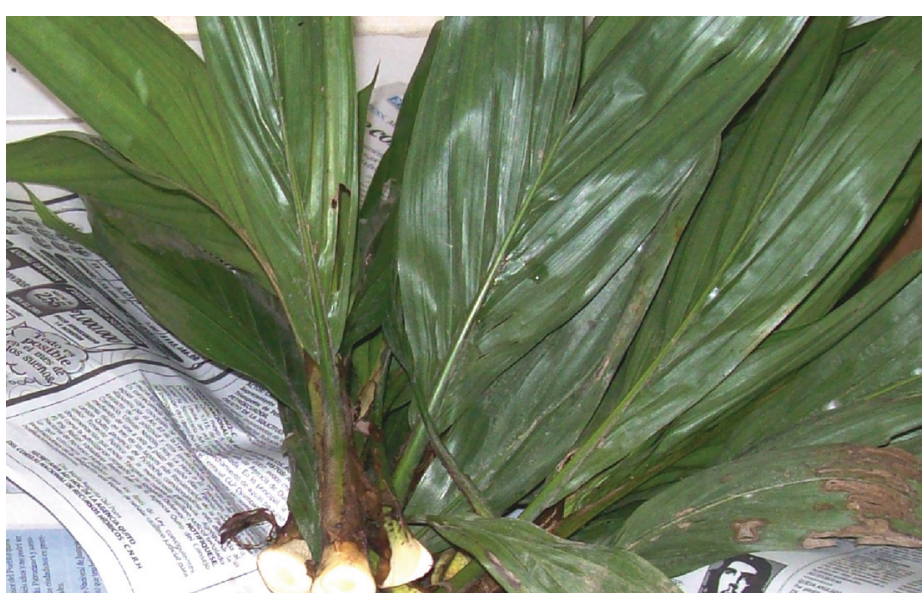

Foto No 8

Corte de raíces del estipe

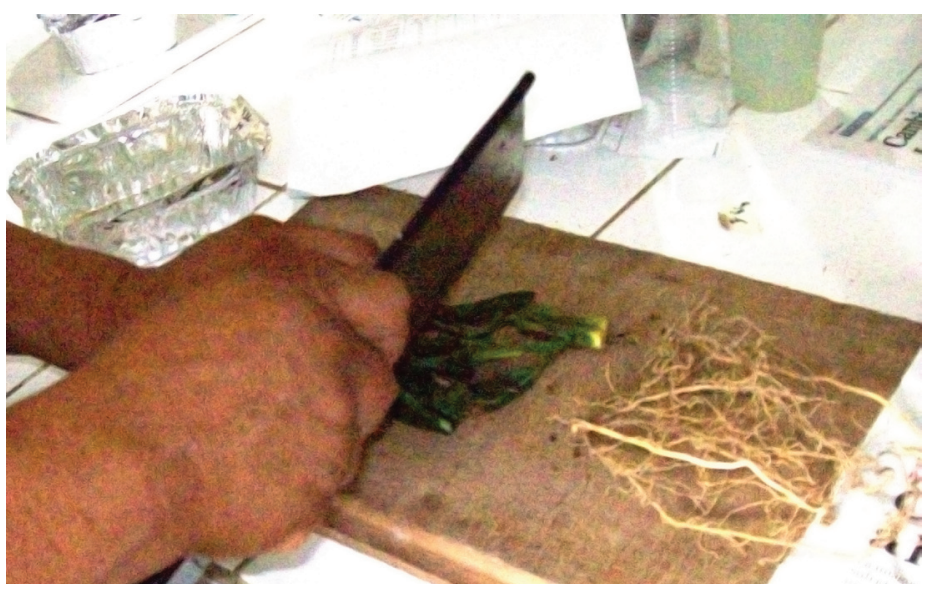

Foto No 9

Pesaje de órganos vegetativos

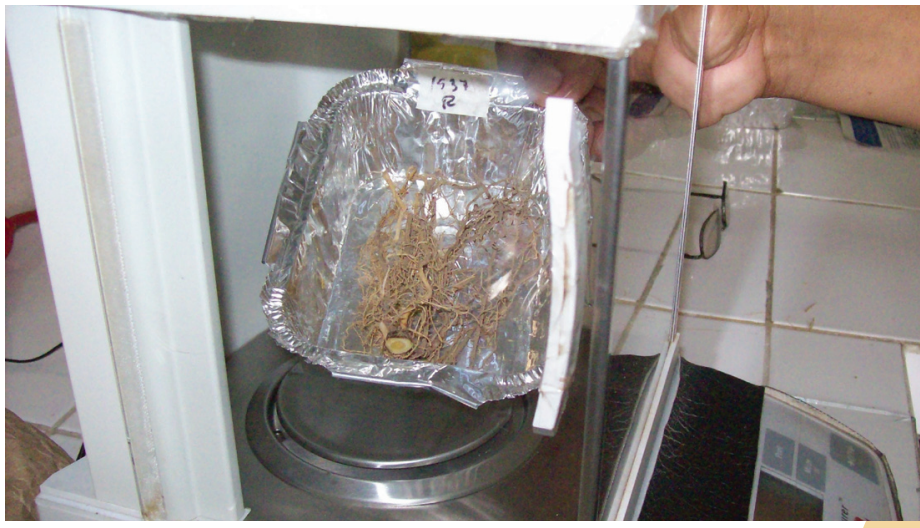




\section{Foto No 10}

\section{Estipe o pseudotallo}

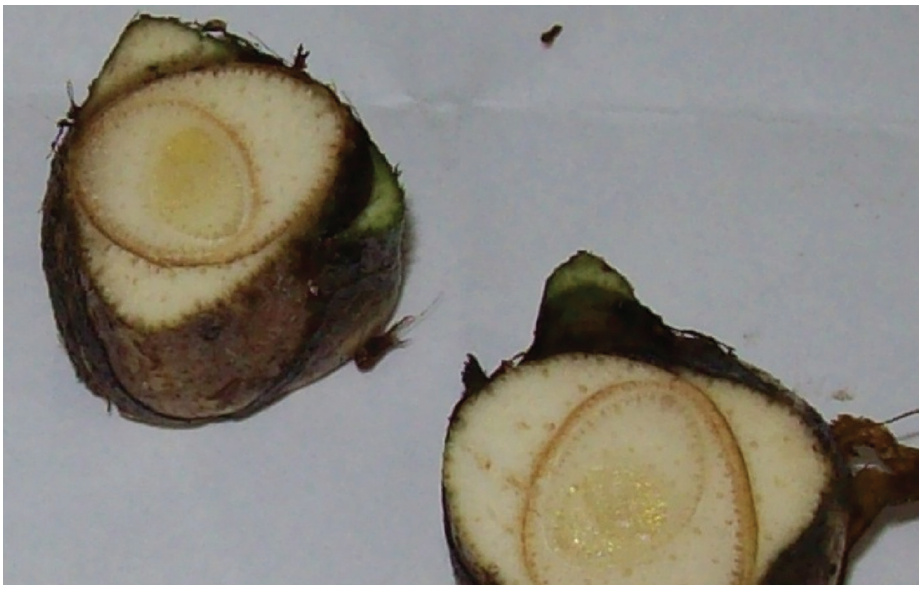

Materia seca (MS): La cantidad de materia seca producida en los diferentes tratamientos se observa en el Cuadro No 36 tanto en previvero como en vivero. A los tres meses de previvero, no se define aún la formación del estipe, por lo que no se consideró tomar este dato, considerándose como follaje el material vegetal sin la raíz; pero al mes sexto, ya se define mejor su formación.

El raquis (nervadura central de cada hoja que sujetan las secundarias de los foliolos) como parte fundamental de la conformación de la hoja, se consideró también tomar este dato por separado a los 11 meses para análisis de absorción y peso de los foliolos, los que sumados, nos dan el total del peso de las hojas. La cantidad de materia seca (MS) acumulada en los órganos vegetativos como raíz, estipe y hojas, se demuestra en el Cuadro No 25. Los resultados de laboratorio a los tres, seis, nueve y once meses de vida de las plantas de vivero, resultantes de tratamientos fertilizados.

\section{Cuadro No 36}

Resumen total de Materia seca en las fases de previvero y vivero

\begin{tabular}{|c|c|c|c|c|c|c|c|c|c|c|}
\hline \multirow{2}{*}{\multicolumn{2}{|c|}{$\begin{array}{c}\text { Etapas } \\
\text { TIEMPO }\end{array}$}} & \multirow{2}{*}{\multicolumn{2}{|c|}{$\begin{array}{c}\text { Previvero } \\
3 \text { mes }\end{array}$}} & \multicolumn{7}{|c|}{ Vivero } \\
\hline & & & & & $6 \mathrm{n}$ & & $9 \mathrm{n}$ & & $11 n$ & nes \\
\hline $\begin{array}{c}\mathrm{X} \\
\text { Tratam. }\end{array}$ & Órgano. & $\begin{array}{l}\text { P.M.S. } \\
\text { Subm. }\end{array}$ & $\begin{array}{c}\% \mathrm{M} . \\
\mathrm{S} . \\
\text { Subm. }\end{array}$ & $\begin{array}{l}\text { Órgano } \\
\text { planta }\end{array}$ & $\begin{array}{l}\text { P M.S. } \\
\text { Subm. }\end{array}$ & $\begin{array}{c}\% \mathrm{M} . \\
\mathrm{S} . \\
\text { Subm }\end{array}$ & $\begin{array}{l}\text { P M.S. } \\
\text { subm }\end{array}$ & $\begin{array}{c}\% \mathrm{M} . \\
\mathrm{S} . \\
\text { Subm. }\end{array}$ & $\begin{array}{l}\text { P M.S. } \\
\text { subm }\end{array}$ & \begin{tabular}{|c}
$\% \mathrm{M}$. \\
$\mathrm{S}$. \\
Subm.
\end{tabular} \\
\hline \multirow{4}{*}{1} & Raíz & 1.30 & 38.19 & Raíz & 14,70 & 21,69 & 19,68 & 18,90 & 22,18 & 25,31 \\
\hline & \multirow{3}{*}{$\begin{array}{l}\text { Hojas } \\
\text { Total }\end{array}$} & \multirow[b]{2}{*}{3.57} & \multirow{3}{*}{23.52} & Estipe & 10,55 & 30,01 & 40,88 & 33,49 & 55,95 & 36,75 \\
\hline & & & & Hojas & 27,26 & 36,74 & 25,60 & 37,75 & 102,72 & 64,48 \\
\hline & & \begin{tabular}{|l|}
4.87 \\
\end{tabular} & & Total & 52,51 & & 86,16 & & 180,85 & \\
\hline \multirow{4}{*}{2} & Raíz & 1.05 & 34.44 & Raíz & 18,28 & 26,78 & 16,23 & 26,31 & 42,24 & 24,23 \\
\hline & \multirow{3}{*}{$\begin{array}{l}\text { Hojas } \\
\text { Total }\end{array}$} & \multirow[b]{2}{*}{3.34} & \multirow{3}{*}{23.9} & Estipe & 12,25 & 33,02 & 31,78 & 37,69 & 40,61 & 39,35 \\
\hline & & & & Hojas & 22,65 & 35,53 & 15,25 & 31,65 & 74,66 & 60,66 \\
\hline & & 4.39 & & Total & 53,18 & & 63,26 & & 157,51 & \\
\hline \multirow{4}{*}{3} & Raíz & 1.02 & 38.19 & Raíz & 27,88 & 30,68 & 16,31 & 25,36 & 21,01 & 27,49 \\
\hline & \multirow{3}{*}{$\begin{array}{l}\text { Hojas } \\
\text { Total }\end{array}$} & \multirow[b]{2}{*}{3.84} & \multirow{3}{*}{23.81} & Estipe & 11,19 & 31,45 & 34,39 & 38,80 & 25,75 & 42,16 \\
\hline & & & & Hojas & 27,61 & 33,79 & 26,67 & 37,22 & 76,38 & 68,97 \\
\hline & & 4.86 & & Total & 66,68 & & 77,37 & & 123,14 & \\
\hline \multirow{4}{*}{4} & & 0.84 & 41.41 & Raíz & 22,16 & 25,23 & 21,15 & 22,64 & 25,22 & 22,94 \\
\hline & \multirow{3}{*}{$\begin{array}{l}\text { Hojas } \\
\text { Total }\end{array}$} & \multirow[b]{2}{*}{3.93} & \multirow{3}{*}{25.26} & Estipe & 11,77 & 32,15 & 47,12 & 34,29 & 35,55 & 33,96 \\
\hline & & & & Hojas & 29,07 & 31,6 & 25,94 & 36,97 & 64,96 & 57,64 \\
\hline & & 4.77 & & Total & 63,00 & & 94,21 & & 125,73 & \\
\hline \multirow{4}{*}{5} & Raíz & 1.03 & 32.81 & Raíz & 18,87 & 24,57 & 19,94 & 21,12 & 34,01 & 21,55 \\
\hline & \multirow[b]{2}{*}{ Hojas } & \multirow[b]{2}{*}{3.95} & \multirow{3}{*}{25.37} & Estipe & 12,40 & 33,59 & 38,81 & 36,76 & 40,11 & 40,61 \\
\hline & & & & Hojas & 24,28 & 35,31 & 26,52 & 37,34 & 81,06 & 66,93 \\
\hline & Total & 4.98 & & Total & 55,55 & & 85,27 & & 155,18 & 30,8 \\
\hline \multirow{4}{*}{6} & Raíz & 0.87 & 40.95 & Raíz & 20,13 & 28,81 & 24,60 & 24,86 & 44,47 & 26,15 \\
\hline & \multirow{3}{*}{ Hojas } & \multirow[b]{2}{*}{4.21} & \multirow{3}{*}{24.52} & Estipe & 11,68 & 32,18 & 36,35 & 35,13 & 37,36 & 38,83 \\
\hline & & & & Hojas & 27,07 & 35,26 & 27,00 & 35,55 & 75,38 & 62,65 \\
\hline & & 5.08 & & Total & 58,88 & 32,18 & 87,95 & 31,59 & 298,26 & 30,69 \\
\hline \multirow{4}{*}{$\begin{array}{c}7 \\
\text { Testigo sin } \\
\text { fertilizar. }\end{array}$} & Raíz & 1.13 & 59.46 & Raíz & 10,71 & 29,81 & 21,24 & 28,06 & 13,29 & 28,3 \\
\hline & Hojas & & & Estipe & 4,40 & 31,47 & 22,00 & 37,51 & 14,29 & 37,81 \\
\hline & & 2.24 & 31.48 & Hojas & 13,10 & 32,89 & 17,94 & 30,72 & 42,04 & 63,97 \\
\hline & 3,37 & 3.37 & & Total & 28,21 & & 61,18 & & 69,62 & \\
\hline
\end{tabular}

\section{Foto No 11}

Sistema radicular en plántula de 6 meses

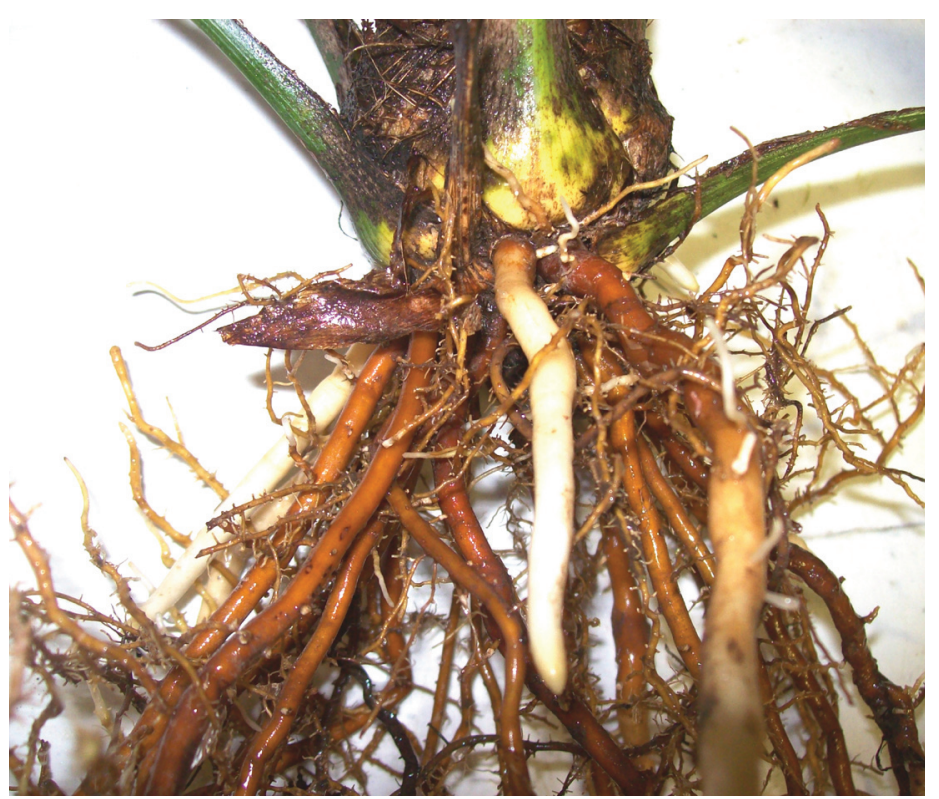




\section{Foto No 12}

Plántula de 9 meses con gran desarrollo del sistema radicular

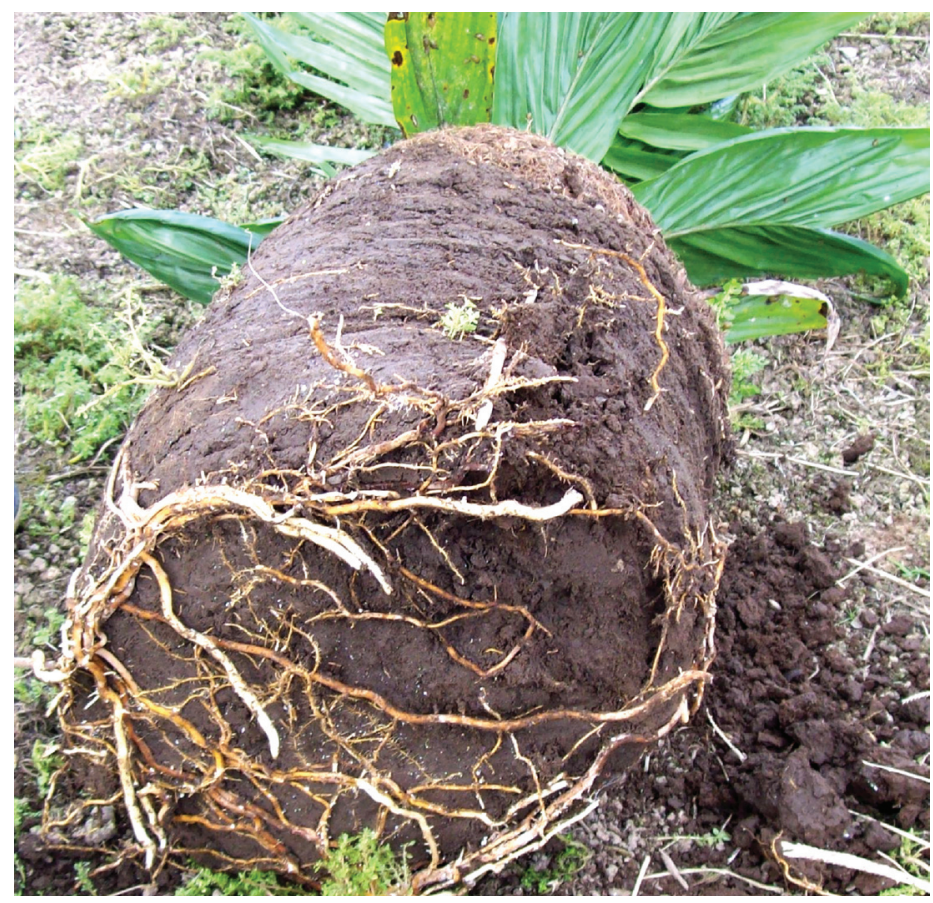

Seguidamente se puede apreciar en el Gráfico No 19 las curvas de acumulación de materia seca en ascenso de acuerdo a la edad, siendo visualmente notable la mayor cantidad de materia seca en las hojas a los 11 meses con 82,91 gramos por planta en comparación con los demás órganos. El estipe con 43.87 gramos y en menor cantidad se acumula en las raíces, con 27.14 gramos por planta (Cuadro No 37).

\section{Cuadro No 37}

Resumen de Materia Seca en gramos acumulada en las fases de previvero y vivero.

\begin{tabular}{|c|c|c|c|c|}
\hline \multirow{2}{*}{$\begin{array}{c}\text { Órganos de la } \\
\text { planta. }\end{array}$} & \multicolumn{4}{|c|}{ Materia seca en gramos/planta } \\
\cline { 2 - 5 } & 3 & 6 & 9 & 11 \\
\hline Raíz & 1,7 & 20,49 & 20,26 & 27,14 \\
\hline Estipe & 0,97 & 11,38 & 42,27 & 43,87 \\
\hline Hojas & 2,19 & 26,38 & 27,38 & 82,91 \\
\hline Total planta & 4,86 & 58,25 & 89,91 & 153,92 \\
\hline
\end{tabular}

En el Gráfico No 19, se demuestra la cantidad de materia seca evaluada en las plántulas desde 3 a 11 meses, en el que se puede apreciar, el incremento paulatino del desarrollo de cada órgano vegetativo. El crecimiento se inicia de manera ascendente hasta los 6 meses tanto en raíz, estipe y hojas; pero luego, se distingue un cambio fenológico para la formación del estipe (tronco o seudotallo), el cual, inicia un ascenso en incremento del $271 \%$ (de 11.38 a 42,27 g.) de materia seca hasta el noveno mes, mientras que la raíz con las hojas mantienen curvas casi paralelas hasta el noveno mes.

A partir del noveno mes hasta el décimo primer mes, se nota un gran cambio fenológico en la formación de hojas, esto debido a que se incrementa tanto el número de hojas, su área foliar y la formación más pronunciada del raquis o nervadura central de las hojas, iniciándose un ascenso en incremento del $203 \%$ en dos meses, mientras que en el caso de la raíz y estipe se mantiene un ascenso casi paralelo desde los 9 a los 11 meses como también se aprecia en el grafico 20 de barras. Esto nos ayuda a determinar el mejor tiempo de fertilización.

\section{Gráfico No 21}

Curvas de incremento de materia seca por órganos vegetativos

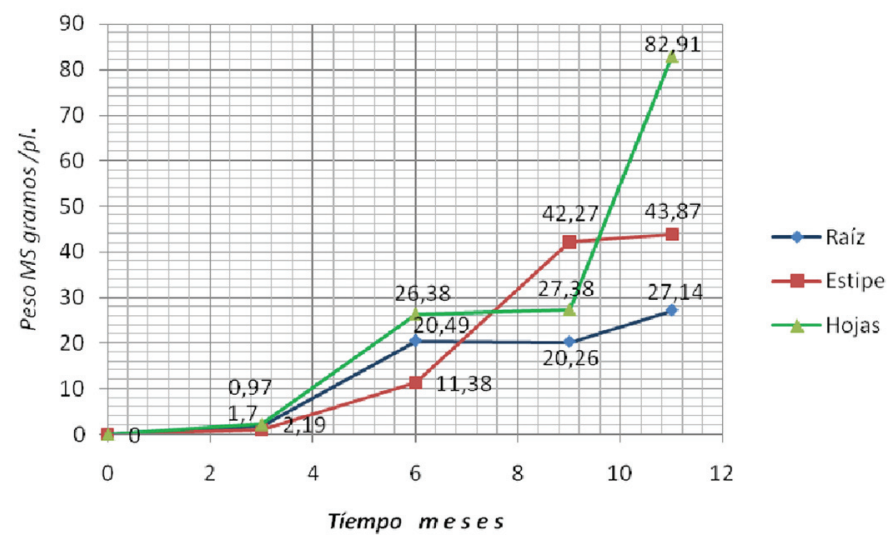




\section{Gráfico No 22}

Incremento de materia seca de los órganos vegetativos

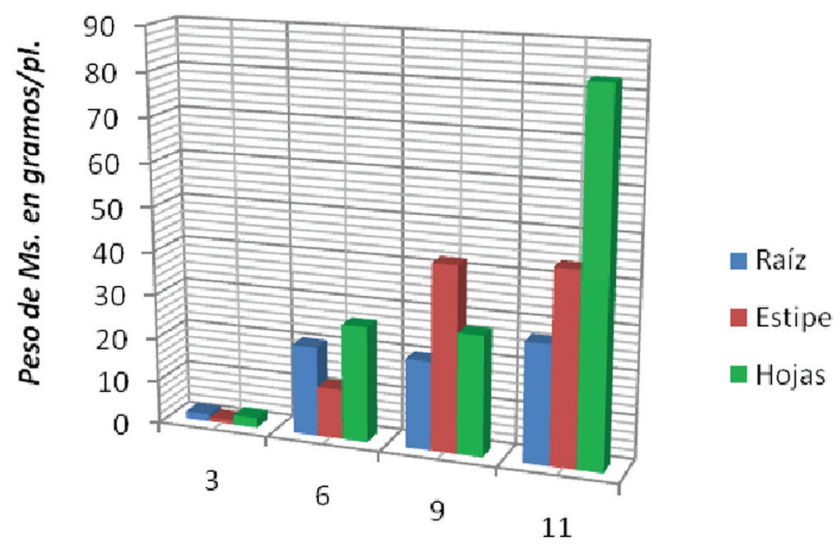

Tíempo meses

El aumento de peso o materia seca, significa que se produce un incremento de la mása foliar como se ha visto reflejado en el crecimiento en altura de planta y diámetro de estipe en los últimos 3 meses Gráficos No 5 y No 15 de ésta investigación en especial en los tratamientos fertilizados. Criterio similar de Ruiz R. que manifiesta que el aumento de peso de las plantas, es dependiente de la tasa de neta asimilación y de la tasa de crecimiento de superficie de las hojas. Y la más grande acumulación de peso subsiguiente al abonamiento es acompañada por el aumento en la superficie de la hoja sin cambiar la tasa de asimilación.

\section{- La absorción de nutrientes}

El concepto de medición de la cantidad consumida de nutrientes por una planta, es la cantidad absorbida por los órganos de absorción en especial por el sistema radicular, es decir que esta es la cantidad requerida de nutrientes para su desarrollo y producción.

Este parámetro, se obtiene, según Berch F. 2003, del asocio del peso seco de los tejidos con las concentraciones de nutrimentos totales presentes en esos tejidos, expresados en gramos o Kg. Así, la absorción, se puede calcular de la parte vegetativa, partes reproductivas, parte radical y de la cosecha obtenida en un cultivo.

La absorción de nutrientes, según Calvache M., se obtiene a partir de la fórmula siguiente:

$$
\text { Cantidad Ab. }=\frac{\text { Peso MS subm. } x \% \text { nutriente }}{\text { g./planta. }}
$$$$
100
$$

En el caso de la nutrición del cultivo de palma aceitera en vivero, subministrada a través de los elementos macro y micro nutrientes, los cuales han sido absorbidos durante el ciclo de vida o fases en 11 meses de vida, evaluados en previvero y vivero, se expresan en el cuadro 27. en unidades de gramos por planta, cantidades promedias entre los tratamientos fertilizados, y considerados de óptima absorción, de acuerdo al desarrollo morfológico de órganos vegetales de las plántulas dados según análisis estadístico.

Para tal efecto, se ha considerado tomar la información de absorción de nutrientes de los órganos de la planta como son: Raíces, órganos foliares como el estipe y hojas medidos a partir del peso de materia seca de las plantas evaluadas de los tratamientos que se establecieron.

Así, el programa de fertilización, que se efectuó por una parte en base a las recomendaciones proporcionadas por la Estación Experimental INIAP Sto. Domingo por trabajarse con el material Híbrido Tenera, y también en base a la Guía de campo de Rankine lan y Fairhurst T. de Enero 2004.

En base a estos antecedentes, se estableció la preparación de las fórmulas nutritivas más un testigo sin fertilizar y de esta manera obtener criterios en la detección de las óptimas cantidades que requiere el cultivo, sirviendo de comparación las variables del desarrollo 
morfológico de las plantas como altura medida en centímetros, número de hojas por planta, diámetro del estipe medido a $1 \mathrm{~cm}$. de altura del suelo y el peso de materia seca de los órganos que sumados dan el peso total de la planta.

\section{- Absorción en Previvero:}

Para previvero, el sustrato utilizado de suelo de la zona de estudio, fue de textura franco arenosa, e interpretado según análisis de laboratorio con niveles de N (bajo), P (alto), K (alto), Ca (medio), y Mg (medio). Además los micronutrientes Cu (alto), B (alto), Fe (alto), Zn (medio) y Mn (medio), se obtuvo los siguientes resultados:

\section{- Resultados de Absorción el Previvero}

La absorción de nutrientes en la fase de previvero (tomada a los tres meses), se demuestra en el Cuadro No 38. Son los contenidos de nutrientes en gramos por planta

\section{Cuadro No 38}

Absorción de Nutrientes en Previvero a los 90 días (3 meses)

\begin{tabular}{|c|c|c|c|c|c|c|c|c|c|c|c|}
\hline $\begin{array}{c}\text { Meses } \\
\text { D.S. }\end{array}$ & N & P & K & Ca & Mg & S & Cu & B & Fe & Zn & Mn \\
\hline 3 & 0,150 & 0,010 & 0,096 & 0,021 & 0,010 & 0,008 & 0,00011 & 0,00019 & 0,00271 & 0,00011 & 0,0006 \\
\hline
\end{tabular}

\section{- Curva de Absorción:}

La curva de absorción, representa el proceso de absorción de los macro y micronutrientes realizado por el cultivo en sus fases de desarrollo y producción. Estos procesos y estudios, son de gran utilidad ya que representan la información básica para establecer las etapas fenológicas más importantes del ciclo del cultivo con el objeto de mejorar el programa de nutrición vegetal.

Las curvas nos permiten conocer la acumulación de nutrientes en el tiempo en los diferentes órganos vejetativos y tejidos de la planta. La graficación de una curva en dos dimensiones, está dada en unidades de peso por planta o por hectárea, frente al transcurso de un ciclo de vida o tiempo determinado del cultivo.

\section{Gráfico No 23}

\section{Curva de Absorción de maco y micronutrientes en Previvero}

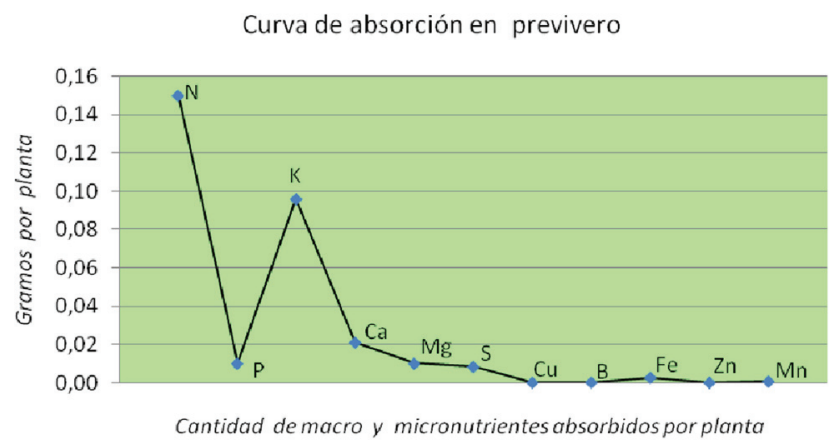

\section{Gráfico No 24}

Absorción de macro y micronutrientes en Previvero

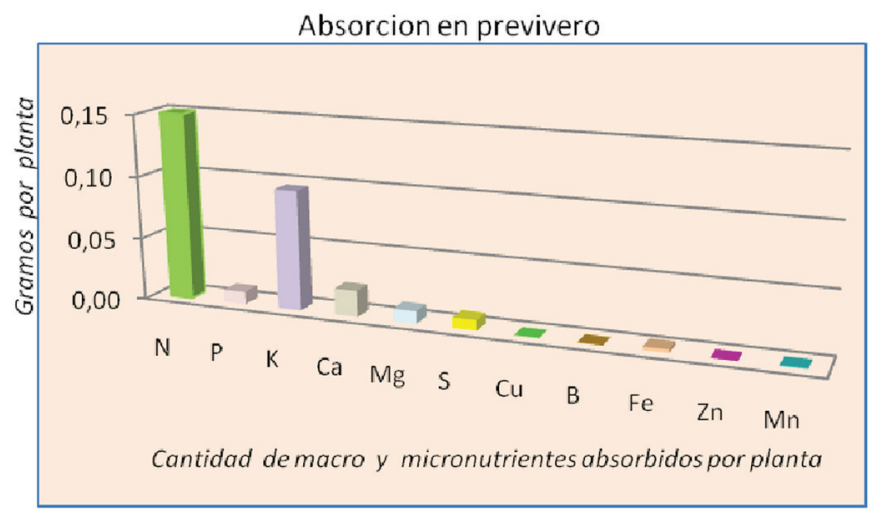


- Absorción de nutrientes en el ciclo total de previvero y vivero

\section{Cuadro No 39.}

Cantidad de macro y micronutrientes absorbidos en fases de previvero y vivero de palma de aceite (g./pl. a los 3, 6, 9 y 11 meses) UTE Sto. Domingo, 2008

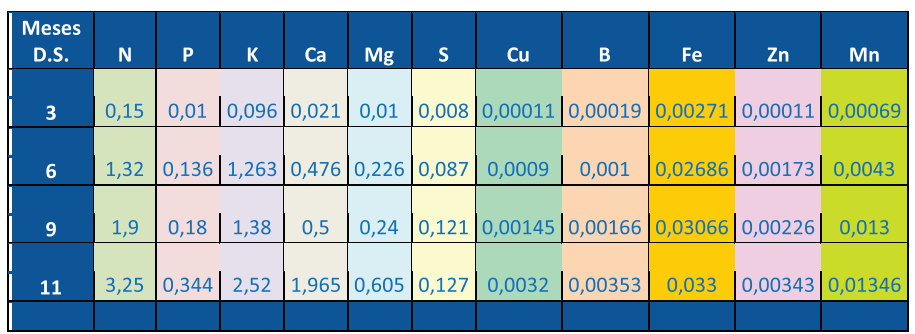

- Gráficaciones de absorción de nutrientes en vivero por elementos

En los gráficos 23, 24, 25 se observa la curva de absorción de los macro-elementos primarios Nitrógeno, Fósforo y Potasio de la fase de vivero de las plantas analizadas. Hay que considerar que el elemento Nitrógeno, es requerido en forma constante con tendencia a ascenso como lo indica la línea, durante el ciclo de vivero de palma. Por lo que es indispensable su aplicación periódica y en ascenso.

\section{Gráfico No 25}

\section{Absorción de Nitrógeno}

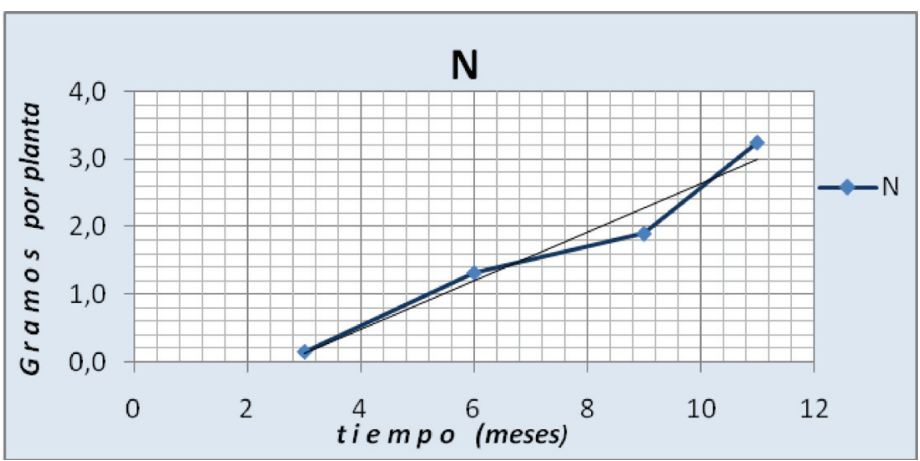

\section{Gráfico 26}

Absorción de Fósforo

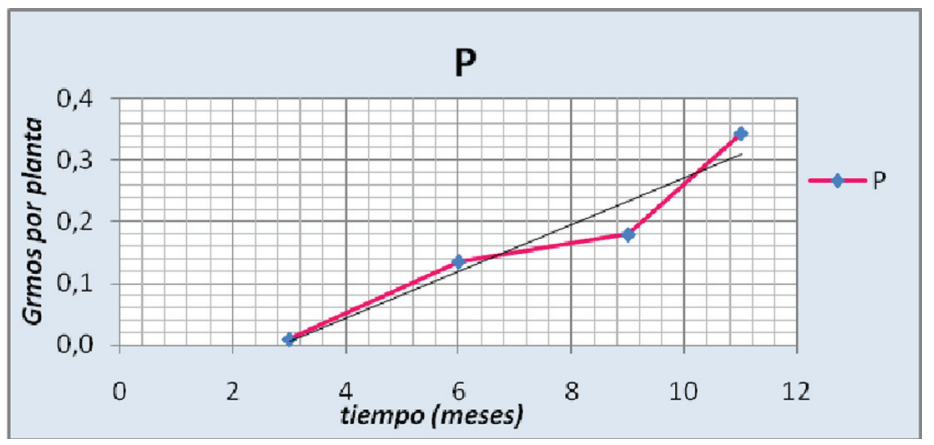

Gráfico No 27

Absorción de Potasio

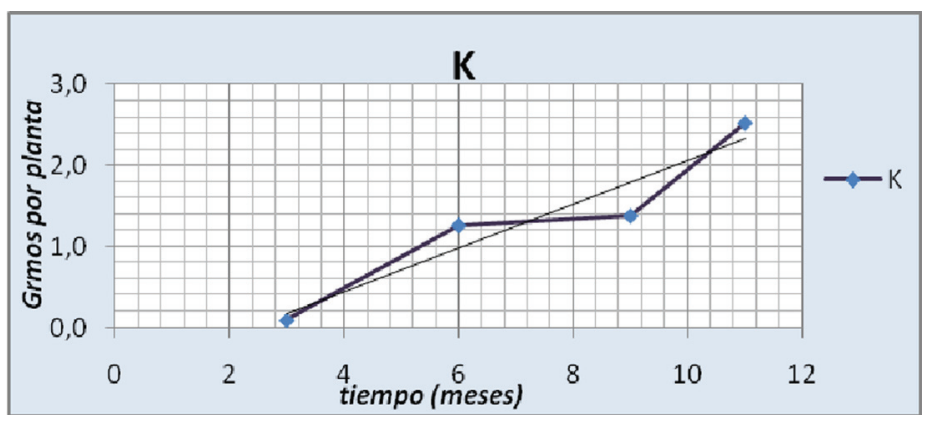

En los Gráficos No 26 y No 27, se puede identificar la relación 9-1-7 de N P K respectivamente entre los tres elementos mayores o primarios de los nutrientes durante el ciclo de vivero.

\section{Gráfico No 28}

Curvas de absorción de los macronutrientes N P K

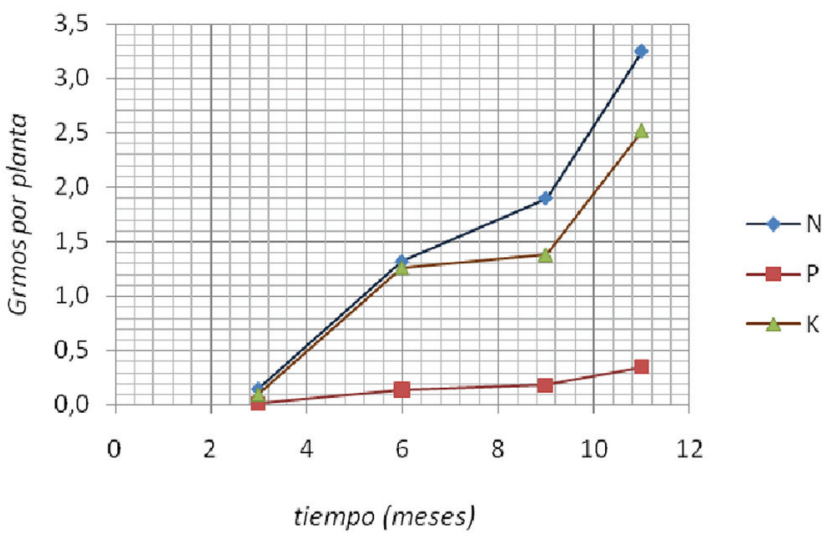


Gráfico No 29

\section{Absorción de N P K}

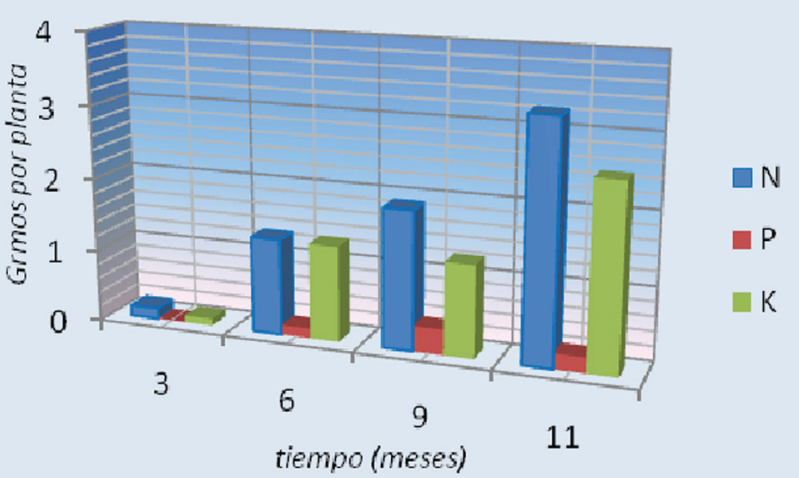

Gráfico No 30

\section{Absorción de Calcio}

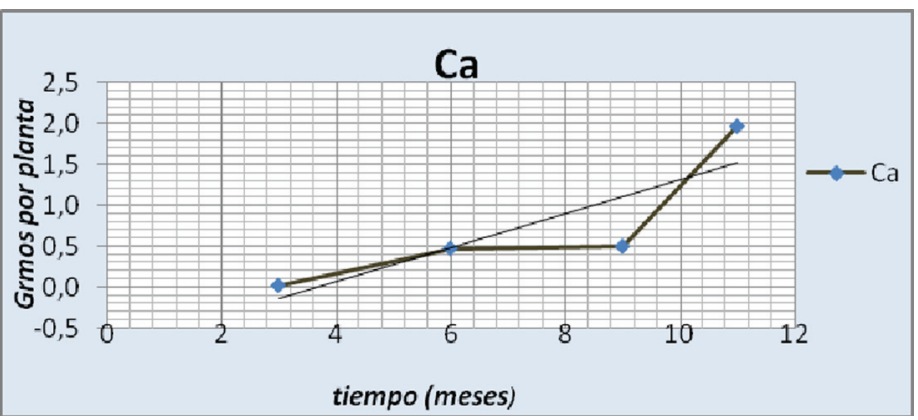

\section{Gráfico No 31}

\section{Absorción de Magnesio}

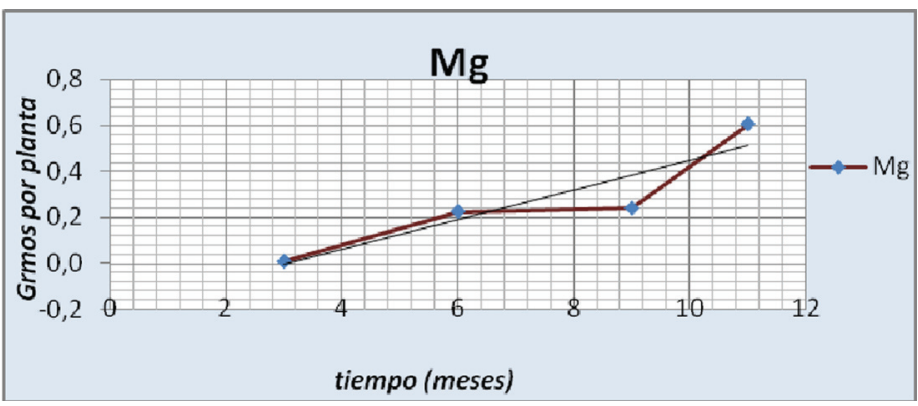

\section{Gráfico No 32}

\section{Absorción de Azufre}

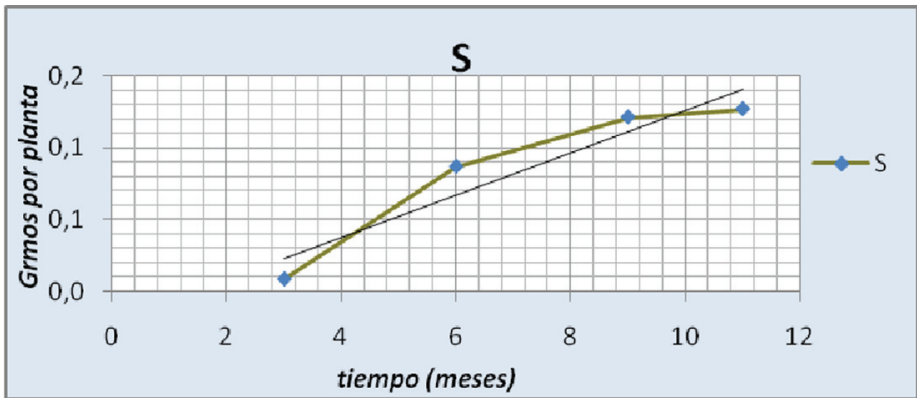

La absorción de macronutrientes primarios y secundarios, se indican en el Gráfico No 31. Las curvas de los elementos $\mathrm{N}, \mathrm{P}, \mathrm{K}, \mathrm{Ca}$, Mg, y S presentes desde el primer año de vida encontrados en los órganos vegetativos de plantas de vivero. Se puede observar la participación del Calcio como principal elemento de los macronutrientes secundarios que se nota un importante incremento a partir del mes 9 para la formación en especial del estipe y raquis de las hojas.

\section{Gráfico No 33}

\section{Absorción de Macronutrientes primarios y secundarios} Absorción de Macronutrientes

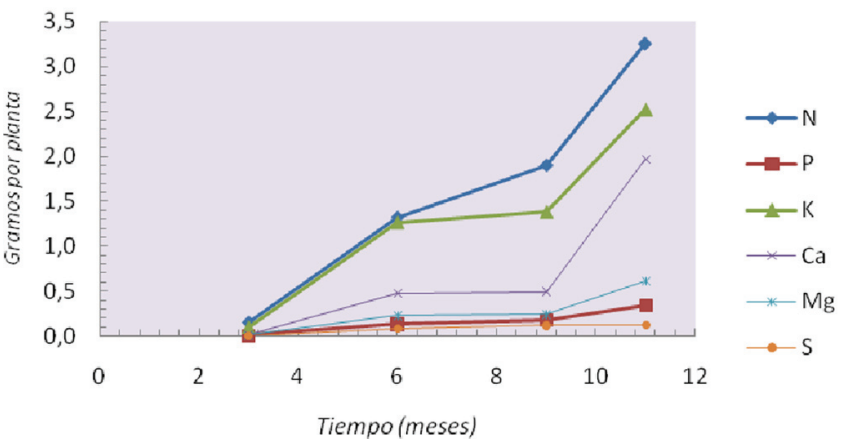




\section{Gráfico No 34}

\section{Absorción de macronutrientes en los 11 meses de vivero}

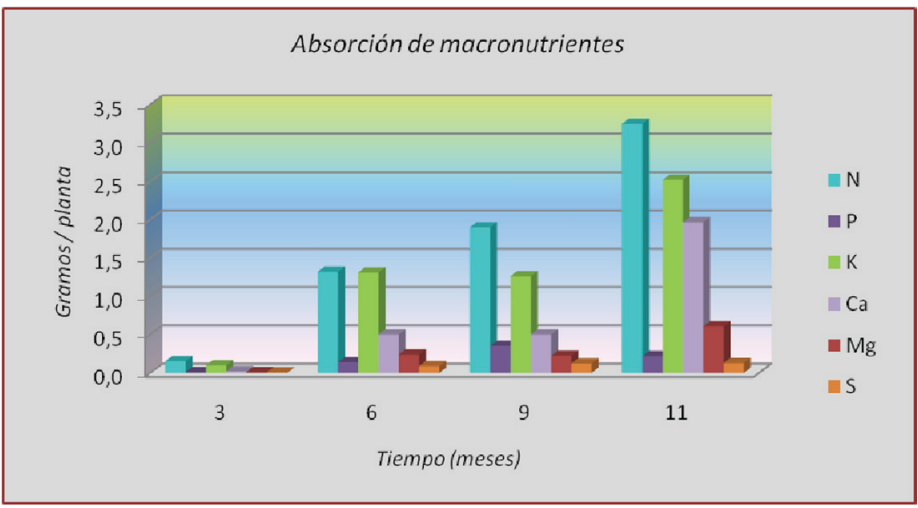

- Micronutrientes o elementos menores

Los micronutrientes $\mathrm{Cu}, \mathrm{B}, \mathrm{Fe}, \mathrm{Zn}$, y Mn, conocidos así a los elementos menores, por ser necesaria su presencia aunque en menor proporción que los mayores, se detallan en el Cuadro No 40. Su importancia es vital para el desarrollo armónico de todas las funciones del desarrollo del cultivo desde sus primeras fases.

La gran diferencia de absorción del Hierro (Fe) de los demás elementos como se aprecia en el Gráfico No 33, se debe en gran parte a la disposición de este elemento en forma excesiva en el suelo de nuestro medio, pero que es absorbido en cantidad muy notable.

\section{Cuadro No 40}

Microelementos absorbidos en previvero y vivero

\begin{tabular}{|c|c|c|c|c|c|}
\hline M.D.S. & $\mathbf{C u}$ & $\mathbf{B}$ & $\mathbf{F e}$ & $\mathbf{Z n}$ & $\mathbf{M n}$ \\
\hline $\mathbf{3}$ & 0,00011 & 0,00019 & 0,00271 & 0,00011 & 0,00069 \\
\hline $\mathbf{6}$ & 0,0009 & 0,001 & 0,02686 & 0,00173 & 0,0043 \\
\hline $\mathbf{9}$ & 0,00145 & 0,00166 & 0,03066 & 0,00226 & 0,013 \\
\hline $\mathbf{1 1}$ & 0,0032 & 0,00353 & 0,033 & 0,00343 & 0,01346 \\
\hline \multicolumn{7}{|l}{} \\
\hline
\end{tabular}

\section{Gráfico No 35}

Curvas de absorción de micronutrientes en previvero y vivero

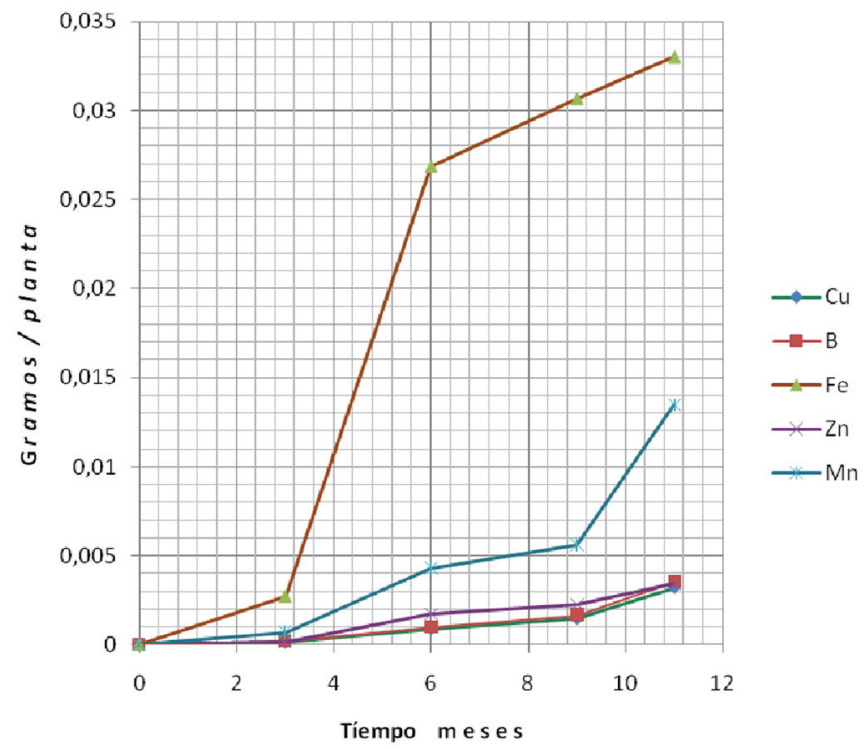

Gráfico No 36

Absorción de micronutrientes

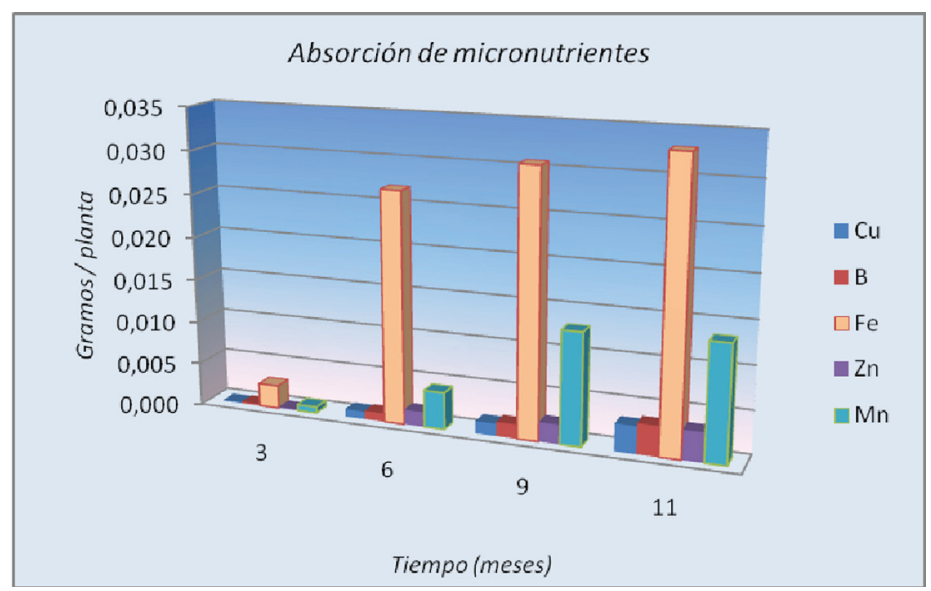

\section{Cuadro No 41}

Cantidad absorbida de macro y micronutrientes a los 11 meses

\begin{tabular}{|c|c|c|c|c|c|c|c|c|c|c|c|}
\hline $\begin{array}{c}\text { Meses } \\
\text { D.S. }\end{array}$ & $\begin{array}{c}\text { Abs. } \\
\mathbf{N}\end{array}$ & $\begin{array}{c}\text { Abs. } \\
\mathbf{P}\end{array}$ & $\begin{array}{c}\text { Abs. } \\
\mathbf{K}\end{array}$ & $\begin{array}{c}\text { Abs. } \\
\mathbf{C a}\end{array}$ & $\begin{array}{c}\text { Abs. } \\
\mathbf{M g}\end{array}$ & $\begin{array}{c}\text { Abs. } \\
\mathbf{S}\end{array}$ & $\begin{array}{c}\text { Abs. } \\
\mathbf{C u}\end{array}$ & $\begin{array}{c}\text { Abs. } \\
\mathbf{B}\end{array}$ & $\begin{array}{c}\text { Abs. } \\
\mathbf{F e}\end{array}$ & $\begin{array}{c}\text { Abs. } \\
\mathbf{Z n}\end{array}$ & $\begin{array}{c}\text { Abs. } \\
\mathbf{M n}\end{array}$ \\
\hline 11 & 3,250 & 0,344 & 2,520 & 1,965 & 0,605 & 0,127 & 0,0032 & $\begin{array}{c}0,003 \\
5\end{array}$ & $\begin{array}{c}0,033 \\
0\end{array}$ & $\begin{array}{c}0,0034 \\
0\end{array}$ & $\begin{array}{c}0,013 \\
5\end{array}$ \\
\hline
\end{tabular}




\section{Gráfico No 37}

Curva de Absorción de macro y micronutrientes

Curva de absorcion en el ciclo de previvero y vivero

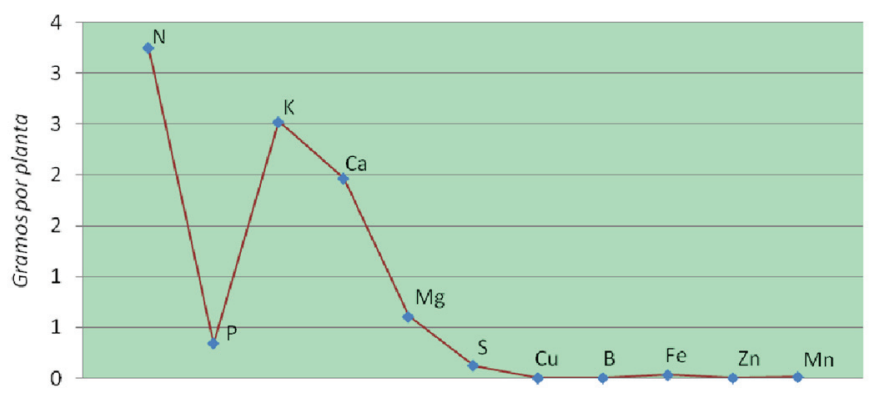

Macroy micronutrientes absorbidos por planta

La absorción total de nutrientes en todo el ciclo de las plantas (fases de vivero y previvero), se resumen en el gráfico 35 como una línea de la relación de cada elemento, en el que se demuestra la absorción de macro y micronutrientes hasta los 11 meses, visible también en el Gráfico No 36.

\section{Gráfico No 38}

\section{Absorción de macro y micronutrientes}

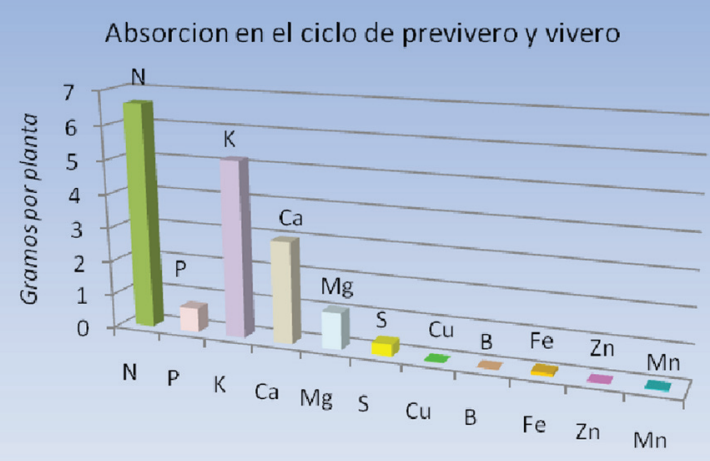

Cantidad de macro y micronutrientes absorbidos por planta

\section{Cuadro No 42}

Absorción de macronutrientes por órganos vegetativos a los 11 me-

ses

\begin{tabular}{|c|c|c|c|c|c|c|}
\hline Órganos & $\mathbf{N}$ & $\mathbf{P}$ & $\mathbf{K}$ & $\mathbf{C a}$ & $\mathbf{M g}$ & $\mathbf{S}$ \\
\hline Raíz & 0,532 & 0,039 & 0,718 & 0,328 & 0,081 & 0,0278 \\
\hline Estipe & 0,736 & 0,064 & 0,466 & 0,446 & 0,097 & 0,0332 \\
\hline Hojas & 1,342 & 0,092 & 0,894 & 0,780 & 0,169 & 0,0385 \\
\hline Raquis & 0,676 & 0,118 & 0,549 & 0,460 & 0,106 & 0,0228 \\
\hline Total & $\mathbf{3 , 2 8 6}$ & $\mathbf{0 , 3 1 4}$ & $\mathbf{2 , 6 2 8}$ & $\mathbf{2 , 0 1 3}$ & $\mathbf{0 , 4 5 2}$ & $\mathbf{0 , 1 2 2 2}$ \\
\hline
\end{tabular}

Gráfico No 39

Curva en superficie de absorción por órganos vegetativos Absorción por órganos a los 11 meses

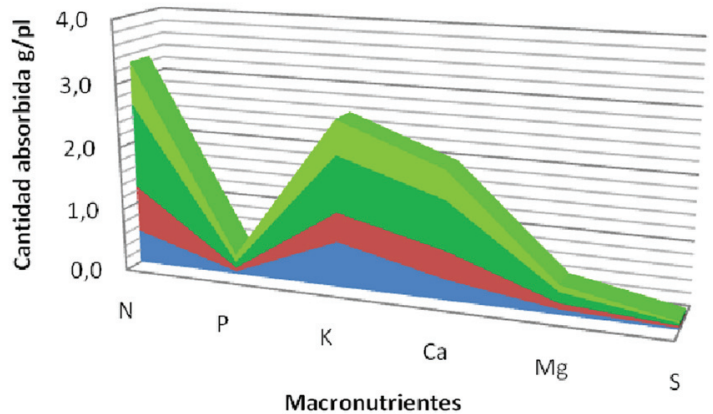

\section{Gráfico No 40}

Absorción de macronutries por órganos vegetativos

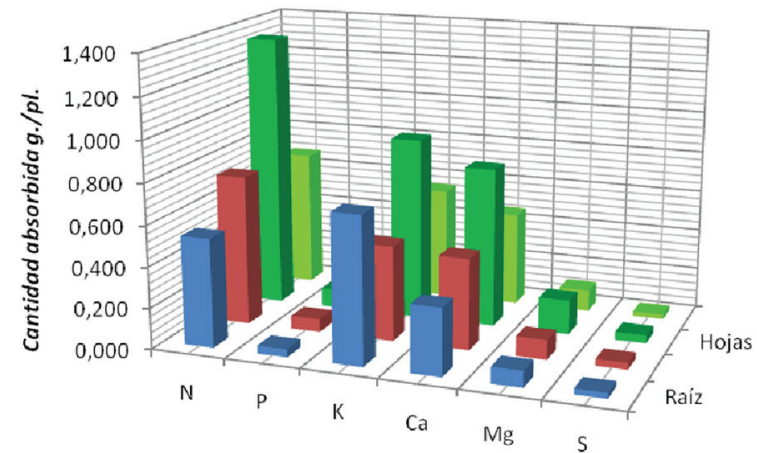

- Raiz

Estipe

- Hojas Raquis
Raquis

Hojas

Estipe

- Raíz

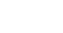

\section{Gráfico No 41}

Porcentaje de absorción de los macronutrientes por planta

\section{Porcentaje de macronutrientes por planta}

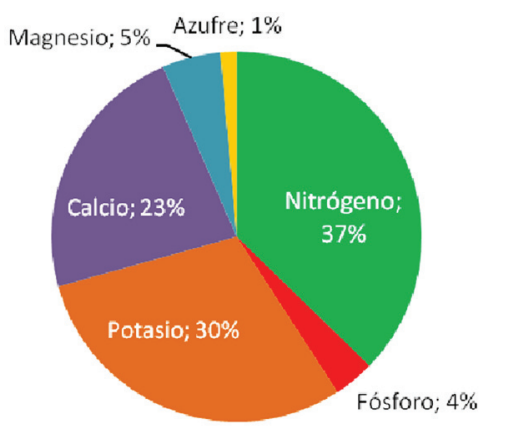

Macronutrientes a los 11 meses$$
\text { (1) }
$$ 


\section{- Cantidad de Humedad para vivero}

La provisión de humedad suficiente al vivero, se la realizó, en las condiciones ambientales del medio, las cuales fueron muy irregulares en los meses conocidos como época seca o de verano, del año 2008, puesto que hubieron lluvias en junio, julio y agosto como se registra en el Cuadro No 43. Los meses más secos fueron de septiembre a diciembre.

En tal virtud, el estudio de humedad dado por tensiómetro se lo pudo identificar mejor en este caso en el mes de noviembre/2008, mes de mayor sequía. En diciembre ya no se registró el mes completo por razones administrativas y además porque a finales del mismo como es conocido, se inician las precipitaciones de la época de lluvias.

\section{Cuadro No 43}

Registro de lluvias en el año 2008 y riego a aplicar en la fase de vivero

\begin{tabular}{|c|c|c|c|c|}
\hline Meses & $\begin{array}{c}\text { LLuvias } \\
\mathrm{mm} \text {. }\end{array}$ & $\begin{array}{l}\text { Riego por } \\
\text { aspersión }\end{array}$ & $\begin{array}{l}\text { Total } \\
\mathrm{mm} \text {. }\end{array}$ & Fases \\
\hline ene-08 & 978 & 00 & 978 & \multirow{4}{*}{ Previvero } \\
\hline feb-08 & 529 & 00 & 529 & \\
\hline mar-08 & 487 & 00 & 487 & \\
\hline$a b r-08$ & 303 & (07) & 310 & \\
\hline may-08 & 248 & 62 & 310 & \multirow{8}{*}{ Vlivero } \\
\hline jun-08 & 187 & 123 & 310 & \\
\hline jul-08 & 486 & 00 & 486 & \\
\hline ago-08 & 156 & 154 & 310 & \\
\hline sep-08 & 60 & 250 & 310 & \\
\hline oct-08 & 57 & 253 & 310 & \\
\hline nov-08 & 46 & 264 & 310 & \\
\hline dic-08 & 21 & 289 & 310 & \\
\hline Total & 3558 & 1395 & 4953 & \\
\hline
\end{tabular}

\section{Gráfico N 42}

\section{Curva de humedad anual (mm.) año 2008}

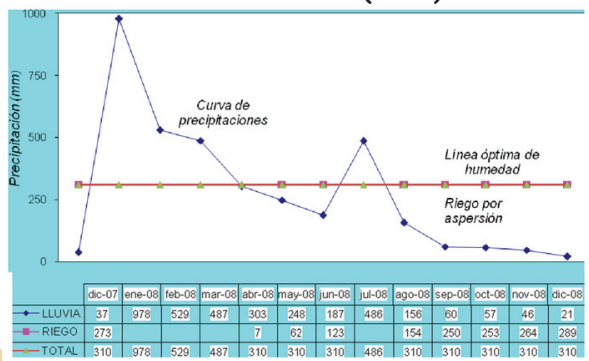

Cada planta sembrada en una funda de $45 \times 39 \mathrm{~cm}$. y de $25 \mathrm{~cm}$. de diámetro (maceta llena con sustrato franco arenoso con de una Área Basal. de $0.0491 \mathrm{m2}$. y volumen de $0.016 \mathrm{m3}$. Se requiere hasta los 3 meses de vivero ( 6 meses total de vida) la cantidad de 300cc.(lámina de $6.1 \mathrm{~mm}$ ) / planta/día, esto es $42.7 \mathrm{~mm} /$ semana, repartidos en 3 riegos de 2 horas c/u. Luego se sube paulatinamente hasta los 6 meses (9 meses totales de vida) hasta la cantidad de 500cc. (Lámina de 10.2 $\mathrm{mm}$ ), semanal $71 \mathrm{~mm}$ de lámina y mensual de $310 \mathrm{~mm}$. Estabilizándose esta cantidad hasta la salida de plantas al mes 11 de vivero. Esto se mantendría en condiciones de sequía. Si existen lluvias debe regirse por la marca de tensiómetro para aplicar así la humedad adecuada.

\section{Foto $\mathrm{N}^{\circ} 13$}

\section{Tensiómetro instalado en la profundidad}

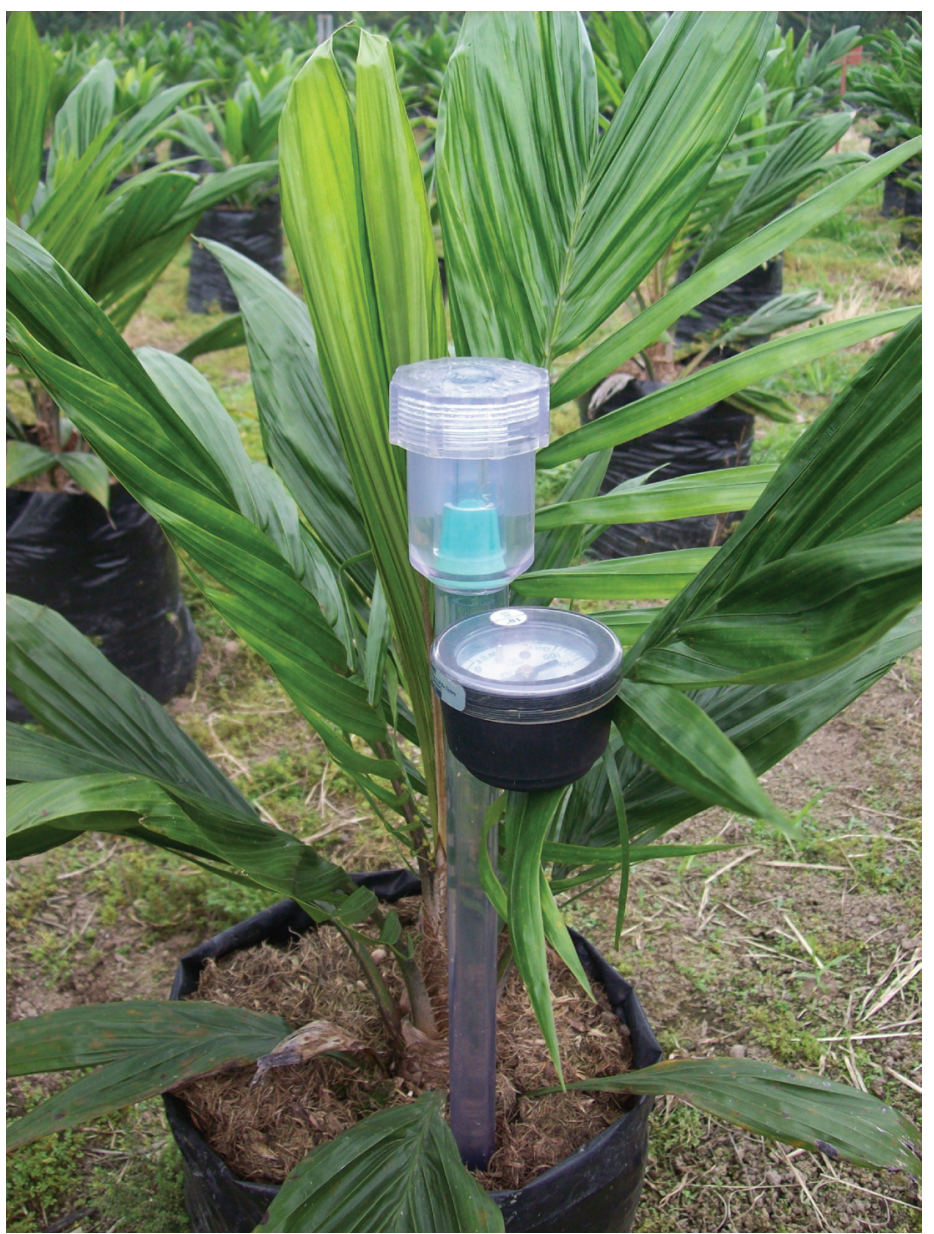




\section{Foto $\mathrm{N}^{\circ} 14$}

\section{Marca del tensiómetro a $30 \mathrm{~cm}$ de centibares}

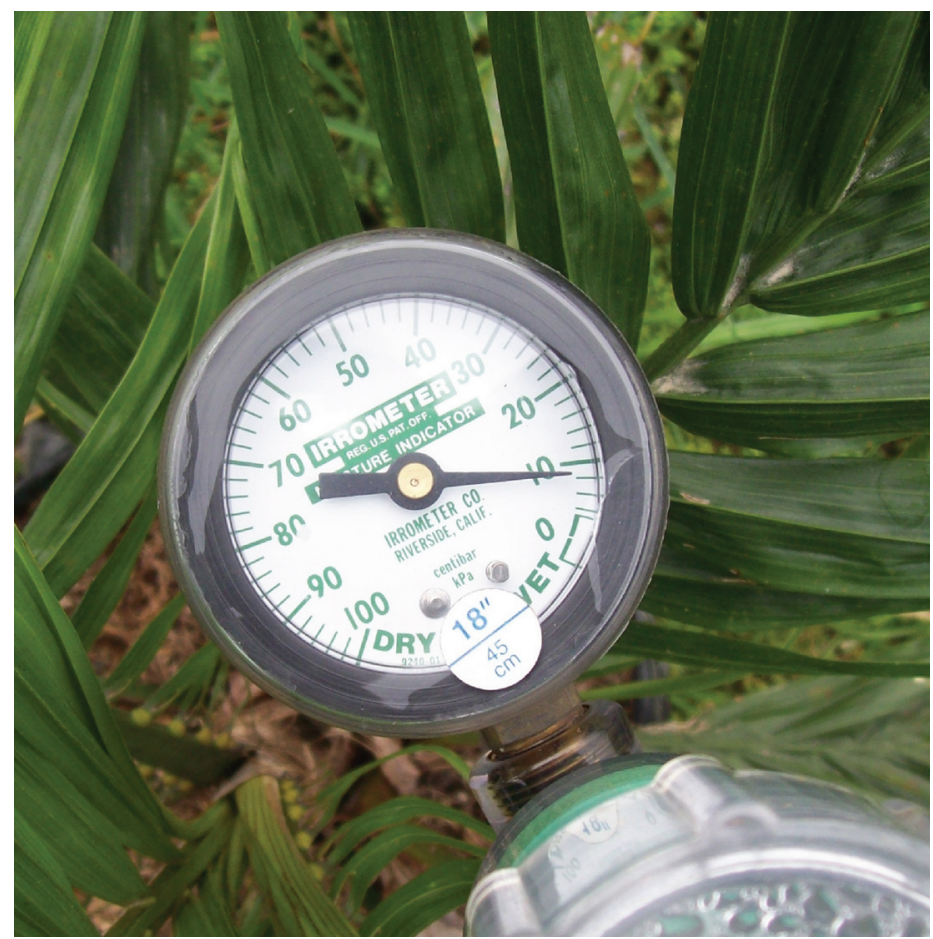

La cantidad de agua compensada por medio del riego, que se realizó por sistema de aspersión, con aspersores UNRAIN - F26 que alcanzan un diámetro de 18 m. Estos cubren una Area de 254 m2 de riego y colocados en forma alterna son 80 aspersores por ha. los cuales cubren toda el área de terreno, mojando no solo las fundas llenas sino también el follaje de las plantas y los espacios o calles entre fundas, lo cual demanda más caudal y volumen de agua que si fuera dirigido a cada funda con su planta.

La cantidad de humedad necesaria, coincide con experiencias de viveristas de la zona e información personal de técnicos, se ha determinado que para cada planta de palma se requiere de 300 a $500 \mathrm{cc}$. de agua diariamente para su normal desarrollo.

Esto, es similar a las condiciones de Malasia, que según (Hartley (W. 1983), hasta los 2 primeros meses, se aplica riego de $8.4 \mathrm{~mm} /$ día (58.8 mm./semana) y en Africa $35 \mathrm{~mm}$ y para plantas mayores a los 6 meses, $70 \mathrm{~mm} /$ semana.

$$
\begin{aligned}
& \text { Cantidad de riego }=\text { Volumen requerido }- \text { Volumen de lluvias } \\
& \text { Mes de Nov. } / 08=3.100-460=2.640 \mathrm{~m} 3 \text { (lámina de } 264 \mathrm{~mm} \text { ) }
\end{aligned}
$$

Para el mes de noviembre (mes más seco), se requirió una Lámina de $264 \mathrm{~mm}=2640 \mathrm{~m} 3 /$ ha. Esta cantidad de agua debe ser repartida durante el mes, esto es un promedio de $8.8 \mathrm{~mm} /$ día, y un caudal promedio de $88 \mathrm{~m} 3 /$ día. Repartidos en 80 aspersores/ ha. = 1,1 m3 / aspersor.

Si la frecuencia de riego para mantener la humedad en capacidad de campo, se riega en promedio cada 24 horas, un volumen de 88 m3 o sea 88.000 lit. / ha., significa un caudal de 1100 lit/ hora dividido para 60 minutos $=18.33$ litros $/$ min/aspersor.; pero se riega 2 horas porque el caudal que emerge cada aspersor es de $9 \mathrm{lit} / \mathrm{min}$. Y mantener así la humedad disponible en el sustrato para cada planta.

Para todo el ciclo de vivero (meses de mayo a diciembre/08, con 240 días) se requirió de 1395 mm, o sea 13.950 m3 de agua/ha para riego por aspersión con 80 aspersores/ha. Si el riego se aplicaría por goteo, o aplicación de agua dirigida a cada planta, la cantidad de agua disminuye notablemente: Por planta se requiere de 102 litros de agua, y para 10.000 plantas que caben/ha, se requieren de $1.020 \mathrm{~m} 3$. Para todo el ciclo de mayo a diciembre para las condiciones reinantes del año 2008.

El volumen de agua por planta para todo el ciclo de vivero, se estableció en 96 litros por planta (en cada maceta) en todo el ciclo de 8 meses de vivero. 


\section{Cuadro No 44}

Tabla de cantidad de riego a aplicarse y cantidad de agua por planta

\begin{tabular}{|c|c|c|c|c|c|c|c|c|}
\hline es 1 & Mes 2 & Mes 3 & Mes 4 & Mes 5 & Mes 6 & Mes 7 & Mes 8 & Total \\
\hline \multicolumn{3}{|c|}{ Lámina de riego } & \multicolumn{2}{|c|}{ Lámina de riego } & \multicolumn{3}{|c|}{ Lámina de riego } & 1969 \\
\hline $3 \mathrm{~mm}$ & $183 \mathrm{~mm}$. & $183 \mathrm{~mm}$ & $245 \mathrm{~mm}$ & $245 \mathrm{~mm}$ & $310 \mathrm{~mm}$. & $310 \mathrm{~mm}$. & $310 \mathrm{~mm}$. & $\mathrm{mm}$. \\
\hline \multicolumn{3}{|c|}{ Cantidad de agua/planta } & \multicolumn{3}{|c|}{ Cantidad de agua/planta } & \multicolumn{3}{|c|}{ Cantidad de agua/planta } \\
\hline $\begin{array}{l}300 \\
: / d i a\end{array}$ & $\begin{array}{l}300 \text { cc. } \\
\text { /día }\end{array}$ & $\begin{array}{c}300 . \\
\text { cc./día }\end{array}$ & $\begin{array}{l}400 . \\
\text { cc./día }\end{array}$ & $\begin{array}{c}400 . \\
\text { cc./día }\end{array}$ & $\begin{array}{c}500 . \\
\text { cc./día }\end{array}$ & $\begin{array}{c}500 . \\
\text { cc./día }\end{array}$ & $\begin{array}{c}500 . \\
\text { cc./día }\end{array}$ & \\
\hline $\begin{array}{l}9 \\
\text { os } / \mathrm{pl} \text {. }\end{array}$ & $\begin{array}{c}9 \\
\text { litros/pl. }\end{array}$ & $\begin{array}{c}9 \\
\text { litros/pl. }\end{array}$ & $\begin{array}{c}12 \\
\text { litros /pl. }\end{array}$ & $\begin{array}{c}12 \\
\text { litros /pl }\end{array}$ & $\begin{array}{c}15 \\
\text { litros/pl. }\end{array}$ & $\begin{array}{c}15 \\
\text { litros/pl. }\end{array}$ & $\begin{array}{c}15 \\
\text { litros/pl. }\end{array}$ & $\begin{array}{l}96 \\
\text { litros }\end{array}$ \\
\hline
\end{tabular}

\section{- Estimación económica de la utilidad}

En el anexo 27, se demuestra los costos estimados de insumos, riego y mano de obra por tratamientos para la producción de plantas de vivero de palma

Según se puede apreciar, el costo de producción de plantas se indica por tratamientos, de los cuales el tratamiento T7 (testigo sin fertilizar), es el más barato y el tratamiento T6 el más costoso, en especial por elevado costo de la Nitrofoska. Esta gran diferencia económica en costo, se dá dependiendo de la cantidad de fertilización aplicada pues el T6 es en el que se aplicó la mayor cantidad de fertilizantes que los demás.

\section{Conclusiones y Recomendaciones}

\section{Conclusiones}

1. Se realizó el trabajo investigativo de campo desde noviembre 2007 hasta diciembre del 2008, En previvero se sembró 2800 plantas, de éstas pasaron al vivero definitivo 1120 plantas para ser tratadas y evaluadas en su nutrición y desarrollo morfológico.

2. Los elementos macro y micronutrientes suministrados a las plantas y sus cantidades absorbidas, encontrados en sus órga- nos vegetativos, son requeridos por el cultivo de palma en fase de vivero, se expresan sus resultados numérocos y en gráficos de curvas: Al finalizar la etapa de previvero a los 105 días, en las variables altura con 35,5 cm., número de hojas 5 y diámetro de estipe10.2mm., ubicándose en el primer rango el tratamiento T5 con fertilización a base de N 12\%, P 12\%, K 17\% Mg 2\% (Nitrofoska 5 g./pl.).

3. Al finalizar la fase de vivero al mes 11, el tratamiento destacado con una altura de $90 \mathrm{~cm}$. fue el T4, con fertilización completa de nitrofoska 195 g. + 120 g.mezcla de fertilizantes simples. En número de hojas el tratamiento T5 con 12 a 13 hojas por planta con la mezcla de 260 g. de Nitrofoska +162 g. mezca de fertilizantes simples y el tratamiento T6 con $71 \mathrm{~mm}$. de diámetro de estipe con 325 g. de Nitrofoska + 198 g de mezcla de fertilizantes simples.

4. La absorción de nutrientes en previvero a los 3 meses, se expresa en gramos/planta de los siguientes nutrimentos: N: 0.15; P:0.010; K: 0.096; Ca: 0.021; Mg: 0.010; S: 0.008; Cu: 0.00011; B: 0.00019; Fe: 0.00271; Zn 0.00011; y Mn: 0.00069 g./pl

Se concluye que los tratamientos $\mathrm{T}_{5}$ con dosis de $5 \mathrm{~g}$./planta de nitrofoska en previvero hasta el mes 3 seguido del T3 con 3.4 g./pl. de mezcla de fertilizantes simples, luego T4 con $3.45 \mathrm{~g} /$ pl.y T6 con $6.25 \mathrm{~g} / \mathrm{pl}$. de nitroforka, son los que demostraron mayor peso de materia seca y fresca siendo la altura de plantas y vigorosidad dependientes de la materia seca.

5. En Vivero hasta el mes 11, la absorción de nutrientes por planta fue: N: 3.25; P: 0.344; K:2.52; Ca: 1.96; Mg: 0.60; S: 0.12; Cu:0.0032; B:0.0035; Fe:0.035; Zn:0.0034; y Mn: 0.0134 g.l planta. Siendo este un valor promedio entre los tratamientos T1, T4, T5, T6 analizados estadísticamente en cuanto a altura, 
númerode hojas, diámetro de estipe y materia seca.

6. La humedad necesaria que se requiere en el medio para plantas de vivero, se establece de 300 a $500 \mathrm{cc} /$ planta/día, lo que significa una lámina de 1969 mm en el ciclo de 8 meses de vivero. En el presente caso, para los meses de mayor sequía del ciclo de vivero (de mayo a diciembre/2008, 240 días) se requirió en en este periodo de $1395 \mathrm{~mm}$, o sea $13.950 \mathrm{~m} 3$ de agua/ha para ser regado por medio del sistema de riego por aspersión, puesto que se contó con lluvias aún en estos meses.

7. Los costos son en relación a un vivero de 10.000/ha; pero se ha calculado por tratamientos el Beneficio Neto, Beneficio-Costo y Rentabilidad. Según anexo 24. La rentabilidad del tratamiento $\mathrm{T} 1$ es del $66 \%$ y y del tratamiento $\mathrm{T} 6$ del $47 \%$. El tratamiento T7 (testigo sin fertilizar), se le calcula un $56 \%$ pero es una planta desnutrida y su costo también es inferior así como su precio de venta.

\section{Recomendaciones}

En base a los resultados morfológicos y materia seca y extracción de nutrientes las fórmulas recomendabas para nutrición son las siguientes:

1. Para la fase de previvero el tratamiento T5 con la aplicación de 5 gramos de la fórmula fórmula compuesta 12-12-17-2 + EM (N $-\mathrm{P}-\mathrm{K}-\mathrm{Mg}+\mathrm{EM}$ ) por planta iniciándose a las 6 semanas con aplicaciones semanales hasta la semana 12 antes del trasplante al vivero definitivo Anexo 13.

2. Para el vivero definitivo, la utilización de las dosificaciones del tratamiento (T4) se puede utilizar con la aplicación de: 195 gra- mos de la fórmula compuesta 12-12-17-2 + EM ( N - P - K - Mg + EM) más fertilizantes simples $57 \mathrm{~g}$. de Nitrato de amonio $\left(\mathrm{NO}_{3}\right.$ $\left.\mathrm{NH}_{4}\right) 33.5 \%$; 12 g. de Fosfato diamónico DAP.(( $\left.\left.\mathrm{NH}_{4}\right)_{2} \mathrm{HPO}_{4}\right) 18$ 46-0 \%; 13.5 g.de Muriato de potasio $\mathrm{KCl}(60 . \%$ de $\mathrm{K} 2 \mathrm{O})$; $34.5 \mathrm{~g}$. de Sulfato de magnesio $\left(2 \mathrm{MgSO}_{4}\right) 49 \% \mathrm{HP}_{4}$.y más 3 gramos de Acido bórico al 17\% hasta el mes 11. según la tabla de anexo 14. Este tratamiento ( $\mathrm{T} 4)$, resulta más conveniente por su fórmula completa y desde el punto de vista económico por el costo y su rentabilidad del $61 \%$.

3. El $\mathrm{N}$ se aplica desde la semana 1 y se incrementa paulatinamente hasta los 180 dias(6 meses) desde aquí se incrementa hasta los 330 días (11 meses) o semana 32

a. El P que se aplica desde el inicio y en mayor cantidad desde los 270 días.

b. El K la necesidad de su aplicación, es similar al anterior elemento.

c. El Ca. Es mayor la necesidad a los 270 días, su aplicación (ver gráficos 31, 32 y 33)

d. $\quad$ El Mg su aplicación desde los 3 meses.

e. $\quad$ El S desde los 3 meses.

f. El Fe no hay necesidad de aplicar, la planta en nuestras condiciones absorbe de acuerdo a su necesidad.

g. El Cu más indispensable a los 210 días.

h. $\quad$ El B a los 4 meses (120 días)

i. $\quad$ El Zn y el Mn desde el mes 4, son requeridos en menor cantidad. La aplicación de todos los elementos, se detalla en el anexo 13 y 14 en tablas para previvero y vivero.

4. Para plantas de vivero, se establece de 300 a $500 \mathrm{cc} /$ planta/ día, lo que significa una lámina de riego por aspersión de 1.969 mm.en el ciclo de vivero. En todo caso, debe apoyar para control de humedad con el tensiómetro cuando este sobrepase 
los 15 centibares se debe proporcionar el riego, considerando también las Ilovisnas medidas con lisímetro, si éstas se presentan en los meses de sequía del ciclo de vivero (de mayo a diciembre, 240 días).

\section{Bibliografía consultada}

1. Biblioteca de la Agricultura Lexus IDEA BOOKS, SA.Rosellón, 186, $1^{\circ}$ y $4^{\mathrm{a}} 08008$ Barcelona - España 1997, pp 93-95

2. Burgos, R. “Nutrición en Palma Aceitera” Presentación Power Point. Departamento de Transferencia de Tecnología ANCUPA. Santo Domingo de los Colorados 2007.

3. Calvache, V. M. Los Micronutrientes Universidad Central del Ecuador Power Point, IMC. Global año, 2007.

4. Chavez, F. Y Rivadeneira J. "Manual del Cultivo de Palma Aceitera" (Elaeis guinees Jacq.) Para la Zona Noroccidental del Ecuador ANCUPA - INIAP Pasquel Producciones Periodísticas tel.2546034, e - mail: pasquelpro@punto.net.ec Quito Agosto 2003 pp 1-125

5. Chavez, F. "Inventario de Plagas del Cultivo de Palma Aceitera" (Elaeis guinees Jacq.) en el Ecuador ANCUPA SESA Pasquel Producciones Periodísticas tel.2546034, e-mail: pasquelpro@ punto.net.ec Enero 2007 Quito Ecuador pp 1-76

6. Haltley, C.W S. "La Palma de Aceite” Compañía Editorial Continental S.A. de C.V. México. Primera edición en español de la segunda edición en ingles. CALZ de Tlalpan № 4620, CECSA México 22. D.F. 1983. 958p.

7. Malavolta, E. Elementos de Nutrición Mineral de Plantas, Edi- tora Agronómica Ceres Ltda., Sao Paulo - Brasil, 1980, pp: 80 -93 .

8. Muterte, W. Director de la oficina para el Sur Este Asiático del Instituto de la Potasa y el Fósforo. 126 Watten Estate Road, Singapore. Documento PDF,2003.4p

9. Padilla, G.W. Ph.D.”Química y Fertilidad de Suelos" Documento PDF CD 4ta Edición, 2005. Quito. Ecuador 185 p.

10. SERVICIO DE INFORMACIÓN Y CENSO AGROPECUARIO (SICA). Cifras agropecuarias del Ecuador. Superficie, Produccion y Ventas, según Cultivos Permanentes del Ecuador. Tabla 14. Disponible

11. en http://www.sica.gov.ec/

12. Rankine, I. R. Serie Palma Aceitera Vol. I. Viveros. Instituto de la Potasa y el Fósforo .Canadá 1998. 112 p.

13. RUIZ R. C. et. al. "La Palma Africana de Aceite" Temás de Orientación Agropecuaria TOA Tomo 149. Colombia,1981. 212 p.

\section{El Investigador}

\section{Ing. César Pillajo Pizarro}

\section{Ingeniero Agrónomo;}

Universidad Central del Ecuador, 1983

Maestría en Nutrición Vegetal, Universidad Tecnológica Equinoccial 


\section{Anexos}

\section{Anexo 1}

Esquema de campo del Previvero

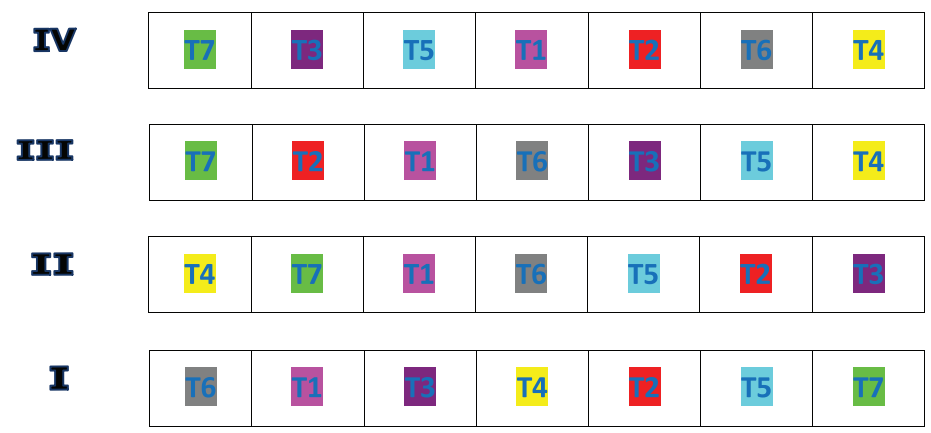

Anexo 2

Altura de plantas en el día de transplante a vivero a los 3.5 meses (15 semanas)

\begin{tabular}{|c|c|c|c|c|c|}
\hline \multirow{2}{*}{ TRATAM } & \multicolumn{5}{|c|}{$\begin{array}{c}\text { Altura de plantas cm. } \\
\text { REPETICIONES }\end{array}$} \\
\cline { 2 - 6 } & $\mathrm{I}$ & II & III & IV & PROMEDIO \\
\hline T1 & 35,2 & 34,8 & 34,0 & 33,8 & 34,4 \\
\hline T2 & 31,3 & 32,0 & 32,3 & 30,5 & 31,5 \\
\hline T3 & 35,5 & 35,3 & 34,0 & 33,2 & 34,5 \\
\hline T4 & 35,5 & 35,3 & 33,3 & 33,2 & 34,3 \\
\hline T5 & 34,8 & 36,3 & 35,3 & 35,0 & 35,3 \\
\hline T6 & 33,3 & 33,5 & 32,5 & 32,5 & 32,9 \\
\hline T7 & 25,5 & 27,5 & 27,3 & 25,8 & 26,5 \\
\hline X & 34,5 & 33,5 & 32,7 & 32,0 & 33,2 \\
\hline
\end{tabular}

\section{Anexo 3}

Gráfico de altura de plantas a los 105 días (3.5 meses)

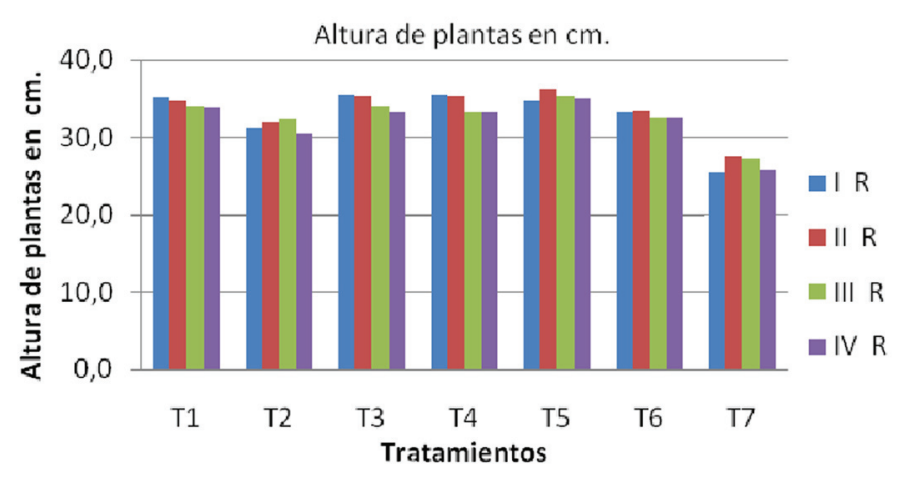

\section{Anexo 4}

Número de hoja por plantas a los 105 días (3.5 meses)

\begin{tabular}{|c|c|c|c|c|c|}
\hline \multirow{2}{*}{ TRATAM. } & \multicolumn{5}{|c|}{ Número de hojas } \\
\cline { 2 - 6 } & I & II & III & IV & X \\
\hline T1 & 5,1 & 5,3 & 5,1 & 5,0 & 5,1 \\
\hline T2 & 4,6 & 4,5 & 4,6 & 4,5 & 4,6 \\
\hline T3 & 5,1 & 5,0 & 5,0 & 5,0 & 5,0 \\
\hline T4 & 5,3 & 5,3 & 5,3 & 5,2 & 5,3 \\
\hline T5 & 5,3 & 5,3 & 5,2 & 5,3 & 5,3 \\
\hline T6 & 5,0 & 5,3 & 5,1 & 5,0 & 5,1 \\
\hline T7 & 4,3 & 4,2 & 4,3 & 4,3 & 4,2 \\
\hline X & 4,9 & 5,0 & 4,9 & 4,9 & 4,9 \\
\hline
\end{tabular}

Anexo 5

Gráfico del número de hojas por planta a los 105 días ( 3.5 meses)

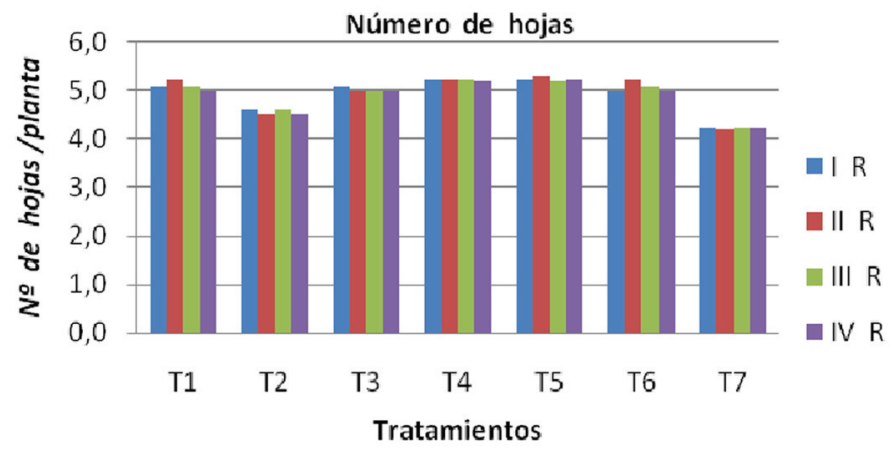

Anexo 6

Diámetro de estipe a los 105 días (3.5 meses)

\begin{tabular}{|c|c|c|c|c|c|}
\hline & \multicolumn{5}{|c|}{$\boldsymbol{\varnothing}$ de Estípete } \\
\hline & I & II & III & IV & X \\
\hline T1 & 10,2 & 10,0 & 10,3 & 10,1 & 10,1 \\
\hline T2 & 9,6 & 9,5 & 9,3 & 9,3 & 9,4 \\
\hline T3 & 10,1 & 10,0 & 10,2 & 9,5 & 10,0 \\
\hline T4 & 10,0 & 10,1 & 10,0 & 9,5 & 9,9 \\
\hline T5 & 10,3 & 10,3 & 10,0 & 10,3 & 10,2 \\
\hline T6 & 10,0 & 10,3 & 10,1 & 10,2 & 10,2 \\
\hline T7 & 8,2 & 8,0 & 8,2 & 7,8 & 8,0 \\
\hline X & 9,8 & 9,7 & 9,7 & 9,5 & 9,7 \\
\hline
\end{tabular}


Anexo 7

Gráfico del diámetro de estipe a los 105 días (3.5 meses)

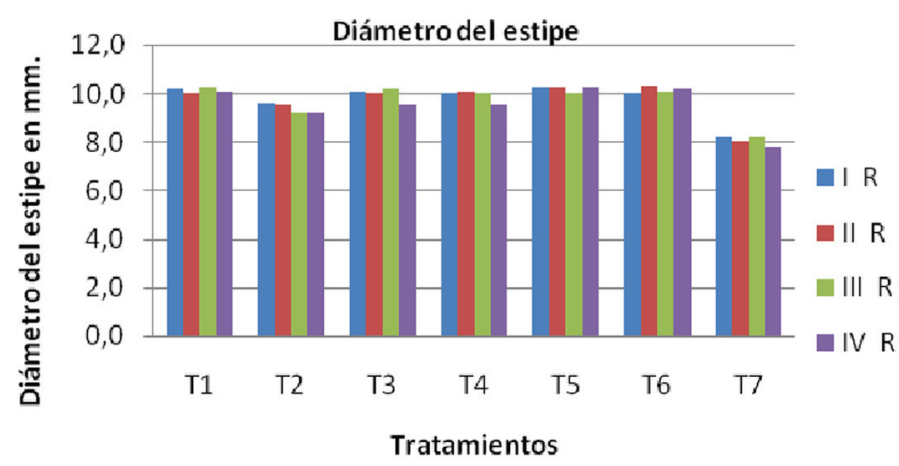

Anexo 8

Altura de planta vivero 330 días (11 meses)

\begin{tabular}{|c|c|c|c|}
\hline TRATAM & Altura cm. & No Hojas & Diámetro cm. \\
\hline T1 & 87,9 & 12,4 & 6,7 \\
\hline T2 & 80,2 & 12,1 & 6,2 \\
\hline T3 & 80,6 & 12,2 & 6,3 \\
\hline T4 & 89,7 & 12,8 & 6,6 \\
\hline T5 & 89,4 & 13,1 & 7,0 \\
\hline T6 & 89,6 & 12,8 & 7,1 \\
\hline T7 & 60,8 & 10,9 & 4,9 \\
\hline X & 82,6 & 12,3 & 6,4 \\
\hline
\end{tabular}

\section{Anexo 9}

Cronograma de fertilización para Previvero

NUTRICIÓN CON FERTILIZANTES SIMPLES

\begin{tabular}{|c|c|c|c|c|c|c|c|c|c|c|c|c|c|c|c|}
\hline \multirow{2}{*}{$\begin{array}{l}\text { FECHA DE } \\
\text { APLICACIÓN }\end{array}$} & \multicolumn{3}{|c|}{ NITRATO DE AMONIO $33.5 \% \mathrm{~g} / \mathrm{Pl}$, } & \multicolumn{3}{|c|}{ DAP $18-46-0 \mathrm{~g} / \mathrm{pl}$} & \multicolumn{3}{|c|}{$\begin{array}{c}\text { MURIATO DE } \\
\text { POTASIO } 60 \% \mathrm{~g} / \mathrm{pl} \text {. }\end{array}$} & \multicolumn{3}{|c|}{$\begin{array}{c}\text { SULFATO DE } \\
\text { MAGNESIO } \\
49 \% \mathrm{~g} / \mathrm{pl} \text {. }\end{array}$} & \multicolumn{3}{|c|}{$\begin{array}{l}\text { MEZCLA } \\
\text { g/pl. }\end{array}$} \\
\hline & T1 & T2 & T3 & T1 & T2 & $\mathrm{T} 3$ & T1 & T2 & T3 & $\mathrm{T} 1$ & T2 & T3 & T1 & $\mathrm{T} 2$ & T3 \\
\hline 15-feb-08 & 0,27 & 0,36 & 0,45 & 0,03 & 0,04 & 0,05 & 0,0525 & 0,07 & 0,0875 & \begin{tabular}{|l|l|}
0,06 \\
\end{tabular} & 0,08 & 0,1 & 0,41 & 0,55 & 0,7 \\
\hline 29-feb-08 & 0,27 & 0,36 & 0,45 & 0,03 & 0,04 & 0,05 & 0,0525 & 0,07 & 0,0875 & 0,06 & 0,08 & 0,1 & 0,41 & 0,55 & 0,7 \\
\hline 07-mar-08 & 0,27 & 0,36 & 0,45 & 0,03 & 0,04 & 0,05 & 0,0525 & 0,07 & 0,0875 & 0,06 & 0,08 & 0,1 & 0,41 & 0,55 & 0,7 \\
\hline 14-mar-08 & 0,27 & 0,36 & 0,45 & 0,03 & 0,04 & 0,05 & 0,0525 & 0,07 & 0,0875 & 0,06 & 0,08 & 0,1 & 0,41 & 0,55 & 0,7 \\
\hline 28-mar-08 & 0,27 & 0,36 & 0,45 & 0,03 & 0,04 & 0,05 & 0,0525 & 0,07 & 0,0875 & $\begin{array}{ll}0,06 \\
\end{array}$ & 0,08 & \begin{tabular}{l|}
0,1 \\
\end{tabular} & 0,41 & 0,55 & 0,7 \\
\hline TOTAL & 1,35 & 1,8 & 2,25 & 0,15 & \begin{tabular}{l|l|}
0,2 \\
\end{tabular} & 0,25 & 0,2625 & 0,35 & 0,4375 & 0,3 & \begin{tabular}{|l|l|}
0,4 \\
\end{tabular} & 0,5 & 2 & 2,75 & 3,4 \\
\hline
\end{tabular}

\begin{tabular}{|c|c|c|c|c|}
\hline \multirow{2}{*}{ TRATAMIENTOS } & \multicolumn{3}{|c|}{ FERTILIZ SIMPLES g/Pl, } & \multirow{3}{*}{$\frac{\mathrm{MgSO4}}{0,3}$} \\
\hline & N 33.5\% & DAP & $\mathrm{K} 2 \mathrm{O}$ & \\
\hline T1 & 1,35 & 0,15 & 0,26 & \\
\hline $\mathrm{T} 2$ & 1,8 & 0,2 & 0,35 & \\
\hline T3 & 2,25 & 0,25 & 0,43 & \\
\hline T4 & \multicolumn{2}{|c|}{ NITROFOSKA } & 3,75 & \\
\hline T5 & \multicolumn{2}{|c|}{ AZUL } & 5,0 & \\
\hline T6 & \multirow{2}{*}{\multicolumn{2}{|c|}{ 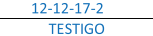 }} & 6,25 & \\
\hline $\mathrm{T7}$ & & & 0,00 & \\
\hline
\end{tabular}

\begin{tabular}{|c|c|c|c|}
\hline \multirow{2}{*}{$\begin{array}{c}\text { FECHA DE } \\
\text { APLICACIÓN }\end{array}$} & \multicolumn{3}{|c|}{ NITROFOSKA g/PI, } \\
\cline { 2 - 4 } & T4 & T5 & T6 \\
\hline 15-feb-08 & 0,75 & 1,00 & 1,25 \\
\hline 29-feb-08 & 0,75 & 1,00 & 1,25 \\
\hline 07-mar-08 & 0,75 & 1,00 & 1,25 \\
\hline 14-mar-08 & 0,75 & 1,00 & 1,25 \\
\hline 28-mar-08 & 0,75 & 1,00 & 1,25 \\
\hline TOTAL & $\mathbf{3 , 7 5}$ & $\mathbf{5}$ & 6,25 \\
\hline
\end{tabular}

Anexo 10

\section{Cronograma de fertilización para Vivero}

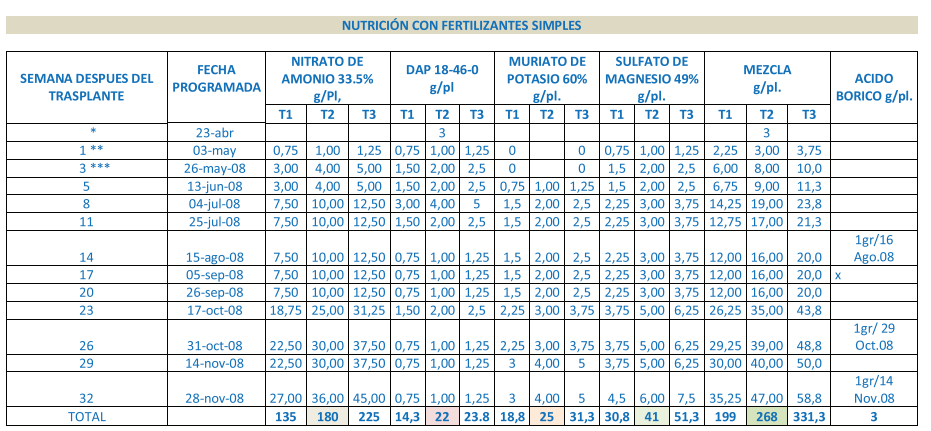

* Se incorpora en el hoyo al momento del trasplante.

*** Ee aplican diluido en drench 50 cc de agua / Pldo Borico se aplica por separado

40 plantas por tratamiento (4 tratamientos)

\section{Anexo 11}

\section{Cronograma para fertilización para Vivero}

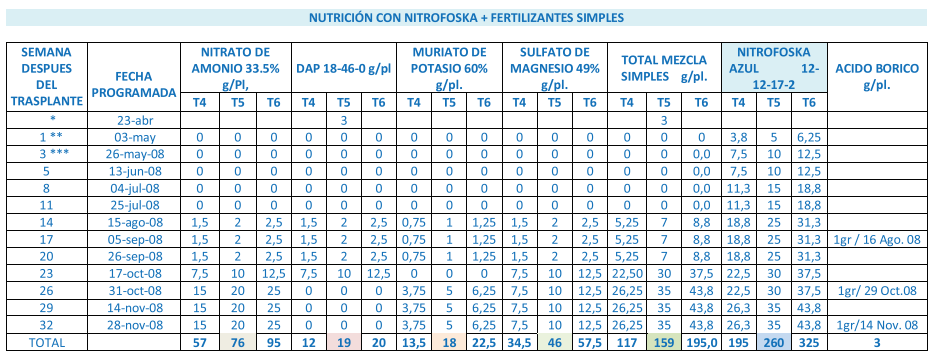

* Se incorpora en el hoyo al momento del trasplante.
$* *$ Se aplican diluido en drench 50 cc de arual pinta.

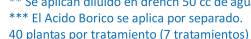

\section{Anexo 12}

\section{Esquema de vivero}

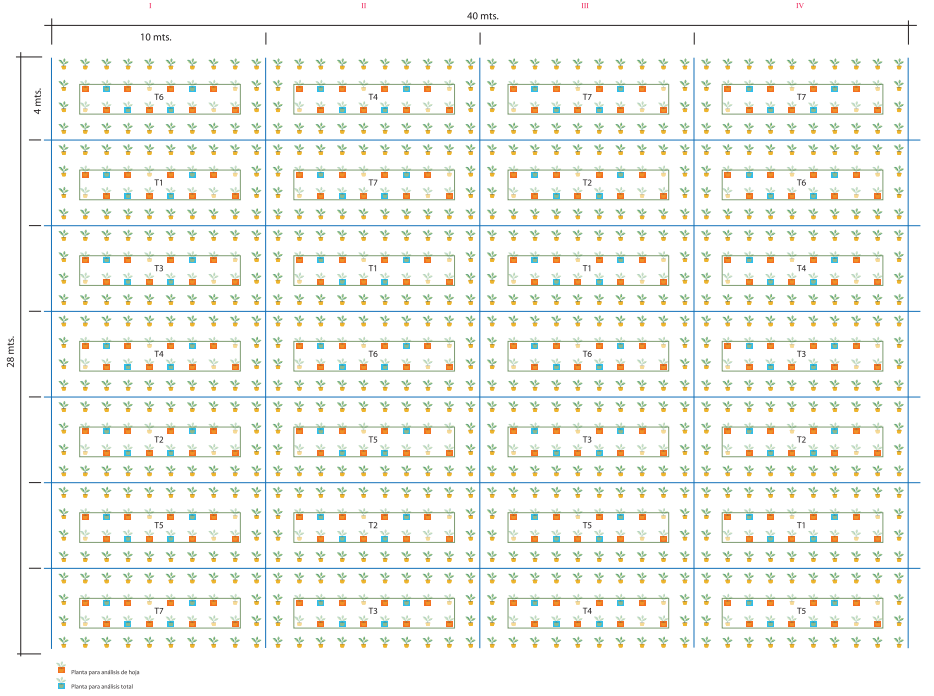


Anexo 13

Tabla de fertilización para Previvero

\begin{tabular}{|c|c|}
\hline $\begin{array}{c}\text { APLICACIÓN SEMANAS } \\
\text { DESPUES DE LA SIEMBRA }\end{array}$ & $\mathbf{1 2 - 1 2 - 1 7 - 2}$ \\
\hline 0 & $\mathrm{~g} \cdot / \mathrm{pl}$. \\
\hline 6 & 0 \\
\hline 8 & 1,0 \\
\hline 9 & 1,0 \\
\hline 10 & 1,0 \\
\hline 12 & 1,0 \\
\hline TOTAL & 1,0 \\
\hline
\end{tabular}

\section{Anexo 14}

\section{Tabla de fertilización para Vivero}

\begin{tabular}{|c|c|c|c|c|c|c|c|}
\hline $\begin{array}{c}\text { SEMANAS } \\
\text { DESPUÉS DEL } \\
\text { TRASPLANTE }\end{array}$ & $\begin{array}{c}12-12-17-2 \\
\text { g./pl. }\end{array}$ & $\begin{array}{c}\text { NO3 NH4 } \\
33,5 \% \\
\mathrm{~g} / \text { pl. }\end{array}$ & $\begin{array}{c}\text { (NH4) })_{2} \text { HPO4 } \\
18-46-0 \\
\text { g./pl. }\end{array}$ & $\begin{array}{c}\text { KCl } 60 \% \\
\text { g./pl. }\end{array}$ & $\begin{array}{c}\text { Mg S04 49\% } \\
\text { g./pl. }\end{array}$ & $\begin{array}{c}\text { MEZCLA E. SIMPLES } \\
\text { g./pl. }\end{array}$ & $\begin{array}{c}\text { ACIDO BóRICO } \\
\text { g./pl. }\end{array}$ \\
\hline $1^{* * *}$ & 3,8 & 0 & 0 & 0 & 0 & 0 & \\
\hline $3^{* * *}$ & 7,5 & 0 & 0 & 0 & 0 & 0 & - \\
\hline 5 & 7,5 & 0 & 0 & 0 & 0 & 0 & \\
\hline 8 & 11,3 & 0 & 0 & 0 & 0 & 0 & \\
\hline 11 & 11,3 & 0 & 0 & 0 & 0 & 0 & \\
\hline 14 & 18,8 & 1,5 & 1,5 & 0,75 & 1,5 & 5,25 & \\
\hline 17 & 18,8 & 1,5 & 1,5 & 0,75 & 1,5 & 5,25 & $1 \mathrm{~g}$ \\
\hline 20 & 18,8 & 1,5 & 1,5 & 0,75 & 1,5 & 5,25 & \\
\hline 23 & 22,5 & 7,5 & 7,5 & 0 & 7,5 & 22,5 & \\
\hline 26 & 22,5 & 15 & 0 & 3,75 & 7,5 & 26,25 & $1 \mathrm{~g}$ \\
\hline 29 & 26,3 & 15 & 0 & 3,75 & 7,5 & 26,25 & \\
\hline 32 & 26,3 & 15 & 0 & 3,75 & 7,5 & 26,25 & $1 \mathrm{~g}$ \\
\hline TOTAL & 195 & 57 & 12 & 13,5 & 34,5 & 117 & 3 \\
\hline
\end{tabular}

\section{Anexo 15}

Altura de planta por tratamiento y repeticiones a los 11 meses

\begin{tabular}{|c|c|c|c|c|c|}
\hline \multirow{2}{*}{ TRATAMIENTO } & \multicolumn{5}{|c|}{$\begin{array}{c}\text { Altura de plantas cm. X } \\
\text { REPETICIONES }\end{array}$} \\
\cline { 2 - 6 } & I & II & III & IV & PROMEDIO \\
\hline T1 & 90,0 & 86,0 & 88,0 & 87,6 & 87,9 \\
\hline T2 & 83,0 & 79,0 & 77,0 & 81,6 & 80,2 \\
\hline T3 & 82,0 & 79,0 & 81,0 & 80,3 & 80,6 \\
\hline T4 & 90,0 & 90,0 & 90,7 & 87,7 & 89,6 \\
\hline T5 & 88,0 & 88,0 & 89,0 & 92,5 & 89,4 \\
\hline T6 & 93,0 & 90,0 & 88,3 & 87,0 & 89,6 \\
\hline T7 & 60,0 & 64,3 & 64,0 & 61,0 & 62,3 \\
\hline X & 72,1 & 82,3 & 82,6 & 82,5 & 82,5 \\
\hline
\end{tabular}

Anexo 16

Barras altura de planta por tratamiento y repeticiones a los 11 meses ALTURA DE PLANTA A 11 MESES

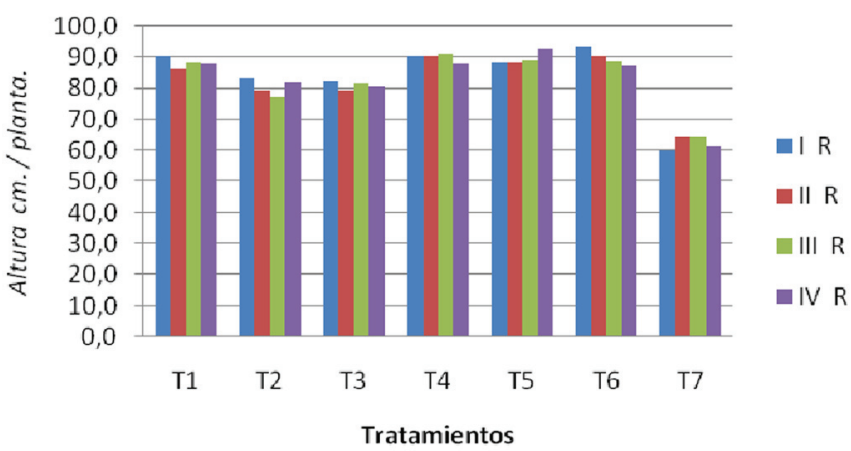

Anexo 17

Número de hojas por tratamiento y repeticiones a los 11 meses

\begin{tabular}{|c|c|c|c|c|c|}
\hline \multirow{2}{*}{ TRATAMIENTO } & \multicolumn{5}{|c|}{ Número de hojas } \\
\cline { 2 - 6 } & $\mathrm{I}$ & $\mathrm{II}$ & $\mathrm{II}$ & $\mathrm{IV}$ & PROMEDIO \\
\hline $\mathrm{T} 1$ & 12,0 & 12,0 & 13,0 & 12,7 & 12,4 \\
\hline $\mathrm{T} 2$ & 12,5 & 12,3 & 11,7 & 11,7 & 12,1 \\
\hline $\mathrm{T} 3$ & 12,3 & 12,3 & 12,0 & 12,3 & 12,2 \\
\hline T4 & 13,0 & 13,0 & 13,0 & 12,3 & 12,8 \\
\hline T5 & 12,7 & 12,7 & 13,0 & 14,0 & 13,1 \\
\hline $\mathrm{T} 6$ & 13,0 & 12,3 & 13,0 & 12,7 & 12,8 \\
\hline T7 & 11,0 & 11,0 & 11,3 & 10,3 & 10,9 \\
\hline $\mathrm{X}$ & 11,8 & 11,5 & & 11,8 & 12,3 \\
\hline
\end{tabular}

Anexo 18

Número de hojas por tratamientos y repeticiones a los 11 meses

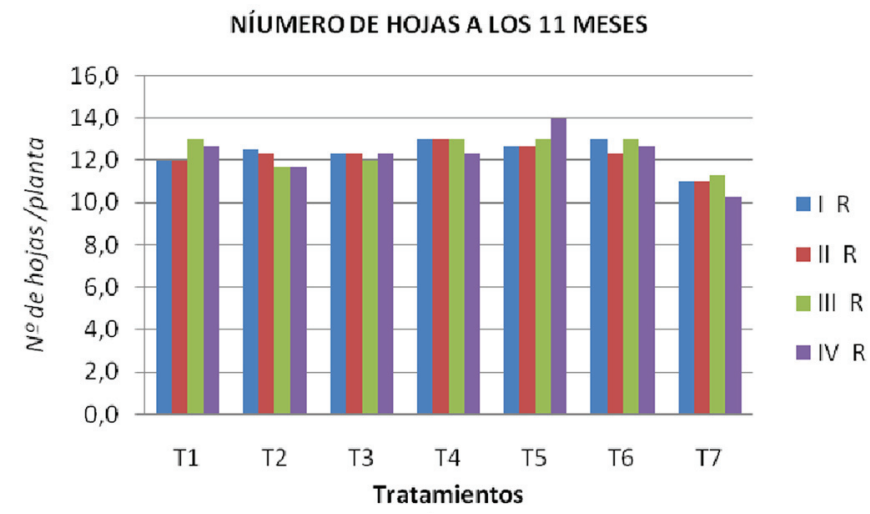


Anexo 19

Diámetro de estipe de plantasa los 11 meses

\begin{tabular}{|c|c|c|c|c|c|}
\hline \multirow{2}{*}{ TRATAMIENTO } & \multicolumn{5}{|c|}{$\varnothing$ de Estípete cm. } \\
\cline { 2 - 6 } & $\mathrm{I}$ & $\mathrm{II}$ & $\mathrm{III}$ & $\mathrm{IV}$ & PROMEDIO \\
\hline T1 & 7,0 & 6,6 & 6,8 & 6,4 & 6,7 \\
\hline T2 & 6,4 & 6,1 & 6,1 & 6,0 & 6,2 \\
\hline T3 & 6,5 & 6,3 & 6,0 & 6,5 & 6,3 \\
\hline T4 & 6,8 & 6,5 & 6,4 & 6,7 & 6,6 \\
\hline T5 & 6,7 & 7,0 & 7,1 & 7,1 & 7,0 \\
\hline T6 & 7,4 & 7,2 & 7,0 & 6,8 & 7,1 \\
\hline T7 & 4,7 & 5,0 & 5,1 & 4,7 & 4,9 \\
\hline X & 6,5 & 6,4 & 6,4 & 6,3 & 6,4 \\
\hline
\end{tabular}

\section{Anexo 20}

Barras del diámetro del estipe por tratamientos y repeticiones a los 11 meses

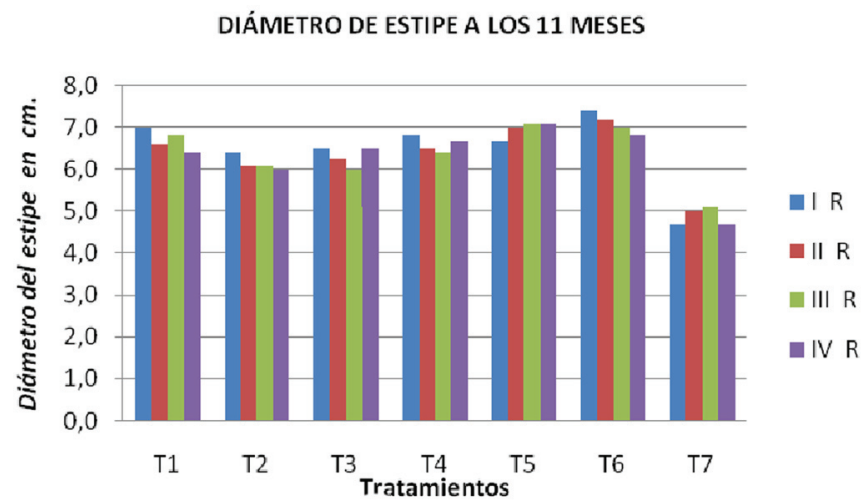

Anexo 21

Materia seca total por tratamientos en gramos/pl.

\begin{tabular}{|c|c|c|c|c|}
\hline Tratamientos & 3 meses & 6 meses & 9 meses & 11 meses \\
\hline T1 & 4,9 & 52,5 & 86,2 & 180,9 \\
\hline T2 & 4,4 & 53,2 & 63,3 & 157,5 \\
\hline T3 & 4,9 & 66,7 & 77,4 & 123,1 \\
\hline T4 & 4,8 & 63,0 & 94,2 & 125,7 \\
\hline T5 & 5,0 & 55,6 & 85,3 & 155,2 \\
\hline T6 & 5,1 & 58,9 & 88,0 & 157,2 \\
\hline T7 & 3,4 & 28,2 & 61,2 & 69,6 \\
\hline
\end{tabular}

Anexo 22

Materia seca 3 meses

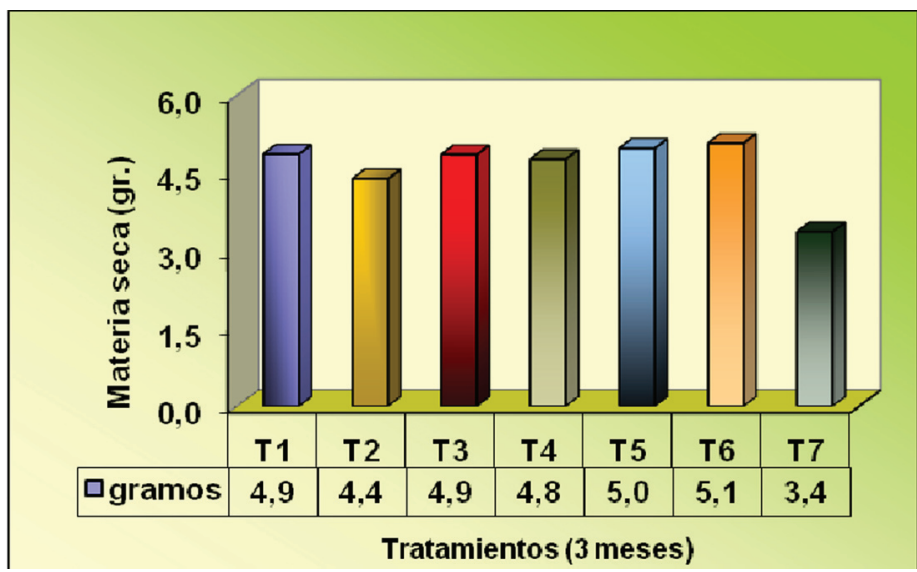

Anexo 23

Materia seca 6 meses

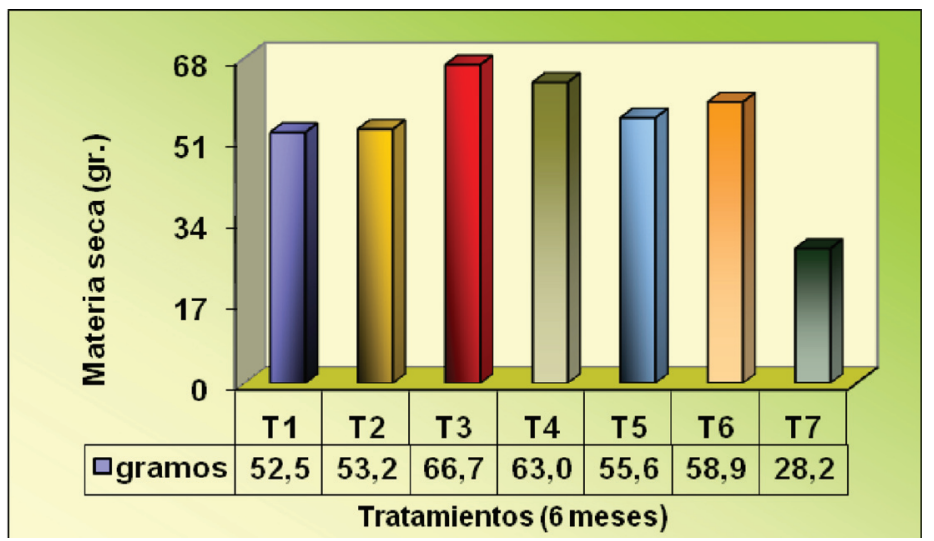

Anexo 24

Materia seca 9 meses

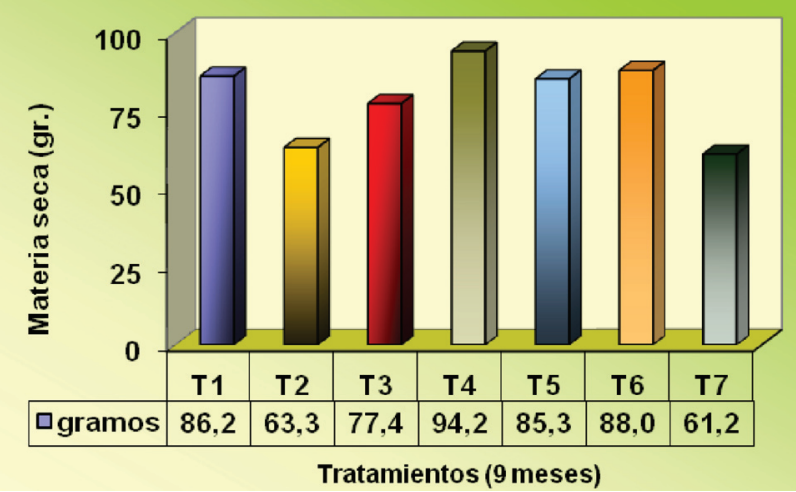


Anexo 25

Materia seca 11 meses

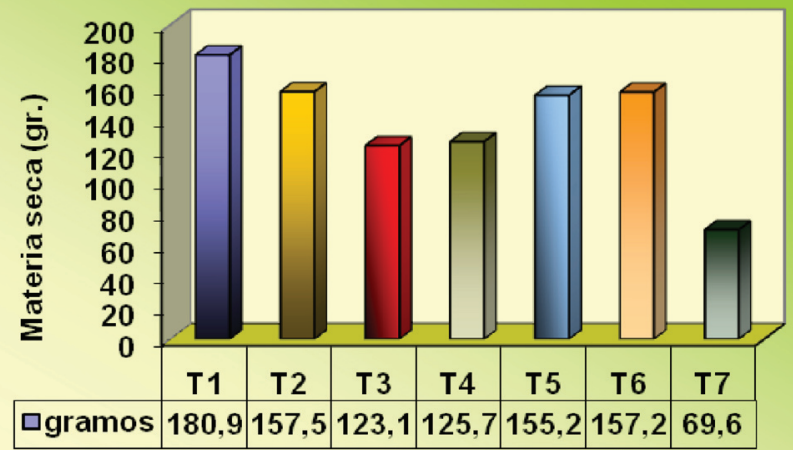

Tratamientos (11 meses)

\section{Anexo 26}

Absorción de macronutrientes por 100 plantas (m2) de semillero

\begin{tabular}{|c|r|r|r|r|r|r|}
\hline TRAT & \multicolumn{1}{c|}{$\mathrm{N}$} & \multicolumn{1}{l|}{$\mathrm{P}$} & \multicolumn{1}{c|}{$\mathrm{K}$} & $\mathrm{Ca}$ & $\mathrm{Mg}$ & $\mathrm{S}$ \\
\hline 1 & 16,80 & 1,00 & 9,30 & 0,019 & 0,800 & 0,008 \\
\hline 2 & 13,80 & 0,80 & 9,50 & 0,021 & 1,000 & 0,078 \\
\hline 3 & 13,08 & 1,10 & 10,60 & 0,021 & 1,300 & 0,010 \\
\hline 4 & 14,19 & 1,00 & 10,10 & 0,026 & 1,200 & 0,009 \\
\hline 5 & 15,07 & 0,90 & 8,90 & 0,022 & 0,800 & 0,007 \\
\hline 6 & 16,70 & 1,00 & 11,30 & 0,024 & 1,300 & 0,010 \\
\hline 7 & 8,72 & 1,10 & 6,80 & 0,014 & 0,700 & 0,007 \\
\hline
\end{tabular}

\section{Anexo 27}

Costos y estimación económica de utilidades de vivero según tratamientos probados en el año 2008 en \$ (USD)

\begin{tabular}{|c|c|c|c|c|c|c|c|}
\hline \multirow[b]{2}{*}{$\begin{array}{c}\text { Costos } \$ \text { (USD) } \\
\text { Egresos }\end{array}$} & \multicolumn{7}{|c|}{ TRA T A M I ENTOS } \\
\hline & \begin{tabular}{|l|} 
F. \\
Simples \\
202
\end{tabular} & \begin{tabular}{|l} 
F. \\
Simples \\
271
\end{tabular} & \begin{tabular}{|l|} 
F. \\
Simples \\
334
\end{tabular} & $\begin{array}{c}\text { Nitrfosk }+ \text { simp } \\
195+120\end{array}$ & $\mid \begin{array}{c}\text { Nitrfosk+simp } \\
260+162\end{array}$ & $\begin{array}{c}\text { Nitrfosk+simp } \\
325+198\end{array}$ & $\begin{array}{l}\text { Sin } \\
\text { Fertilizar }\end{array}$ \\
\hline Concepto & $\mathrm{T} 1$ & $\mathrm{~T} 2$ & T3 & \begin{tabular}{|c|}
$\mathrm{T} 4$ \\
\end{tabular} & \begin{tabular}{|c|}
$\mathrm{T} 5$ \\
\end{tabular} & \begin{tabular}{|c|} 
T6 \\
\end{tabular} & $\mathrm{T} 7$ \\
\hline Humbráculo & 0,020 & 0,020 & 0,020 & 0,020 & 0,020 & 0,020 & 0,020 \\
\hline Análisis suelo & 0,004 & 0,004 & 0,004 & 0,004 & 0,004 & 0,004 & 0,004 \\
\hline Semilla & 1,000 & 1,000 & 1,000 & 1,000 & 1,000 & 1,000 & 1,000 \\
\hline Fertilizantes & 0,193 & 0,213 & 0,264 & 0,445 & 0,592 & 0,739 & 0,000 \\
\hline $\begin{array}{l}\text { Insumos y } \\
\text { herramient }\end{array}$ & 0,250 & 0,250 & 0,250 & 0,250 & 0,250 & 0,250 & 0,250 \\
\hline Maquinaria agr. & 0,006 & 0,006 & 0,006 & 0,006 & 0,006 & 0,006 & 0,006 \\
\hline Riego & 0,100 & 0,100 & 0,100 & 0,100 & 0,100 & 0,100 & 0,100 \\
\hline Mano de obra & 0,150 & 0,150 & 0,150 & 0,150 & 0,150 & 0,150 & 0,150 \\
\hline Total egresos & 1,723 & 1,743 & 1,794 & 1,975 & 2,122 & 2,269 & 1,530 \\
\hline Costo por planta & 1,723 & 1,743 & 1,794 & 1,975 & 2,122 & 2,269 & 1,530 \\
\hline $\begin{array}{l}\text { Valor por planta } \\
\text { en mercado }\end{array}$ & 5,000 & 5,000 & 5,000 & 5,000 & 5,000 & 5,000 & 3,500 \\
\hline Beneficio Neto & 3,277 & 3,257 & 3,206 & 3,025 & 2,878 & 2,371 & 1,970 \\
\hline Beneficio/Costo & 0,66 & 0,65 & 0,64 & 0,61 & 0,58 & 0,47 & 0,56 \\
\hline Rentabilidad & $66 \%$ & $65 \%$ & $64 \%$ & $61 \%$ & $58 \%$ & $47 \%$ & $56 \%$ \\
\hline
\end{tabular}

Anexo 28

Semillas pregerminadas y siembra en fundas de previvero
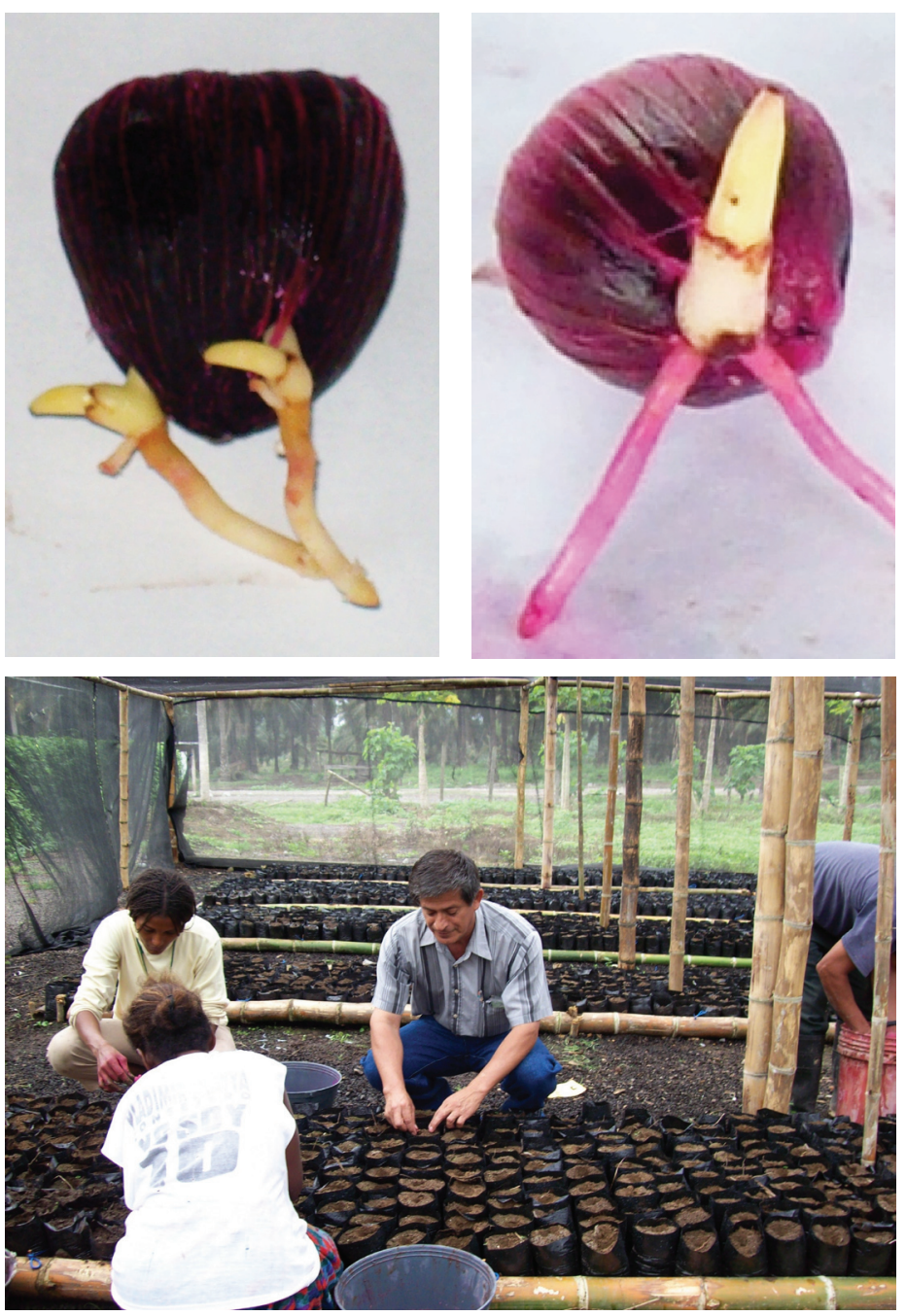


\section{Hat of}




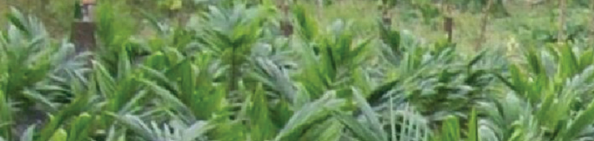

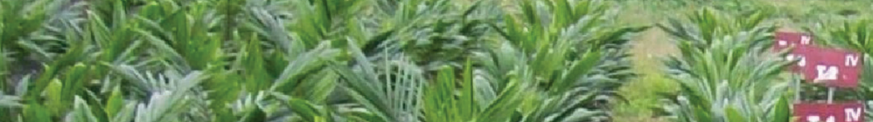

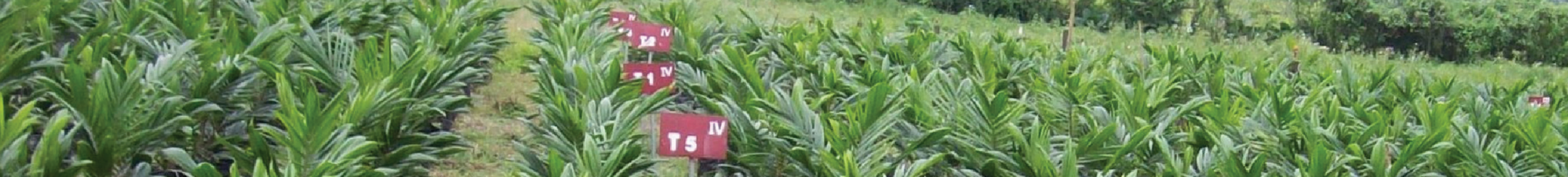

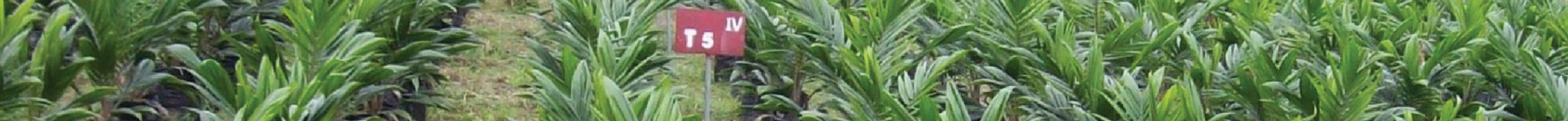

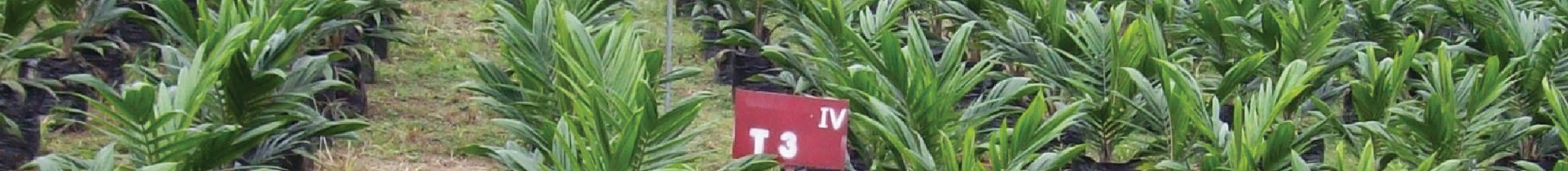
(1)

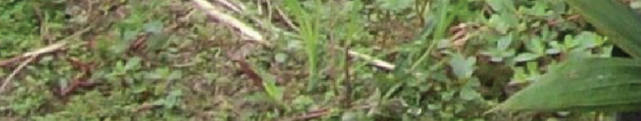

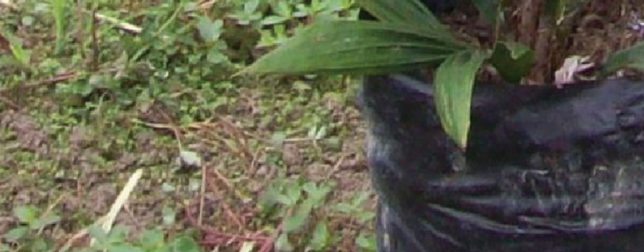

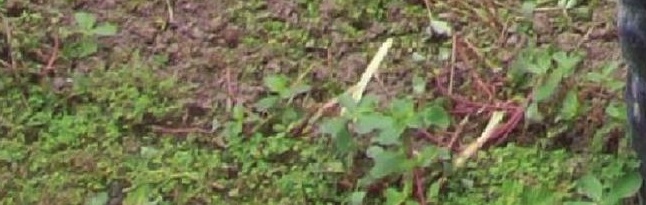
Nive $-\infty$ and End 2 t. (3) 1 -

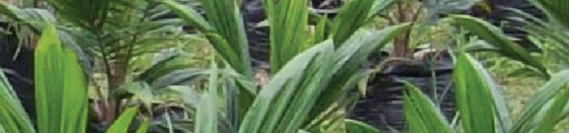
divis 



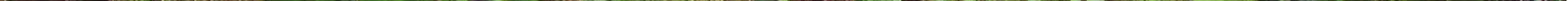

